\title{
The Investigation of Passive Blade Cyclic Pitch Variation Using an Automatic Yaw Control System
}

\author{
A Subcontract Report \\ K. H. Hohenemser \\ A. H. P. Swift
}

Final Report by

Washington University Technology Associates, Inc.

St. Louis, Missouri

August 1982

Prepared Under Subcontract No. XH-1-1052-1

SERI Technical Monitor: Richard L. Mitchell

Solar Energy Research Institute

A Division of Midwest Research Institute

1617 Cole Boulevard

Golden, Colorado 80401

Prepared for the

U.S. Department of Energy

Contract No. EG-77-C-01-4042 



\section{FOREWORD}

Washington University Technology Associates is pleased to submit this Final Report on The Investigation of Passive Blade Cyclic Pitch Variation Using An Automatic Yaw Control System under Solar Energy Research Institute Division, Subcontract No. XE-1-1052-1 and Midwest Research Institute Prime Contract No. EG-77-C-01-4042.

We wish to thank the Solar Energy Research Institute for awarding the subcontract for this work to WUTA Corporation. This work was directed for SERI until October, 1981 by Dr. Irwin Vas, former Branch Chief, Wind Energy Branch. Mr. Richard Mitchell had management responsibility throughout the performance period program. The subcontract was administered by Ms. Lori Miranda.

The report covers the Contract and Amendment One performance period of January 1 to December 31, 1981. The principal investigator was Dr. Kurt H. Hohenemser. Dr. Andrew H. P. Swift performed the analytical and the atmospheric test work. Mr. David Sanderson participated in the design of the automatic controls and in their bench testing. The Woodward Governor Company in Rockford, Illinois made available without charge and bench tested the hydraulic constant speed governor used for one of the two automatic control systems under investigation. The Gould Electric Motor Division in St. Louis, Missouri delivered free of charge a specially designed single phase four-pole induction generator and investigated its characteristics in their laboratory. The Union Electric Company in St. Louis, Missouri installed a system of meters and performed tests - also free of charge - to determine the quality of the electric energy fed by the generator into their grid.

According to the original subcontract the work, except for evaluation and report writing, was to be completed by May 31, 1981. By that time the subcontract goal had been achieved within the available mean wind speed of up to $11 \mathrm{~m} / \mathrm{sec}(25 \mathrm{mph})$. In the expectation of encountering higher mean wind speeds later in the year, Amendment one to the subcontract extended the performance period without funding to December 31, 1981. When during June, July, August and September no higher mean wind speeds occurred than had been encountered before, it was decided not to wait any longer for higher winds. Instead, the subcontract goals were expanded to include the investigation of the automatic passive yaw control system in the case of an electric grid connected generator. This could be done either by adding a synchronous inverter to the alternator, or by replacing the variable speed alternator by a constant speed induction generator. The latter route, though aerodynamically less efficient, was found to be substantially less costly and was, therefore, selected. Electrical controls for cut-in and cut-out of the induction generator at synchronous speed had to be developed. Atmospheric testing of the new configuration was performed in October, 1981. The extension of the contract goal without funding increase was only possible because neither $\mathrm{Dr}$. Hohenemser nor $\mathrm{Dr}$. Swift charged their time to the subcontract after June $30,1981$. 

The investigation of passive cyclic pitch variation using an automatic yaw control system made use of the test equipment and of the results of an earlier study documented in the Final Report to SERI of December 1980 titled "The Yawing of Wind Turbines with Blade Cyclic Pitch Variation". The atmospheric test equipment consisted of a horizontal axis wind turbine with vane controlled upwind two-bladed rotor of $7.6 \mathrm{~m}$ (25 ft) diameter having passive cyclic pitch variation. The machine was mounted on a Unarco Rhon SSV steel tower of $18 \mathrm{~m}(60$ ft) height which had been made tiltable to facilitate installation and maintenance of instrumentation for measuring performance and dynamic loads. The alternator was tuned and loaded by a $6 \mathrm{ohm}$ resistance in such a way that the wind turbine operated with maximum aerodynamic efficiency at all wind and rotor speeds up to the rated rotor power of $10 \mathrm{~kW}$. An automatically triggered electric furl actuator prevented over-speeds and over-torques by furling the rotor which means yawing the rotor out of the winds. Unfurling had to be accomplished by a manual toggle switch for the furl actuator.

For the present investigation the atmospheric test equipment was modified to accept two alternative fully automatic yaw or furl control systems. The first system was of the active type and included a hydraulic single acting constant speed governor as i.t is used for aircraft propeller controls. Upon reaching the rotor speed limit, the governor delivered pressurized oil to a hydraulic furl actuator which then overcame the unfurling spring force and furled the rotor. When the rotor speed fell below the set value, the governor admitted oil flow from the hydraulic actuator into the oil reservoir and the rotor was unfurled by the spring. The active automatic yaw control system worked very well and held even in highly gusting winds the power-off rotor speed to within $\pm 10 \%$ of its set value.

The second automatic control system was of a purely mechanical passive type. The rotor thrust, which was laterally off-set from the yaw axis, in combination with a yawing component of the rotor torque due to uptilt of the rotor axis overcame at rated power the unfurling spring and furled the rotor. The analytically predicted and experimentally substantiated negative rotor yaw damping would cause excessive furling rates unless alleviated by a furl damper. The passive furl control system which is simpler and more reliable than the active hydraulic governor control system was found to accurately limit rotor. speed and rotor torque to the set values. However, due to excessive bearing friction, unfurling during decreasing wind speed was substantially delayed. The passive system was tested both in conjunction with the variable speed alternator and with a constant speed induction generator tied to the electric grid.

The tests were supported by a specially developed dynamic yawing analysis. Both analysis and tests indicated that the two-bladed passive cyclic pitch wind rotor can be effectively torque or speed limited by rotor yaw control systems which are less costly and more reliable than the conventional blade feathering control systems. 

TABLE OF CONTENTS

Page

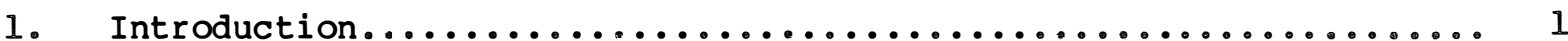

2. Anlaysis of wind Turbines in Yawed Flow ................ 5

2.1 Aerodynamic Analysis with Constant Inflow.............. 5

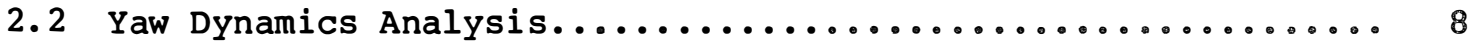

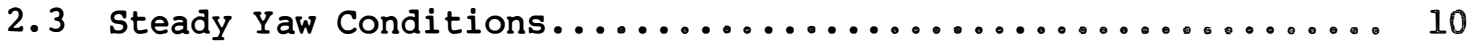

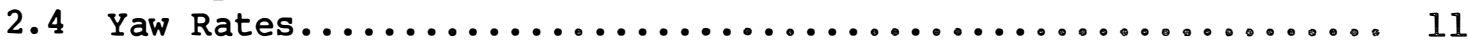

2.5 Blade Angle of Attack Distributions................ 11

2.6 Yaw Stability and Damping....................... 14

3. Control Systems Design............................ 15

3.1 Active Yaw Control Design....................... 15

3.2 Passive Yaw Control Design....................... 17

4. Atmospheric Test Results.......................... 23

4.1 Test Results for Active Yaw Control................. 23

4.2. Test Results for Passive Yaw Control................. 25

4.2.1 Passive Yaw Control With Alternator.............. 25

4.2.2 Passive Yaw Control With Induction Generator........ 38

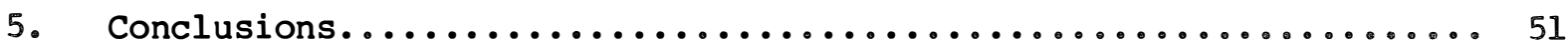

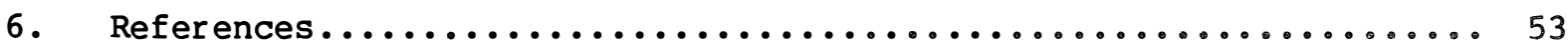

Appendix A - Assembly Drawings

A-1 Assembly Drawing for Yaw Control Systems.............. AI

A-2 Assembly Drawing for Hydraulic Governor............... A2

A-3 Assembly Drawing for Hydraulic Cylinder............... A3

Appendix B - Rotor With Passive Cyclic Pitch Variation as a Member of a Family of Hinged Rotors

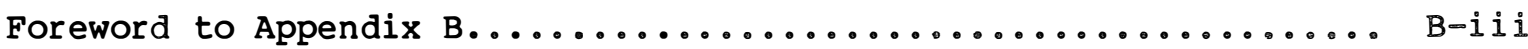

Summary of Appendix B...........................

Table of Contents of Appendix B..........................

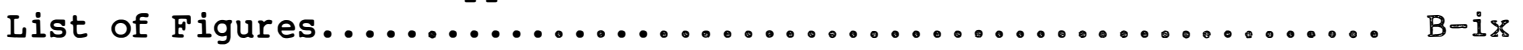

Nomenclature List............................... B-ssi

Text Sections Bl to B8............................ B $-1 / B-23$ 

1-1 Axial and Cross Sectional View of Blade Pair With Common Pivot............................. 3

1-2 Furl Angle and Rotor Yaw Angle................... 4

2-1 Thrust Coefficient vs. Rotor Yaw Angle for Constant Torque Coefficients and Speed Ratios.................. 6

2-2 Power Coefficient vs. Tip Speed Ratio for Constant Torque Coefficients and Rotor Yaw Angles............... 7

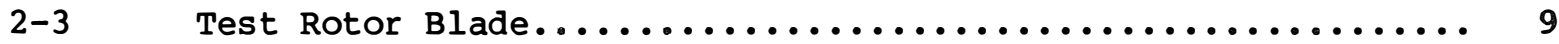

2-4 Angle of Attack Distribution, $60^{\circ}$ Yaw Angle,

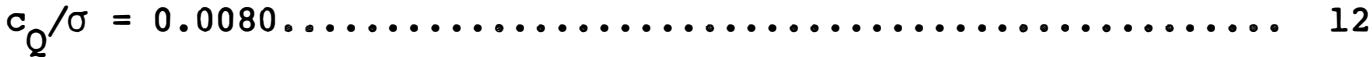

2-5 Angle of Attack Distribution, $60^{\circ}$ Yaw Angle,

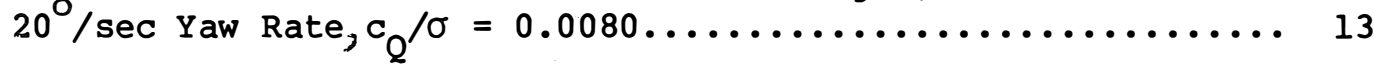

3-1(a) Equivalent Rotor Thrust for 200 Rpm vs. Wind Speed For Constant Furl Angles and For Constant $c_{Q} / \sigma \ldots \ldots \ldots \ldots . . .20$

3-1 (b) Power-off Rpm vs. Wind Speed..................... 20

4-1 Time History for Power-off Active Rpm Control........... 24

4-2 Equivalent Thrust at Begin of Furl and Unfurl for Power-off Run of May 14, 1981..................... 27

4-3 Typical Furling in Response to a Gust From 7 to $14 \mathrm{~m} / \mathrm{sec}$ (15 to $30 \mathrm{mph}$ ), Power-on Run of May 14, 1981............. 28

4-4 Digital Data for Power-on Run With Alternator on May 14, 1981

(a) Log Samples (N) vs. Wind Speed (M/S) ............. 30

(b) Furl Angle (X) vs. Wind Speed (M/S) ............ 31

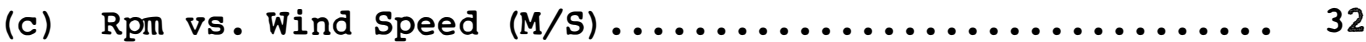

(d) Rotor Torque (NM) vs. Wind speed (M/S)............ 33

(e) Rotor Thrust (N) vs. Wind Speed (M/S) ............ 34

(f) Cyclic Pitch vs. Wind Speed (M/S) .............. 35 
LIST OF EIGURES

(continued)

$\underline{\text { Page }}$

4-5 Upper wind Speed vs. Lower wind Speed Reading.......... 37

4-6 Digital Data for Power-on Run With Induction

Generator, October 18, 1981

(a) Log Samples (N) vs. Wind Speed (M/S) ............. 41

(b) Furl Angle $(X)$ vs. Wind speed (M/S) ............. 42

(c) Rpm vs. Wind speed (M/S) .................... 43

(d) Rotor Torque (NM) vs. Wind speed (M/S) ........... 44

(e) Rotor Thrust (N) vs. Wind Speed (M/S) ............ 45

(f) Cyclic Pitch vs. Wind Speed................... 46

4-7 Digital Data for Power-off Run With Induction Generator, October 18, 1981

(a) Log Samples (N) vs. Wind Speed (M/S) ............. 47

(b) Rpm vs. Wind Speed (M/S) .................... 48

(c) Rotor Power (kW) vs. Wind Speed (M/S) ............ 49 


\section{IIST OF TABLES}

$\underline{\text { Page }}$

$2-1 \quad$ Comparison of Results, $c_{Q} / \sigma=0.0080 \ldots \ldots \ldots \ldots \ldots \ldots \ldots \ldots$

2-2 Comparison of Results, $c_{Q} / \sigma=0.0010 \ldots \ldots \ldots \ldots \ldots \ldots \ldots \ldots$

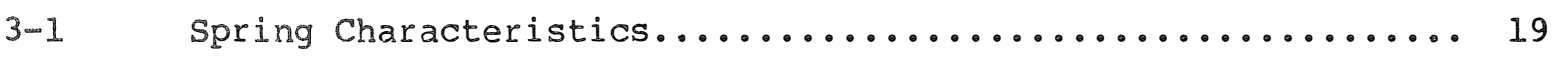

4-1 Induction Generator Properties................... 38 



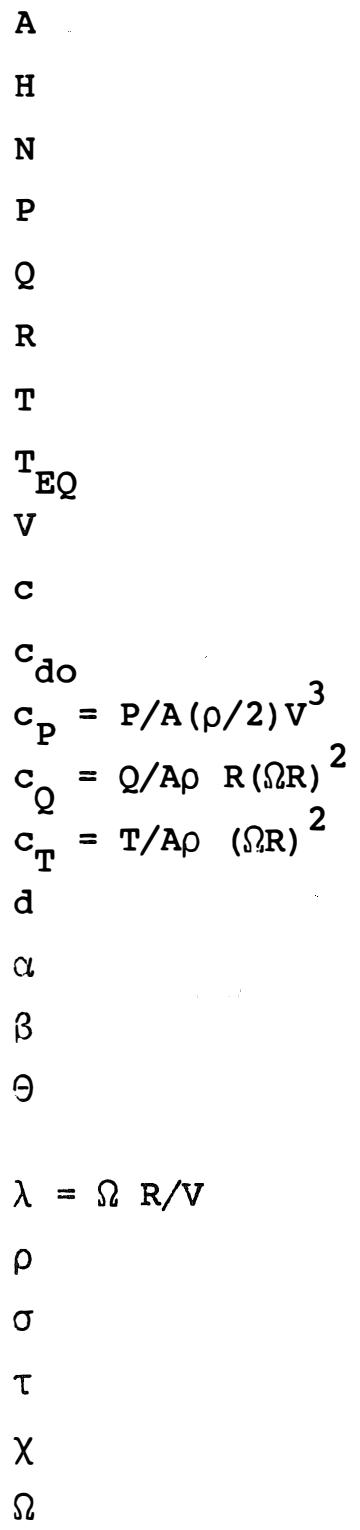

Rotor Disk Area

In-plane Rotor Force

Number of Sample Sets

Rotor Power Output

Rotor Torque

Rotor Radius

Rotor Thrust

Equivalent Rotor Thrust, Eq.3-1

Wind Velocity

Lateral Yaw Axis off-set

Profile Drag Coefficient

Power Coefficient

Torque Coefficient

Thrust Coefficient

Distance Rotor Center to Yaw Axis

Blade Angle of Attack

Rotor Axis Uptilt Angle

Blade Pitch Angle at $0.7 \mathrm{R}$, Positive Toward Feathering

Tip Speed Ratio

Air Density

Rotor Solidity Ratio

Angular Deflection About Blade Pivot

Yaw or Furl Angle

Angular speed of Rotation 
Rotor speed control by yawing requires rapid yaw rates which are incompatible with two bladed rigid or teetering rotors. To avoid excessive vibration and teeter motions a type of two bladed rotor with passive cyclic pitch variation was investigated. The rigid blade pair was free to oscillate about a common pivot with which the blades formed a small prelag angle, see Fig. 1-l. This simple and rugged wind rotor was found capable of high yaw rates without imposing vibratory hub moments and without producing noticeable out-of-plane blade excursions. The wind rotor was tail vane stabilized. Rotor yaw angles were introduced by "furling" the rotor with respect to the tail vane, see Fig. 1-2 which defines the yaw angle and the furl angle. They are usually approximately equal to each other.

The two bladed 7.6 meter (25 ft) diameter horizontal axis wind turbine under study was designed to operate up to rated power with near constant rotor torque coefficient. This was achieved by letting the rotor torque be proportional to the square of the rotor speed. The constant torque coefficient was selected for maximum aerodynamic rotor efficiency which was obtained at all rotor and wind speeds up to the condition of rated power. The three phase variable speed alternator with three tuning capacitors produced three phase ac which was transformed into dc by three rectifier diodes. With a constant resistance load of $6 \mathrm{ohm}$ the desired constant torque coefficient was obtained up to a rotor power of $10 \mathrm{~kW}$ that occurred at $227 \mathrm{rpm}$ of the rotor and at 9.7 meter per second (22 $\mathrm{mph}$ ) wind speed. Somewhat above rated rpm the alternator torque would reach a maximum and then decline resulting in a rotor runaway condition. The conventional means of controlling rotor speed consist of a blade feathering mechanism. The purpose of the study was to find out whether the complex feathering control mechanism with its emergency back-ups by brakes or spoilers could be omitted and replaced by a simpler and more reliable rotor yaw control system.

In Appendix B the characteristics of the rotor type of Fig. 1-1 are compared to those of other hinged rotor types. All hinged rotors avoid the transfer of gyroscopic moments to the rotor hub. However, quite complex hinge arrangements are usually adopted in order to prevent Coriolis moments from simultaneous coning and flapping. The rotor type of Fig. 1-1 alleviates blade flapping by the strong coupling between flapping and cyclic pitch variation. Due to this supression of flapping by passive cyclic pitch variation, blade elastic coning can be substantial without causing appreciable Coriolis moment effects. This explains the smoothness of operation of this rotor type despite large yaw rates. In the absence of passive cyclic pitch variation achieved by the Fig. 1-1 rotor type, the blades must be either very stiff to prevent appreciable coning, or one needs three or more bladed rotors to avoid the usually severe vibations of two-bladed elastic rotors. 
During the first phase of the study reported in Ref. 1, 2, and 3 the steady and dynamic rotor yaw conditions were first investigated with a small scale model in the wind tunnel and then with a fully instrumented 7.6 meter (25 ft) diameter rotor in the atmosphere. During this phase the rotor could be furled and unfurled with the help of an electric constant rate actuator. There was an overspeed relay which triggered the furling motion of the actuator at $230 \mathrm{rpm}$. Unfurling was performed by manual operation of the actuator toggle switch. During the second phase of the study to be reported in the following, two alternative automatic furl control systems were designed, built, bench tested and tested in the atmosphere. The tests were supported by a yaw dynamics analysis developed for this purpose. Finally, the variable speed alternator was replaced by a grid connected constant speed induction generator. The task of the yaw control system was then to limit the torque to the rated torque and to prevent runaway in case of electric grid failure. The yaw control characteristics of this configuration were studied analytically and experimentally. Some results of the second study phase relating to the alternator configuration were reported in Ref. 4 and 5 . 


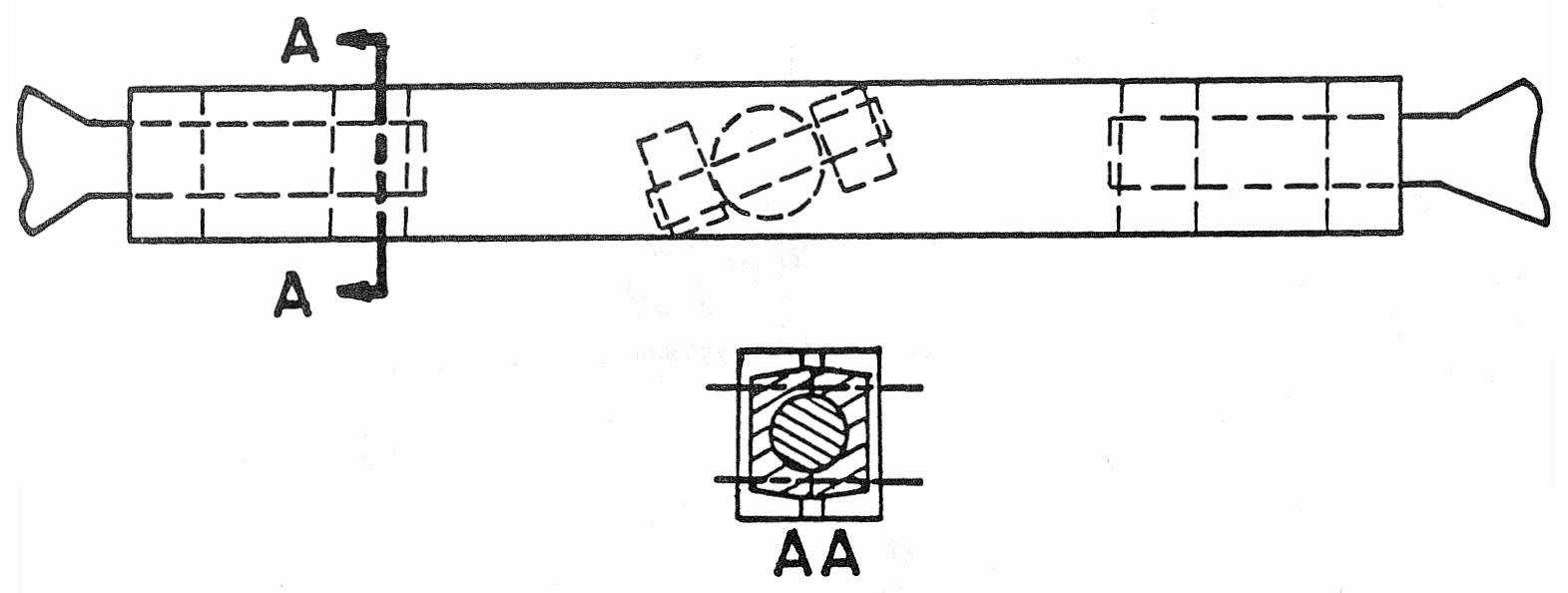

FIGURE 1-1. AXIAL AND CROSS SECTIONAL VIEW OF BLADE PAIR WITH COMMON PIVOT 


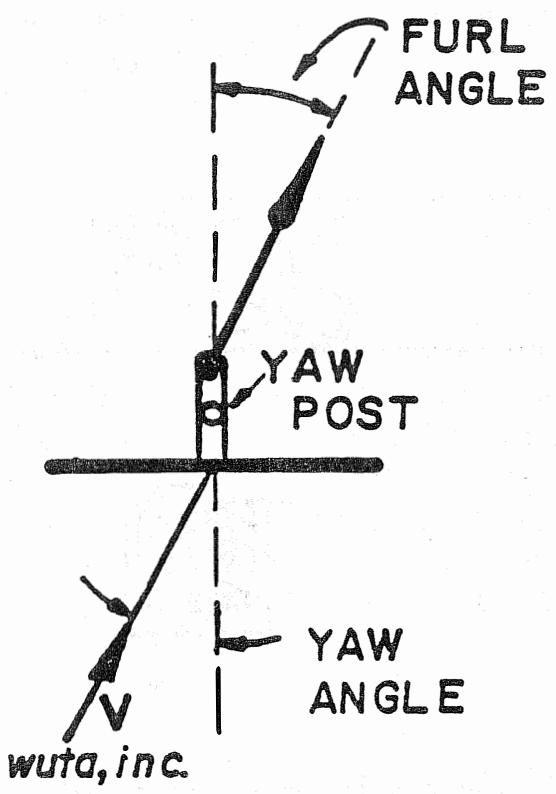

FIGURE 1-2. FURL ANGLE AND ROTOR YAW ANGLE 
During the first study phase reported in Ref. 2 only steady conditions were analyzed. For zero yaw angle the prop code of Ref. 6 was applied. For non-zero yaw angles a modification of NASA developed helicopter tables and charts of Ref. 7 was used. During the second study phase to be reported here the classical aerodynamic analysis of lifting rotors in oblique flow of Ref. 8 was applied to steady conditions and then expanded to include dynamic yaw conditions. The classical aerodynamic analysis assumed constant inflow velocity through the rotor disk. Momentum and energy relations in combination with blade airfoil data yield the aerodynamic loads. The latest among numerous extensions of the classical analysis to variable inflow over the rotor disk in Ref. 9 is applicable not only to steady but also to unsteady flow conditions. The results of this variable inflow analysis agreed well with those of the more cumbersome prescribed wake analysis widely used in rotorcraft aerodynamics. The yaw dynamics analysis developed during the second phase applies the variable inflow concept of Ref. 9. We will begin, however, by showing some results from the classical aerodynamic analysis applied to wind turbines.

\subsection{AERODYNAMIC ANALYSIS WITH CONSTANT INFLOW}

The classical analysis of Ref. 8 assumes untapered untwisted blades. The analysis can be used as an approximation for tapered and twisted blades if the blade solidity ratio and the blade pitch angle are taken for the 0.7 radius station. For the experimental rotor the blade solidity ratio is $\sigma=0.032$ and the blade pitch angle at the 0.7 radius station is $\theta=-0.5^{\circ}$. The minus sign indicates the direction away from feathering. The airfoil was represented by a constant lift slope and by a quadratic relation between profile drag coefficient $c_{D o}$ and blade angle of attack

$$
c_{\text {Do }}=0.010+0.5(\alpha)^{2}
$$

which is typical of many airfoils up to the stall limit. The mean angle of attack at the 0.7 radius station was used in Eq. 2-1 with the effect of cyclic pitch on the angle of attack being neglected.

Two computer generated graphs for the experimental rotor are shown in Figs. 21 and 2-2. Fig. 2-1 presents the thrust coefficient $\left(c_{T} / \sigma\right)$ vs. yaw angle $(X)$ for constant values of speed ratio $(v=V / \Omega R)$ and torque coefficient $\left(c_{0} / \sigma\right)$. Fig. 2-1 indicates that for constant torque coefficient, $\left(c_{0} / \sigma\right)$ the thrust coefficient $\left(c_{\mathrm{T}} / \sigma\right)$ is also constant and independent of the yaw angle $(X)$. The tuning capacitors and the $6 \mathrm{ohm}$ resistance load of the alternator resulted in a constant torque coefficient of $c_{0} / \sigma=0.0080$, the associated thrust coefficient was $c_{T} / \sigma=0.12$. Fig. 2-1 shows that the thrust coefficient for zero power, $c / \sigma=0$, is much smaller. This fact will be significant for the passive yaw control system to be discussed later. 


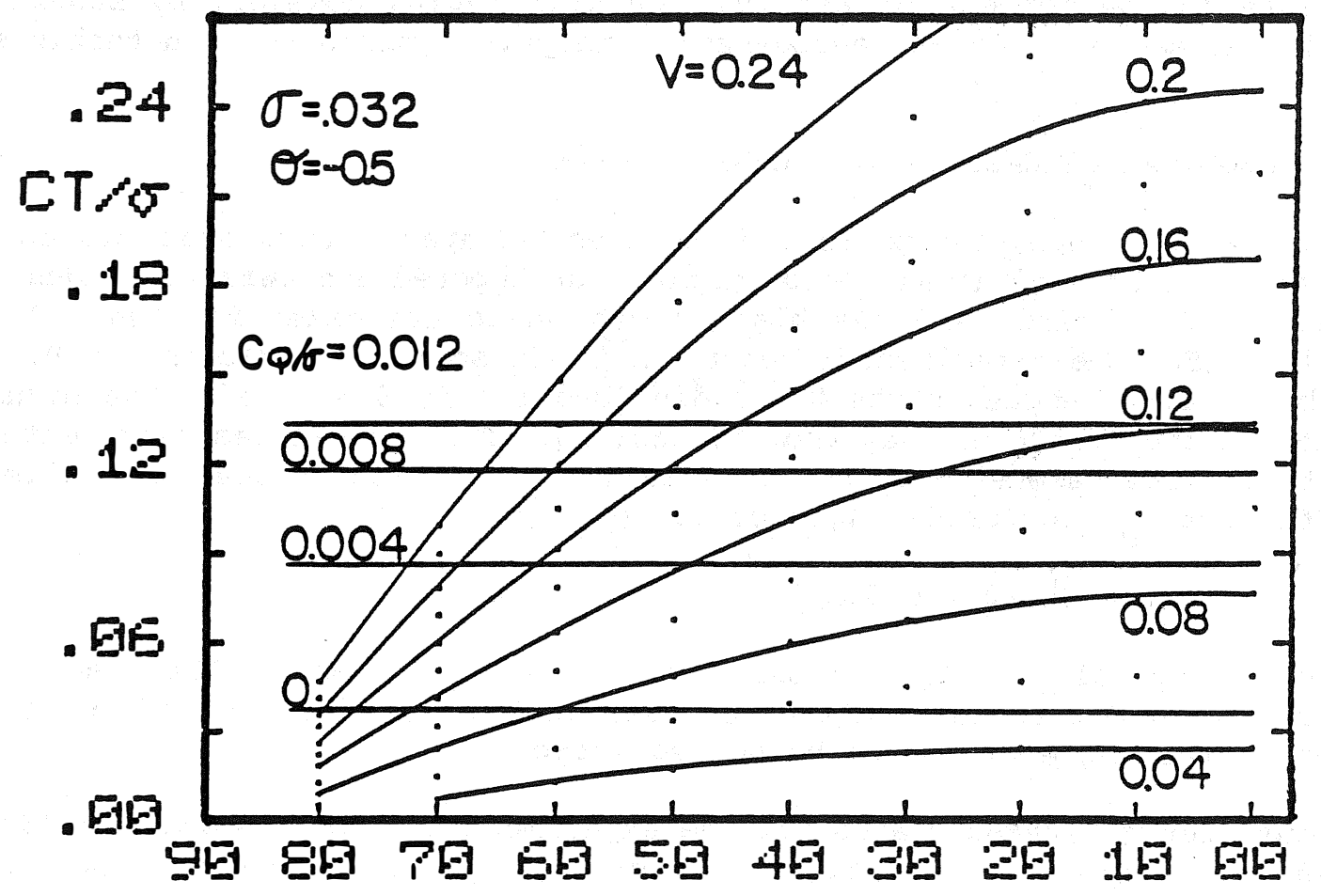

FIGURE 2-1. THRUST COEFFICIENT VS. ROTOR YAW ANGLE FOR CONSTANT TORQUE COEFFICIENTS AND SPEED RATIOS 


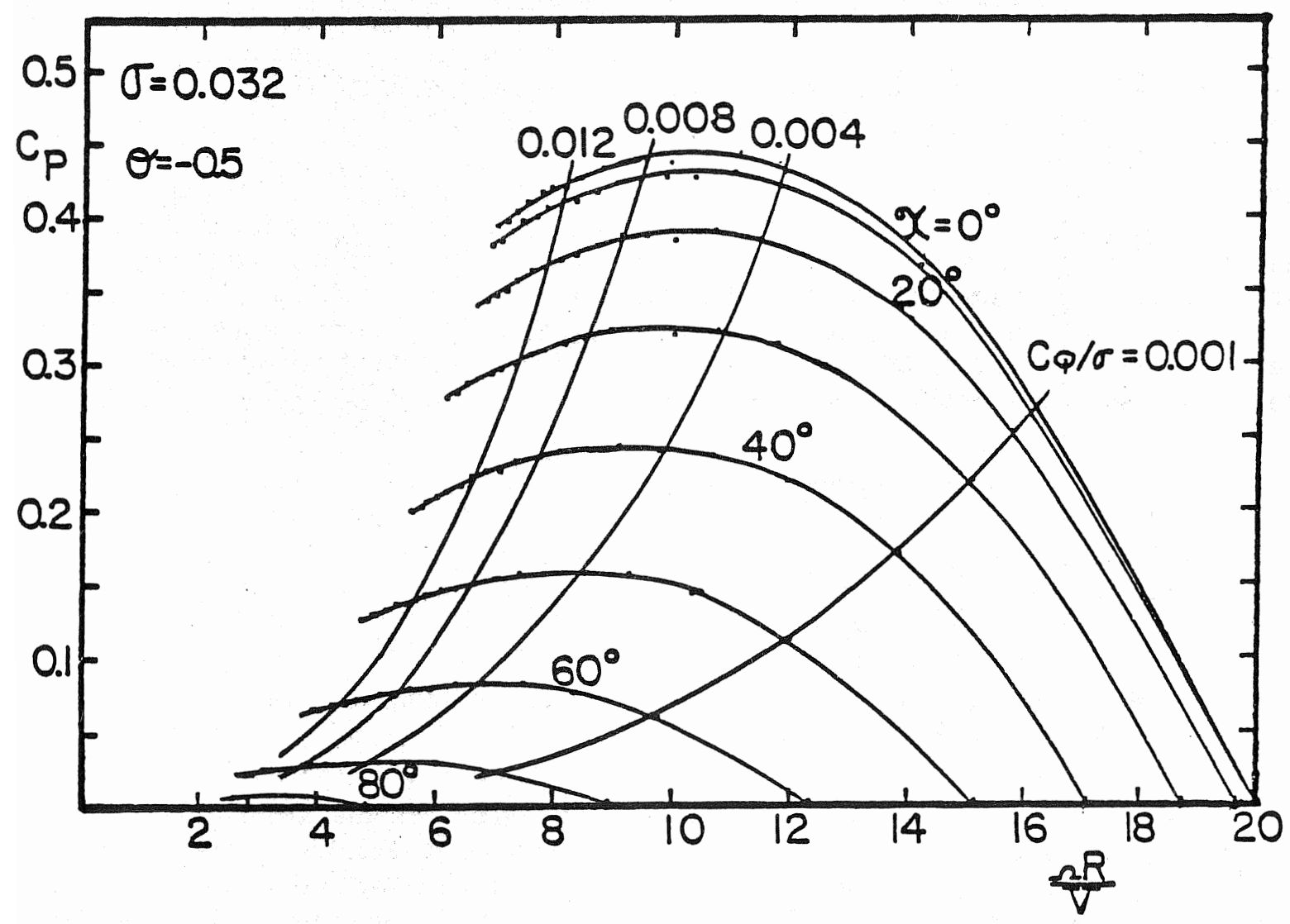

FIGURE 2-2. POWER COEFFICIENT VS. TIP SPEED RATIO FOR CONSTANT TORQUE COEFFICIENTS AND ROTOR YAW ANGLES 
Fig. 2-2 presents the power coefficient ( $c_{p}$ - aerodynamic rotor efficiency) vs. tip speed ratio $(\Omega R / V=1 / v)$ for constant values of yaw angle $(X)$ and torque coefficient $(c / \sigma)$. It is seen that for small yaw angles the torque coefficient, $\left(c^{2} / \sigma=0.0080\right)$, produces a near maximum of the rotor aerodynamic efficiency $c_{p}$ at a tip speed ratio of $\Omega R / V=9.6$. Up to rated power this tip speed ratio and the value of $c_{p}$ remain constant whereby the rotor speed varies in proportion to the wind speed. For higher than rated wind speed $(9.7 \mathrm{~m} / \mathrm{sec}$ or $22 \mathrm{mph}$ ) the wind turbine will operate along the $\mathrm{c} / \mathrm{T}=0.0080$ line whereby rotor speed and rotor power are kept constant while the yaw angle $(\chi)$ increases and the aerodynamic efficiency $\left(c_{p}\right)$ decreases. Thus wind energy is dissipated by rotor yawing, and rotor power and rotor speed are limited to their rated values. Graphs similar to those of Fig. 2-2 have been obtained by analysis in Ref. 10, and from test results in Ref. 11 .

\section{2 YAW DYNAMICS ANALYSIS}

In contrast to the classical analysis the yaw dynamics analysis developed in Ref. 12 includes the effects of blade taper, twist and cyclic pitch variation. The analysis is based on the dynamic inflow modeling of Ref.9. The effects of pitching and rolling moments on the induced flow are neglected. This is justified for steady conditions. However, during yaw rates the gyroscopic moment will have some effect on the induced flow.

A simple structural modeling of the rotor, widely used in helicopter flight mechanics, was adopted. The blades were assumed to be rigid in bending. The blade pair could freely oscillate about the center pivot, see Fig. 1-1. Elastic coning was included by providing a coning flexure at the rotor center dimensioned to yield the correct coning frequency as measured with the actual blade. The system equations were written in state variable form whereby the 8 state variables were defined as follows:

$\begin{array}{ll}\text { Angular deflection about pivot } & \tau \\ \text { Its rate } & \dot{\tau} \\ \text { Elastic blade coning } & \beta_{e}^{e} \\ \text { Its rate } & B_{e}^{e} \\ \text { Rotor angular speed } & \nu \\ \text { Induced velocity ratio } & \chi \\ \text { Yaw angle } & \dot{X} \\ \text { Its rate } & \end{array}$

The time derivatives of all state variables appeared on the left hand side of the state equations. The blade was divided into five segments having chord and pitch setting according to the distributions shown in Fig. 2-3. The inner 29\% of the blade, representing the shank, were omitted. The reason for the long shank was that the available blades for the three-bladed Astral-Wilcon Model 10B were used in order to save time and expenses. In a new design the shank could be shortened by $50 \%$ and the airfoil section correspondingly extended. This would increase the aerodynamic efficiency by $10 \%$ and would double the starting torque at a given wind velocity. 
NACA Airfoil No. 23024

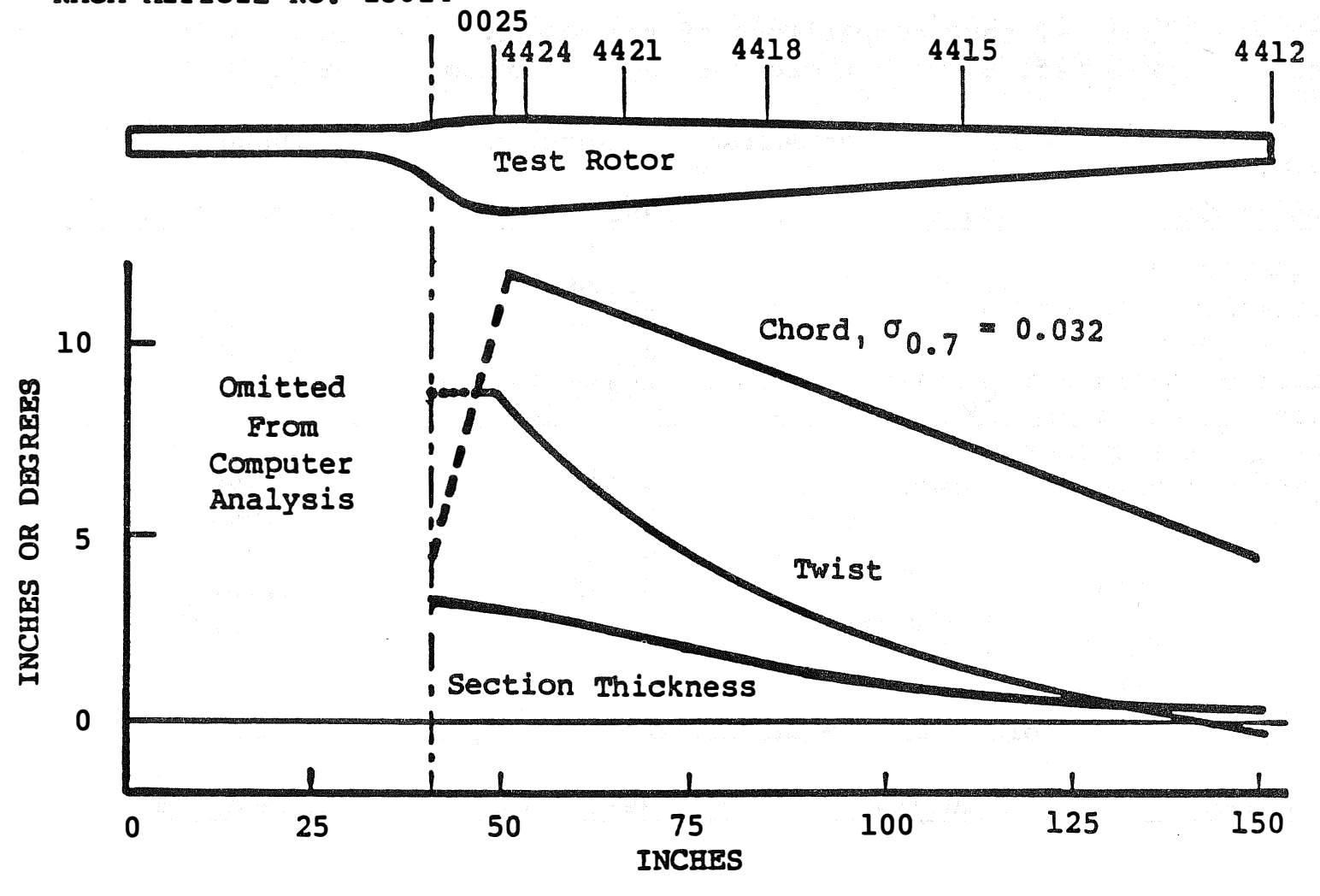

FIGURE 2-3. TEST ROTOR BLADE 
For the airfoil the same assumptions were made as before, constant lift slope and a profile drag coefficient according to Eq. 2-l. The angle of attack, $(c)$ varied now from blade segment to blade segment and with time. A Prandtl-Betz tip loss factor B, Ref. 8, was assumed, whereby blade elements outboar.d of BR have profile drag but no lift. For power-on $B=0.96$, for power-off with the lower thrust coefficient $B=0.98$. The aerodynamic blade loads were determined with the usual assumptions: Radial flow is ignored, wake rotation is neglected, and flapping angles are small. The system state equations were time integrated with the predictor-corrector method assuming initial values for the 8 state variables. For steady conditions the classical analysis served well in the selection of these initial values, so that the new equilibrium state for the refined analysis was reached after a short time.

\subsection{STEADY YAW CONDITIONS}

Table 2-1 and 2-2 show comparisons of the steady state results for the classical analysis Ref. 8, with those for the yaw dynamics analysis.

Table 2-1. Comparison of Results, $c_{Q} / \sigma=0.0080$

Yaw Angle Quantity

Class. Anal. Refined Anal.

\begin{tabular}{llll}
$15^{\circ}$ & $V / \Omega R$ & 0.108 & 0.111 \\
& $\nu$ & 0.020 & 0.017 \\
& $C_{T} / \sigma$ & 0.112 & 0.101 \\
& $C_{P}$ & 0.402 & 0.371 \\
\hline \multirow{2}{*}{$60^{\circ}$} & $V / \Omega R$ & 0.186 & 0.200 \\
& $\nu$ & 0.010 & 0.008 \\
& $C_{T} / \sigma$ & 0.112 & 0.096 \\
& $C_{P}$ & 0.079 & 0.064 \\
& $\left.\tau P_{230} \mathrm{rpm}\right)$ & -- & $\pm 1.9^{\circ}$
\end{tabular}

Table 2-2. Comparison of Results, $c_{Q} / \sigma=0.0010$

Yaw Angle Quantity Class. Anal. Refined Anal.

\begin{tabular}{llll}
$15^{\circ}$ & $V / \Omega R$ & 0.064 & 0.062 \\
& $\nu$ & 0.018 & 0.017 \\
& $C_{T_{T} / \sigma}$ & 0.053 & 0.050 \\
& $C_{P}$ & 0.26 & 0.28 \\
\hline \multirow{2}{*}{$80^{\circ}$} & $V / \Omega R$ & 0.265 & 0.271 \\
& $\nu$ & 0.0031 & 0.0025 \\
& $C_{T} / \sigma$ & 0.052 & 0.042 \\
& $C_{P}$ & 0.0034 & 0.0031
\end{tabular}


Table 2-1 is for the power-on condition, Table 2-2 is for the power-off condition assuming that $c_{0} / \sigma=0.0010$ represents the friction torque. The differences in results between the two types of analysis are surprisingly small, so that Figs. 2-1 and 2-2 for the classical analysis represent reasonable approximations to steady state yaw conditions. The cyclic pitch amplitude power-on for $60^{\circ}$ yaw angle and $230 \mathrm{rpm}$ is $\pm 1.9^{\circ}$. For $15^{\circ}$ yaw angle and for the power-off condition at $80^{\circ}$ yaw angle the cyclic pitch amplitude is even smaller.

\subsection{YAW RATES}

When a yaw rate is superimposed to a yawed condition the cyclic pitch amplitude is increased for positive yaw rate which increases the yaw angle, it is reduced for negative yaw rate. A $20 \%$ sec positive yaw rate at $60^{\circ}$ yaw angle increases the cyclic pitch amplitude at $230 \mathrm{rpm}$ from $\pm 1.9^{\circ}$ to $\pm 4.5^{\circ}$. The cyclic pitch amplitude due to yaw rate is inversely proportional to rotor speed so that a given yaw rate produces lower cyclic pitch amplitudes at higher rotor speed. This was clearly observed during the tests. Actually encountered yaw rates are caused by wind direction changes and by furl rates from the control system. Responses to wind direction changes of up to $20 \%$ sec were observed. In order to prevent excessive cyclic pitch amplitudes, the control systems were designed to produce not more than $20 \%$ sec furl rate.

\subsection{BLADE ANGLE OF ATTACR DISTRIBUTION}

Oblique flow as well as cyclic pitch amplitudes produce rapid changes in blade angle of attack. For a given radial blade station the maximum angle of attack condition is of short duration so that stall is substantially delayed as compared to steady flow airfoil tests. For the inner blade portion where stall begins, the boundary layer is thinned by centrifugal effects, causing another delay in blade stall. Even in axial flow the use of two-dimensional flow stall data leads to a strong over-emphasis of stall effects, see Ref. 13. There are hardly any data available on the effects of a combination of radial flow and of rapid angle of attack and flow velocity changes on blade stall. In order not to introduce questionable assumptions, stall was omitted entirely. Instead, angle of attack distributions over the rotor disk were computed. Such distributions can give a rough idea under what conditions one can expect partial blade stall. Fig. 2-4 shows the blade angle of attack distribution for the power-on condition at $230 \mathrm{rpm}$ and $60^{\circ}$ yaw angle. The retreating blade moving away from the in-plane wind component shows the highest angles of attack and may stall along its inner portion. Fig. 2-5 shows the angle of attack distribution at $230 \mathrm{rpm}$ for a combination of power-on $60^{\circ}$ yaw angle with a $20 \%$ sec positive yaw rate. The high angle of attack region of the retreating blade is now larger and the stall region, if stall occurred, would extend further outboard as compared to the steady state $60^{\circ}$ yaw angle condition of Fig. 2-4. A lower rotor speed than $230 \mathrm{rpm}$ would further enlarge the stall region. However, at lower than rated $r$ pm the yaw control system is not in operation and high yaw angles do not occur. 


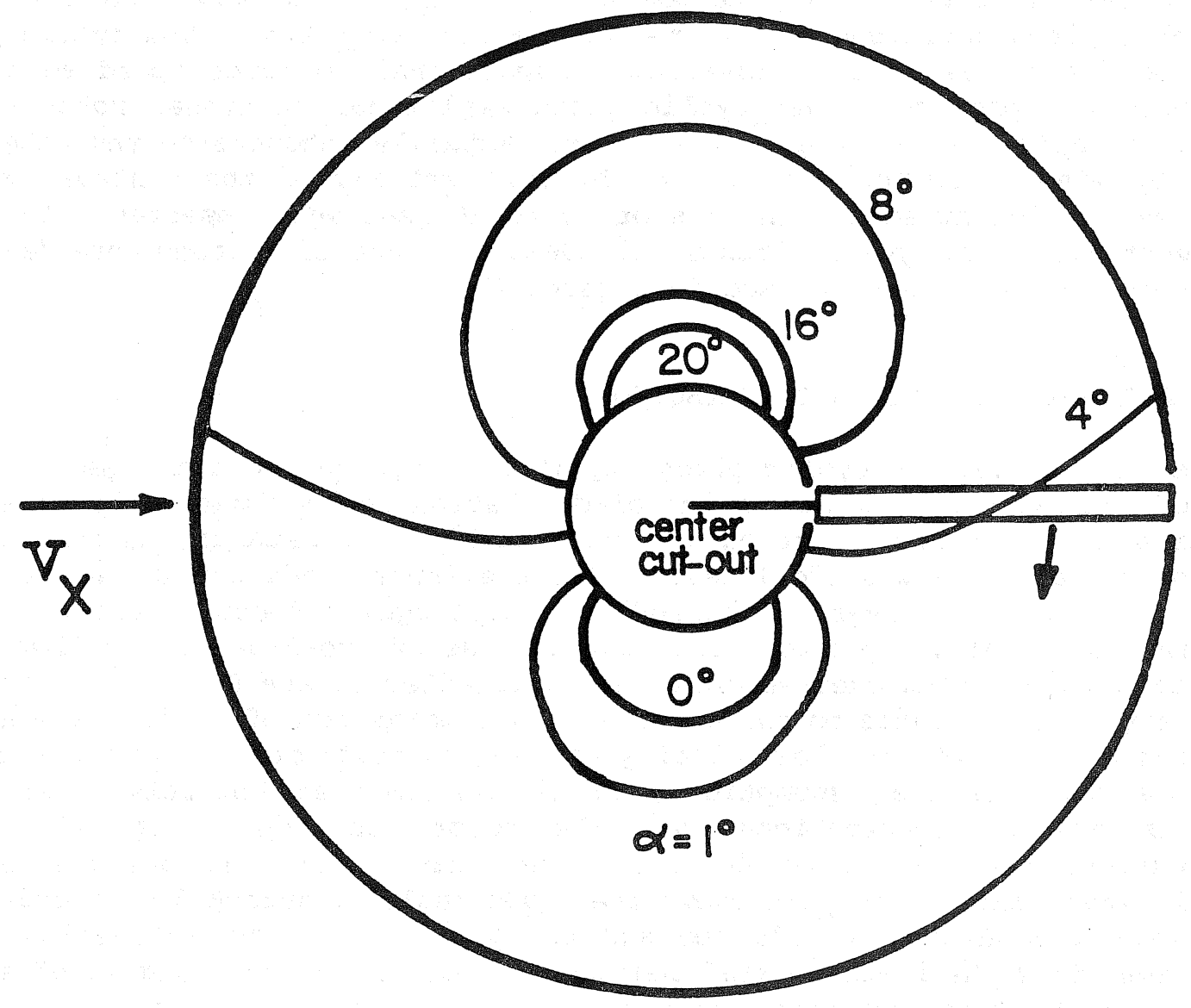

FIGURE 2-4. ANGLE OF ATTACK DISTRIBUTION, $60^{\circ}$ YAW ANGLE, ${ }_{Q} / \sigma$
$=0.008$ 


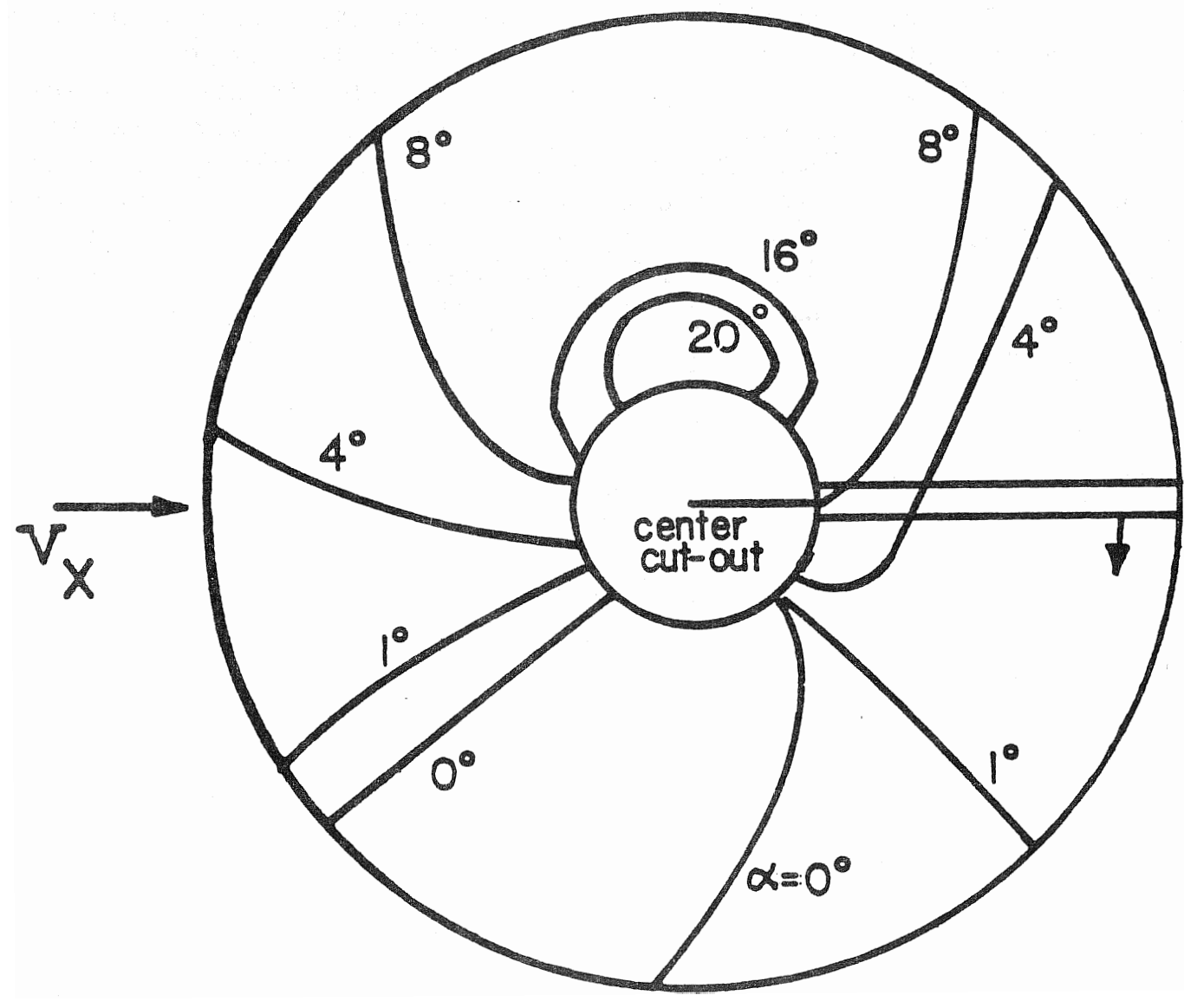

FIGURE 2-5. ANGLE OF ATTACK DISTRIBUTION, $60^{\circ}$ YAW ANGLE, $20^{\circ} / \mathrm{SEC}$ YAW RATE, $C_{Q} / \sigma=0.008$ 


\subsection{YAW STABILITY AND DAMPING}

The yaw dynamics analysis was used to determine the yaw stability and the yaw damping of the experimental wind rotor. The yaw stability is negative, that means a positive yawing moment is produced by yawing to positive yaw angles. Up to about $45^{\circ}$ yaw angle the stability derivative at $230 \mathrm{rpm}$ is $-20 \mathrm{Nm} / \mathrm{rad}(-15$ $\mathrm{ft}-\mathrm{lb} / \mathrm{rad}$ ), whereby the minus sign indicates instability. This value refers to the blades alone without shanks and hub. Beyond $45^{\circ}$ yaw angle the unstable yawing moment increases less than proportional to yaw angle. The yaw instability is generated by a rotor side force located $.68 \mathrm{~m}(2.25 \mathrm{ft})$ upwind of the yaw axis. The rotor instability is overcompensated by the stabilizing tail vane.

The yaw damping from the rotor blades is also negative, that means a positive yaw rate produces a positive yawing moment. The damping derivative is at 230 $\mathrm{rpm},-94 \mathrm{Nm} / \mathrm{rad} / \mathrm{sec}(-70 \mathrm{ft}-\mathrm{lb} / \mathrm{rad} / \mathrm{sec})$. The minus sign indicates negative damping. For constant furl angle the negative rotor damping is overcompensated by the positive tail vane damping. During furling or unfurling of the rotor, when the tail vane remains aligned with the wind direction, the negative rotor damping is not aerodynamically overcompensated. A mechanical furl damper is required in order to assure positive furl damping. For the passive furl control system the hydraulic damper was set such that a maximum equilibrium furl rate of about $20 \%$ sec was obtained. 
SECTION 3.0

CONTROL SYSTEMS DESIGN

The configuration of the atmospheric test equipment used during the first study phase and described in Ref. 2 was modified to allow the testing of two alternative fully automatic furl control systems. The first automatic furl control system was an active type using a hydraulic single-acting constant speed governor to provide oil flow to a servo cylinder to furl the rotor upon reaching rated rotor speed. Unfurling was accomplished by a return spring when the constant speed governor admitted oil from the hydraulic cylinder to the oil reservoir when below rated speed. The second automatic furl control system was purely mechanical and a passive type. The rotor thrust, due to the lateral off-set from the yaw axis, and the yawing moment from the rotor torque component, due to the uptilt of the rotor axis were the two driving forces. The two forces overcame the unfurling spring above rated power and furled the rotor. The two alternative automatic control systems will be described in more detail with the help of the assembly drawings in Appendix A.

\subsection{ACTIVE YAW CONTROL SYSTEM}

The top view in Fig. A-l shows the following components.

- Bearing block for rotor shaft.

- Shaft mounted gearbox with 15:1 gear ratio.

- Alternator, belt driven from gearbox output shaft with $1.66: 1$ ratio of pulley diameters for a total of 25:1 alternator to rotor rpm ratio.

- Hydraulic governor, belt driven from gearbox output shaft with 1:1.5 ratio of pulley diameters for a total of 10:1 governor to rotor $\mathrm{rpm}$ ratio.

- Adjustable furl stop, set between $80^{\circ}$ and $90^{\circ}$ furl angle.

- Yaw post, off-set by $114 \mathrm{~mm}$ (4.5 inch) laterally from rotor axis.

- Tail boom with tail vane.

- Boom pin assembly with arms for spring and for hydraulic cylinder. These arms were at $45^{\circ}$ to the rotor axis.

- Unfurl tension spring. For the active control system the spring had $89 \mathrm{~mm}$ ( 3.5 inch) mean diameter, 60 coils and $11.1 \mathrm{~mm}(7 / 16$ inch) wire diameter. For the passive control system the spring had the same mean diamter and the same number of coils, but $7.9 \mathrm{~mm}$ (5/16 inch) wire diameter. 
- Hydraulic cylinder, acting as servo for the active control system, as damper for the passive control system.

- Electric actuator in series with hydraulic cylinder. It had $25.4 \mathrm{~mm}$ (one inch) per second constant rate and was powered by 12 volt dc. It served as an emergency furling back-up in case of governor oil pressure loss, and as means to stop the rotor.

The axial view in Fig. $A-1$ is repeated from Fig. 1-l. It shows the inner portion of the rotor which was the same as for the first study phase and described in detail in Ref. 2. The side view in Fig.A-1 shows the same components as listed above. Note the uptilt of the rotor axis with respect to the horizontal and the uptilt of the center lines of spring, hydraulic cylinder and electric actuator.

Fig. A-2 shows an assembly drawing of the constant speed hydraulic governor Model 210681 manufactured by the Woodward Governor Company for the control of aircraft propellers. The governor was mounted with horizontal axis. The working fluid was drained from the governor into a reservoir located directly below. There was a supply line from the reservoir to the governor and a pressure line from the governor to the servo cylinder. For propeller applications the supply line is pressurized to $345 \mathrm{kPa}(50 \mathrm{psi})$. In the atmospheric test equipment the supply line pressure was negative since the fluid level in the reservoir was 6 inch below the governor pump. Though this was the first time the governor operated with a negative supply pressure, no difficulties were encountered after the lines were properly bled. The governor relief valve was set at $1380 \mathrm{kPa}(200 \mathrm{psi})$ which is lower than for propeller applications. The governor consumed, at rated rpm, 250 watts. Below rated rpm the power consumption fell in proportion to the cube of the rpm ratio. The governor controlling rpm could be adjusted between 950 and $2700 \mathrm{rpm}$ corresponding to 95 to 270 rotor rpm.

The governor bench tests were performed first with the governor alone at the Woodward Governor Company laboratory. Later the complete active furl control system was bench tested at the WUTA laboratory. Fig. A-3 shows the assembly drawing of the hydraulic cylinder made by Victor Fluid Power. It was used as a servo cylinder for the active furl control system and as a damper for the passive furl control system. In the first case one port was open, the other connected to the governor. In the second case the ports were interconnected by an oil line with a valve and an oil reservoir with a pressurized air space.

The governor had a very steep rise of oil pressure with overspeed error so that the relief oil pressure of (200 psi) was reached at only 18 overspeed. Bearing friction, servo friction and changes in spring force when furling had, therefore, a negligible effect on the regulated rotor speed. The oil flow rate, however, increased only slowly with rotor speed error. The maximum flow rate of the governor produced about $15 \%$ sec furl rate. An analysis of the active furl control system predicted a well damped control mode with a natural frequency of 0.14 cycles/sec. The low frequency is caused by the sluggish response of the oil flow rate to rotor speed errors. The analytical predictions were confirmed by the experiments. 


\subsection{PASSIVE YAW CONTROL SYSTEM}

The passive yaw control system, though simpler, more reliable, and independent of servo power with its energy loss, required the solution of the following problems.

- Dynamic Instability. Because of the negative aerodynamic damping of the upwind rotor, unstable modes can develop. Their supression requires artifical furl damping.

- Overspeed after Loss of Power. At the same rotor speed the power-off rotor thrust is much smaller than the power-on thrust, see Fig. 2-1. Thus after a loss of power, the rotor speed must increase substantially to increase the thrust to its previous value. To alleviate this overspeed after loss of power, the difference in power-on and power-off furling moment at any given rotor speed must be reduced.

- Overspeed from Unfurling Spring. The unfurling spring has its lowest force in the unfurled position. In the furled position it produces a substantially higher force tending toward overspeeding unless alleviated by a suitable kinematics.

- Contamination from Rotor In-plane Force. As the rotor furls, an inplane aerodynamic force develops which adds to the yawing moment from the rotor thrust. It has a large effect on the control characteristics and is difficult to predict quantitatively.

- Contamination from Bearing Friction. The tail boom bearing friction moment is sizeable in relation to the spring moment and causes a large hysteresis effect.

In view of these problems it was decided to first develop the active control system with its better predictability and presumably better control performance. The hydraulic single acting woodward governor had a long history of successful and reliable operation in large numbers of propeller airplanes and could be expected to perform well in wind turbine applications. The bench tests with the active control system confirmed the expectation that this system would function well and would present few problems. It was then decided to immediately follow up with the passive control system in a configuration suitable for power-off testing of both systems'in the atmosphere. A simple way was found of laterally off-setting the yaw axis by $114 \mathrm{~mm}$ ( $4.5 \mathrm{inch}$ ). This offset was built in before the machine left the laboratory. The yaw axis off-set did not prevent power-off operation of the active governor system since the control function was insensitive to the loading of the servo cylinder. However, for power-on operation the active system, due to the off-set, would be overloaded. The plan was to test in the atmosphere both furl control systems power-of $E$ and then to remove the off-set of the yaw post for power-on governor testing. To change from the governor system to the passive thrust control system it was only required to replace the servo cylinder by an identical cylinder rigged as a hydraulic damper. In addition, the $11.1 \mathrm{~mm}(7 / 16$ inch) return spring had to be replaced by the $7.9 \mathrm{~mm}(5 / 16$ inch) spring, see Fig. $A-1$. 
Of the 5 problems mentioned before, the first was solved by an adjustable damper. The damping force could be increased until dynamic instability was removed. The second problem was initially avoided by testing only power-off conditions. The third problem was solved by introducing a kinematic relation whereby the spring moment arm became smaller for greater furl angle, thus compensating in part, for the increased spring force. The fourth problem was attacked by an elaborate analytical study which allowed estimation of the inplane force of the rotor. The fifth problem was alleviated, however not completely solved during the second study phase. The original tail boom pin friction moment of $115 \mathrm{Nm}$ ( $85 \mathrm{ft}-1 \mathrm{~b})$, caused by the two closely spaced sleeve bearings and the high gravity moment of the tail boom, was reduced to $24 \mathrm{Nm}$ (18 ft-lb) by adding a support strut to the top of the boom and a third furl bearing $228 \mathrm{~mm}$ ( 9 inch) above the boom center. Another source of friction was the break-out friction of the hydraulic damper. As received, the piston and the rod seals were designed for $13,800 \mathrm{kPa}(2000 \mathrm{psi})$ pressure. They produced an unacceptable break-out force. The piston seal was removed. The internal leakage that resulted was small as compared to the flow through the adjustable valve. The rod seal was reduced in diameter. It was now compatible with the damper pressure of 34 to $68 \mathrm{kPa}$ ( 5 to $10 \mathrm{psi}$ ) and had a reduced break-out friction, provided there were no appreciable lateral loads on the rod. Initially such lateral load was transmitted by the weight of the electric actuator. The actuator was then balanced by a weight located on the spring side and indicated in Fig. A-1.

Due to the piston rod which extends only toward one side of the piston, a given piston travel displaces less fluid on the side of the rod than on the opposite side. To compensate for the difference in fluid displacement a pressurized reservoir partly filled with air was added. The line connecting the two ports of the cylinder had an adjustable valve to change the damper force per rate of displacement. For a prototype version this experimental adjustable damper should be replaced by a commercially available damper of 10 inch stroke and with a fixed damping force per specified rate of displacement, whereby a low break-out force is a necessary requirement.

Both furl control systems were tested in the atmosphere in the power-off condition which is more severe than the power-on condition because of the greater runaway tendency of the rotor. The active governor system worked to satisfaction and could be expected to perform equally well or better in poweron conditions. The passive control system had excessive hysteresis from breakout friction and could be expected to show a substantial difference between the controlled power-on and power-off $\mathrm{rpm}$. It was decided to limit the subsequent work toward the perfection of the passive furl control system with its greater simplicity, lower initial cost and greater reliability.

The configuration used for the power-off atmospheric tests was not suitable for power-on testing of the passive system. The yaw axis had been displaced to the left of the rotor axis seen in the downwind direction. The yawing moment from the rotor thrust and from the yaw component of the rotor torque were additive. This would produce a very large difference in rotor speed between the power-on and the power-off conditions. The yaw axis off-set was, therefore, changed 
from the left to the right side of the rotor axis seen in the downwind direction, as shown in Fig. A-1. Now the yawing moment from the rotor thrust is opposite to the yaw component of the rotor torque. When applying rotor power, the increase in yawing moment from the increased rotor thrust (see Fig. 2-1) is partly compensated by the opposite yawing moment of the rotor torque component.

The equivalent thrust $\mathrm{T}_{\mathrm{EQ}}$ is defined by

$$
\mathrm{T}_{\mathrm{EQ}}=(\mathrm{T} \mathrm{c}+\mathrm{H} \mathrm{d}-\mathrm{Q} \beta) / \mathrm{C}
$$

It represents the rotor thrust corrected for the effects of in-plane force $\mathrm{H}$ and for the yaw component from rotor shaft uptilt $Q \beta$. Fig. 3-1(a) shows analytical values of the equivalent thrust $T_{\text {at }} 200 \mathrm{rpm}$ vs. wind speed for constant yaw or furl angles and for constant torque coefficients $c / \sigma$. The analysis was based on the method developed in Ref. 12. It assumed ${ }^{2}$ degree rotor axis uptilt angle and $114 \mathrm{~mm}$ (4.5 inch) lateral off-set $c$ of the yawing axis. The equivalent thrust moment from rotor thrust, rotor torque and inplane side force is balanced above rated wind speed by the moment of the unfurling spring. This moment is a function of the furl angle. Though the spring force increases with furl angle, the moment arm of the spring with respect to the yaw axis first increases and then decreases with furl angle. The following table gives for 4 furl angles the spring extension in inch, the spring moment arm with respect to the yaw axis in inch and the equivalent spring force in $1 b$.

Table 3. Spring Characteristics

\begin{tabular}{llcc}
$\begin{array}{l}\text { Furl } \begin{array}{l}\text { Angle } \\
\text { (Degree) }\end{array} \\
\text { Dering } \\
15\end{array}$ & $\begin{array}{l}\text { Extension } \\
\text { (Inch) }\end{array}$ & $\begin{array}{c}\text { Spring } \\
\text { Moment Arm } \\
\text { (Inch) }\end{array}$ & $\begin{array}{c}\text { Equivalent } \\
\text { Spring Force } \\
\text { (lb) }\end{array}$ \\
\hline 40 & 21.0 & 7.7 & 210 \\
65 & 24.5 & 8.5 & 260 \\
90 & 28.3 & 7.7 & 270 \\
& 31.0 & 5.5 & 220
\end{tabular}

The spring extension is taken from the force free position. The equivalent spring force for each of the furl angles shown in Fig. 3-1(a) is indicated by the dash line. For a constant rotor speed of $200 \mathrm{rpm}$, as would occur with a grid connected induction generator, furl angles and torque coefficients are those taken along the dash line. Up to $13.4 \mathrm{~m} / \mathrm{sec}$ ( $30 \mathrm{mph}$ ) or 40 degree furl angle the torque coefficient remains constant at $c / \sigma=0.011$. Because of the constant rpm the rotor power is also constant between $9.8 \mathrm{~m} / \mathrm{sec}$ ( $22 \mathrm{mph}$ ) or 15 degree furl angle and $13.4 \mathrm{~m} / \mathrm{sec}(30 \mathrm{mph})$ or 40 degree furl angle. For higher wind speeds the torque coefficient and the associated power decline. For example, at $17 \mathrm{~m} / \mathrm{sec}$ ( $38 \mathrm{mph}$ ) or 60 degree furl angle the torque coefficient is $c / \sigma=0.0080$. At $19.2 \mathrm{~m} / \mathrm{sec}(43 \mathrm{mph})$ or 70 degree furl angle the torque coefficient is $c / \sigma=0.0060$. At $22 \mathrm{~m} / \mathrm{sec}(49 \mathrm{mph})$ or 80 degree furl angle the torque is $c / \sigma \stackrel{0}{=} 0.0030$. Thus there is with increasing wind speed and with increasing furl angle a gradual decrease in rotor power. 


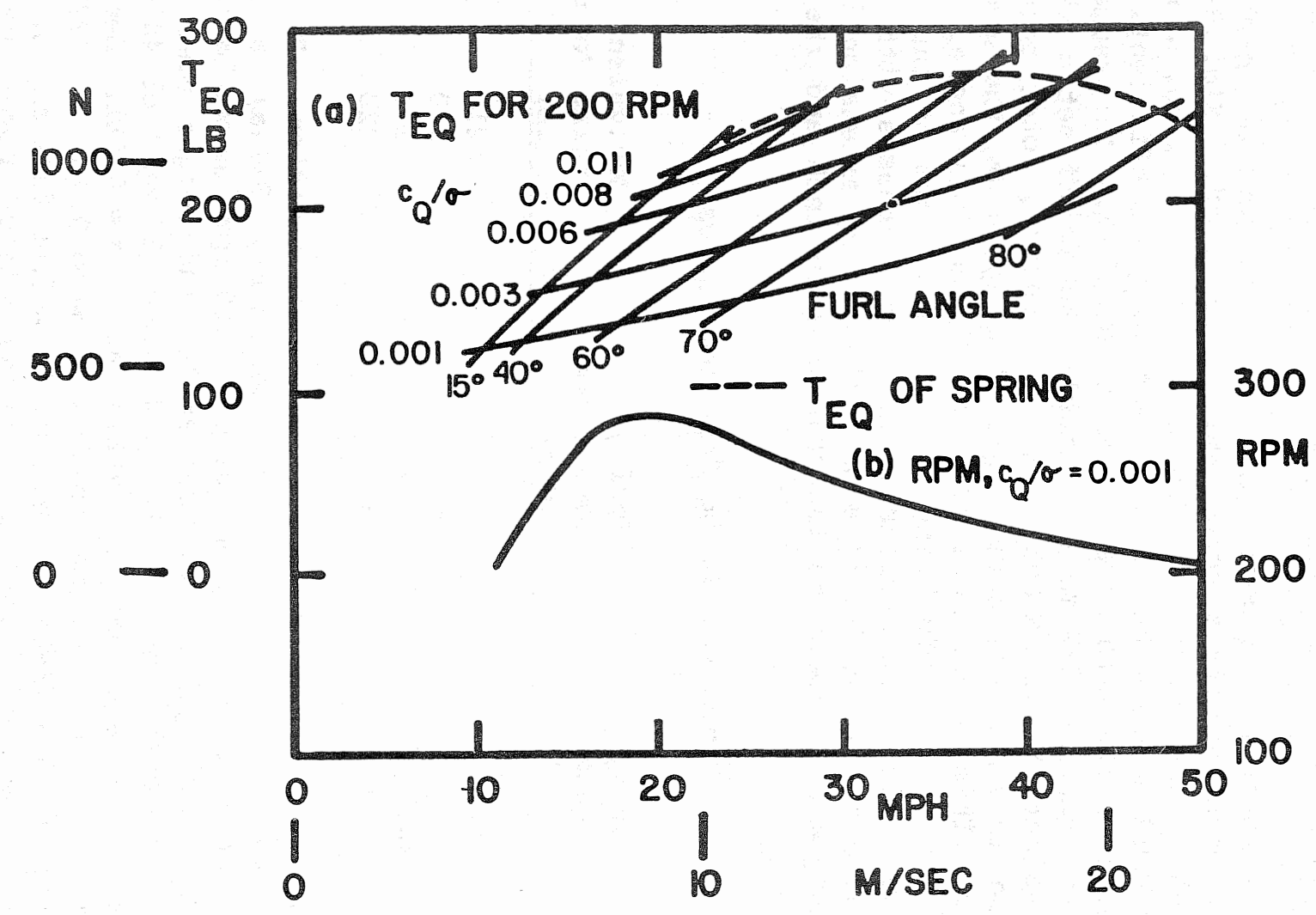

FIGURE 3-1(a). EQUIVALENT ROTOR THRUST FOR 200 RPM VS. WIND SPEED FOR CONSTANT FURL ANGLES AND FOR CONSTANT $c_{Q} / 0$ 
Somewhat above $22 \mathrm{~m} / \mathrm{sec}(49 \mathrm{mph}$ ) the rotor would require a power input from the grid in order to maintain constant rotor speed. The Electromatics wind turbine relay (see Section 4.2.2) which is needed anyway in order to prevent motoring at low wind speed, will then disconnect the generator from the grid. The wind turbine will now autorotate at a speed of less than $200 \mathrm{rpm}$. There is no need for the conventional wind speed triggered power cut-out device at high wind speed. There is also no need for braking the wind turbine speed after power cut-out as is done in conventional designs. The turbine should survive storms in autorotation in almost edgewise position to the wind direction whereby the rotor thrust is much smaller than for power-on operation, see Fig. 2-1.

The characteristics for constant torque coefficient operation as with the tuned alternator can also be found from Fig. 3-1(a). Up to 60 degree furl angle the curve $c_{0} / \sigma=0.0080$ is below the dash line. This means that the rotor speed will be greater than $200 \mathrm{rpm}$. For example, at 40 degree furl angle the rotor equivalent thrust is $980 \mathrm{~N}(220 \mathrm{lb})$, the spring equivalent force is $1160 \mathrm{~N}_{1} / 260$ 1b). To obtain balance, the rotor speed assumes the value $200(260 / 200)^{1 / 2}=$ $217 \mathrm{rpm}$. At 60 degree furl angle and $c_{0} / \sigma=0.0080$ the rotor equivalent thrust and the spring equivalent force are equal so that the rotor speed will be 200 $\mathrm{rpm}$. Since rotor power at given torque coefficient varies with the cube of the r pm, the rotor power at 60 degree furl angle or $17 \mathrm{~m} / \mathrm{sec}(38 \mathrm{mph})$ is reduced to 0.78 times the power at 40 degree furl angle or $10.7 \mathrm{~m} / \mathrm{sec}(24 \mathrm{mph})$. Beyond 17 $\mathrm{m} / \mathrm{sec}$ ( $38 \mathrm{mph}$ ) the rotor speed would drop below $200 \mathrm{rpm}$ since the equivalent thrust at $c / \sigma=0.0080$ increases in relation to the equivalent spring force. Because of Increasing blade stall, see Figs. 2-4 and 2-5, the rotor cannot sustain a torque coefficient of $c / \sigma=0.0080$ at furl angles much over 60 degree. If the alternator demands this torque coefficient but the rotor cannot supply it, the rotor speed would collapse. Thus the alternator should not remain connected to its load during storms if a collapse of rotor speed and severe stall operation is to be avoided. Beyond some furl angle in the vicinity of 60 degree the alternator load should be shed. Fig. 3-1(a) shows what will happen in this case. Assuming that $c / \sigma=0.0010$ represents the drive system and alternator loss after disconnecting the alternator load, the rotor will now autorotate with $c_{0} / \sigma=0.0010$. If the load disconnect had been performed at 60 degree furl angle or $17 \mathrm{~m} / \mathrm{sec}$ ( $38 \mathrm{mph}$ ) wind speed, the furl angle would adjust to somewhat below 80 degree. The spring equivalent force at 80 degree furl angle is $1070 \mathrm{~N}(240 \mathrm{lb})$. The rotor equivalent thrust is $850 \mathrm{~N}$ (190 1b). The autorotational speed is $200(240 / 190))^{1 / 2}=225 \mathrm{rpm}$.

The rotor speed for $c_{0} / \sigma=0.0010 \mathrm{vs}$. wind speed is shown in Fig. 3-1(b). The maximum autorotational speed occurs at $9 \mathrm{~m} / \mathrm{sec}(20 \mathrm{mph})$. It declines at higher wind speeds. The maximum autorotational speed will not be encountered in normal operation since at $9 \mathrm{~m} / \mathrm{sec}(20 \mathrm{mph})$ the generator load will normally be connected. With induction generator the rotor speed will then be $200 \mathrm{rpm}$, with alternator it will be $217 \mathrm{rpm}$. In case of an accidental shedding of the generator load or of the grid power one can use a grid power sensing relay for the electric actuator which would furl the rotor all the way so that it would stop rotating after grid failure. As soon as the grid power is restored, the electric actuator would move to the unfurl position allowing the wind turbine to restart. Alternatively the electric actuator could furl the rotor not all the way but only to 70 or 80 degree furl angle so that it would keep autorotating at reduced speed. 

SECTION 4.0

ATMOSPHERIC TEST RESULTS

After completing the modifications described in the preceding section the test equipment was reassembled at the site and was ready for testing on March 20, 1981. Testing of the configuration with the alternator extended through May, 1981. Both the active furl control system with the hydraulic constant speed governor and the passive furl control system were tested. During this period the tower was raised 18 times bringing the total number of tower raisings since May 23, 1980 to 64. The test equipment was operated for 25 hours, bringing the total number of operational hours since May 23, 1980 to 121. Mean wind speeds up to $11 \mathrm{~m} / \mathrm{sec}(25 \mathrm{mph})$ were encountered which is only half the wind speed range shown in Fig. 3-l(a). After waiting four months in vain for higher wind speeds, it was decided to replace the alternator by a grid connected induction generator. As explained before, the passive furl control system is well suited to interface with a constant speed electric generator.

The configuration with induction generator was ready for testing on October 1 , 1981. The tower was raised in October, 19818 times bringing the number of raisings since March 20, 1981 to 26 and the total number of raisings since May 23. 1980 to 72. The equipment was operated in October, 1981 for 20 hours, bringing the number of operational hours since March 20, 1981 to 45 and the total number of operational hours since May 23, 1980 to 141. Both the tests with the alternator and with the induction generator configuration showed substantial hysteresis in the passive furl control system which was caused by excessive friction of the sleeve bearings for the tail vane boom.

\subsection{TEST RESULTS WITH ACTIVE CONTROLS}

The active yaw control system was only tested in the power-off condition which is the more critical one from the point of view of preventing overspeeds. Only analog data were taken. Fig. 4-1 shows a typical time history of 44 seconds duration. The wind speed varied between 4.4 and $20 \mathrm{~m} / \mathrm{sec}$ (10 and $45 \mathrm{mph}$ ), whereby the initial steep rise from 10 to $35 \mathrm{mph}$ occurred within 6 seconds. The rotor speed is kept to a mean value of $200 \mathrm{rpm}$ within less than \pm 108 . The furl angle trace shows a natural frequency of 0.14 cycles/sec which had been predicted by the analysis. The maximum furl rates are about $15 \% / \mathrm{sec}$, also according to prediction. The cyclic pitch varies between \pm 2 and \pm 6 degree amplitude. The yaw post angle oscillations are essentially $180^{\circ}$ out of phase with the furl angle oscillations which is caused by the selection of positive yaw post angle opposite to that of positive furl angle. The effects of wind direction changes which influence the yaw post angle but only indirectly the furl angle cause the two traces to be not exactly in anti-phase.

In summary one can state that the active furl control system worked well and kept the power-off rotor speed close to the set value of $200 \mathrm{rpm}$ despite very large wind fluctuations. The reliability of the propeller governor should be 


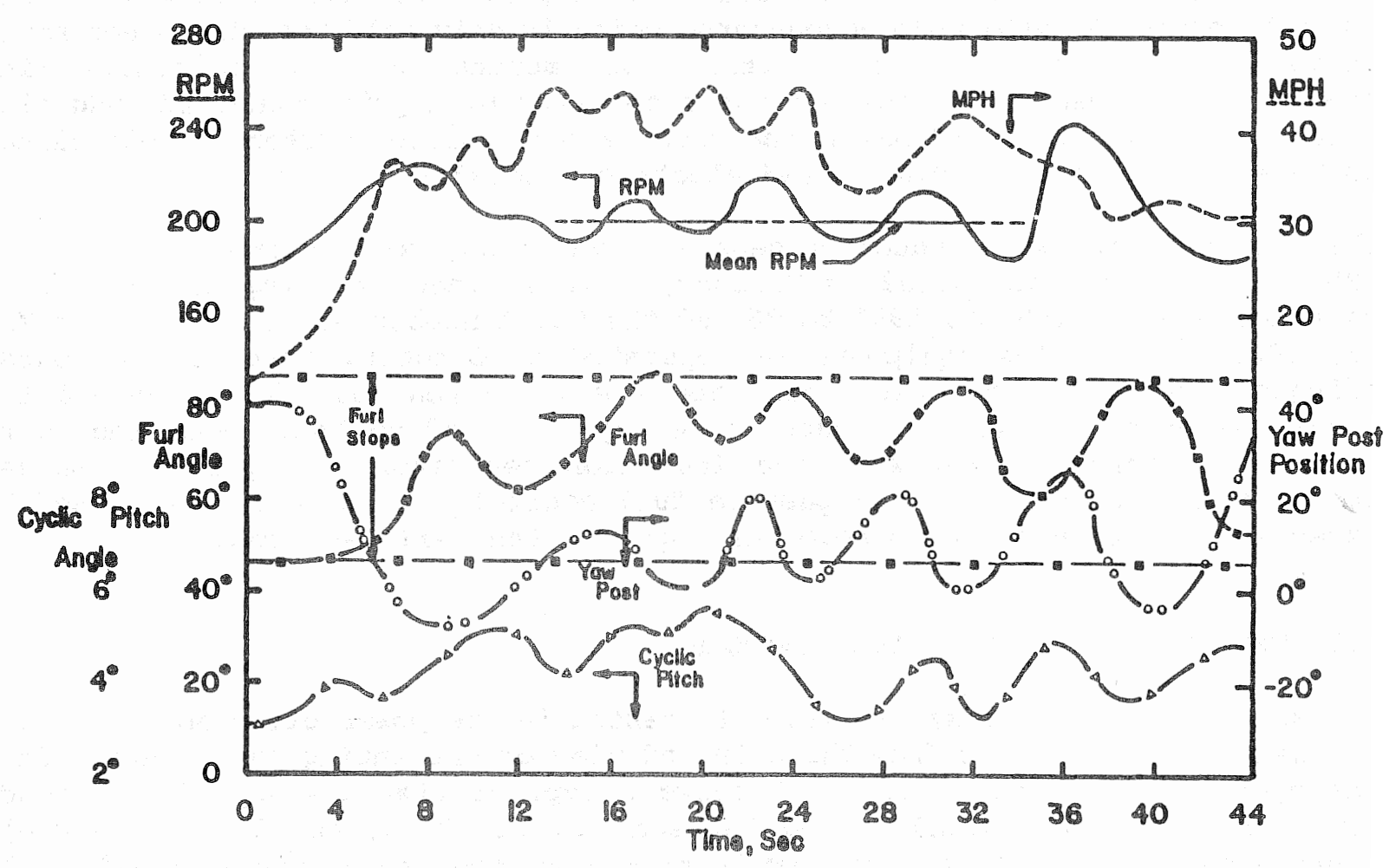

FIGURE 4-1. TIME HISTORY FOR POWER-OFF ACTIVE RPM CONTROL 
very good. However, since a loss of oil pressure at high wind speed would cause a runaway condition, a separate emergency system is needed. One could consider the use of the governor oil pressure for unfurling and of the spring for furling. The turbine would then always stop in the furled position and would not self start in an upcoming wind. This would require a separate starting system. For the present configuration the turbine stops in the unfurled position and is ready for self-starting as soon as sufficient wind is available.

\subsection{TEST RESULTS WITH PASSIVE YAW CONTROI}

The passive yaw control system was tested more elaborately than the active system. Both power-on and power-off conditions were tested. Both analog and digital data were taken. Both the alternator and the induction generator configurations were studied with respect to the passive furl control characteristics. As explained before, these characteristics are quite different from each other. The reasons for the abbreviated testing of the active furl control system in comparison to the more elaborate testing of the passive furl control system were the following. The active system functioned well in the critical power-off condition with its tendency toward rapid overspeeding during gusts. One could expect it to function even better for power-on conditions. It was. therefore concluded that the tests with the active system were adequate for an evaluation of its potential. In contrast, the passive furl control system. though ultimately more desirable, needed some development testing to overcome its various problems. Furthermore, the active furl control system with hydraulic constant speed governor was not suitable in case of a constant speed induction generator which required a torque control rather than a rotor speed control. The passive furl control system, as explained before, could be expected to be compatible also with a constant speed induction generator.

\subsubsection{Passive Yaw Control With Alternator}

The passive yaw control system was first tested power-off in the atmosphere on March 20, 1981. Development testing extended to the end of Apri1, 1981. The system exhibited some of the anticipated problems. It was unstable unless artifically damped, the rotor speed increased with furl angle because of the increasing spring force, and the contamination with friction moments required the reduction to about one-half of the furling $r$ pm before unfurling began. Part of the friction was caused by the seals in the hydraulic damper. The seal for the piston was removed and the seals for the rod were reduced in size. The oil reservoir for the damper had an air space on top to accept the oil from the rod displacement. Tests were conducted with closed and vented reservoir. In the latter case the damper force would occasionally collapse leading to a high furl rate. The damper functioned best when the reservoir was not vented but rather pressurized to about $30 \mathrm{kPa}(5 \mathrm{psi})$ in the unfurled position. The pressure increased to $70 \mathrm{kPa}(10 \mathrm{psi})$ in the furled position. This springlike behavior of the damper was compensated by relasing the unfurl spring to a lower preload. A valve in the line connecting the two ports of the hydraulic cylinder allowed varying of the damper force. 
Atmospheric power-off tests were conducted without the damper, with the damper valve wide open, one-half closed and two-third closed. Even without the damper the passive furl control system functioned well up to sizeable gusts. However, an occasional severe gust produced an unstable furl runaway with furl stop impact. This occurred when the negative rotor yaw damping overcame the system friction. Adding the damper with open valve improved the situation but did not prevent an occasional unstable behavior. With the final two-third closed valve setting no such unstable condition has been encountered.

The system was now ready for power-on testing which, however, required a reversal of the lateral yaw axis off-set and of the furl direction. The equipment was disassembled at the site, transported to the WUTA laboratory and reassembled once more on the pedestal. In addition to installing the yaw post with opposite lateral off-set and to reversing the furl direction, a rotor lock was designed and built to allow raising and lowering the tower in high winds. The modified equipment was ready for renewed testing at the site on April 16, 1981. Power-on runs were performed on May 1,11 and 14, 1981. The rotor speed at the beginning of furling varied between 180 and $220 \mathrm{rpm}$ and at the beginning of unfurling between 150 and $160 \mathrm{rpm}$. The principle of using a combined passive rotor thrust and rotor torque control with opposite yawing moment was successful in reducing the spread between power-on and power-off rotor speed in the mean to $25 \mathrm{rpm}$.

In contrast to the rotor speed there was much less scatter in the rotor thrust. If one corrected the actual rotor thrust for the contribution of the rotor torque to the yawing moment, see Eq. (3-1), the equivalent thrust at the beginning of furling was in the mean $890 \mathrm{~N}(200 \mathrm{lb})$, at the beginning of unfurling it was in the mean $445 \mathrm{~N}(100 \mathrm{lb})$. Little difference in these values was observed between power-on and power-off conditions. Fig. 4-2 shows an example of the relation between furl angle and equivalent thrust for a poweroff run. There is not much scatter about the mean values of the equivalent thrust for furling and unfurling. The one to two ratio between the unfurling and the furling equivalent thrust remained throughout the tests including those with the induction generator.

Fig. 4-3 shows a typical furling in response to a gust. The figure is a copy of the oscillograph record and shows thrust, furl angle, torque and wind speed vs. time. The rpm is noted for 3 time instants. In contrast to Fig. 4-1 for the active control, the furling and unfurling process for the passive system was not continuous but occurred in steps with a constant furl rate. The negative rotor yaw damping moment is a linear function of the furl rate. The hydraulic damper moment is a quadratic funciton of the furl rate. Equilibrium between these to opposing moments is achieved only at a specific furl rate which depends on the damper setting. The size of the furl step, about 30 degree furl angle change in the case shown in Fig. 4-3, presumably depends on the break-out friction and should become smaller when this friction is reduced. 
- BEGIN FURL

$X$ BEGIN UNFURL

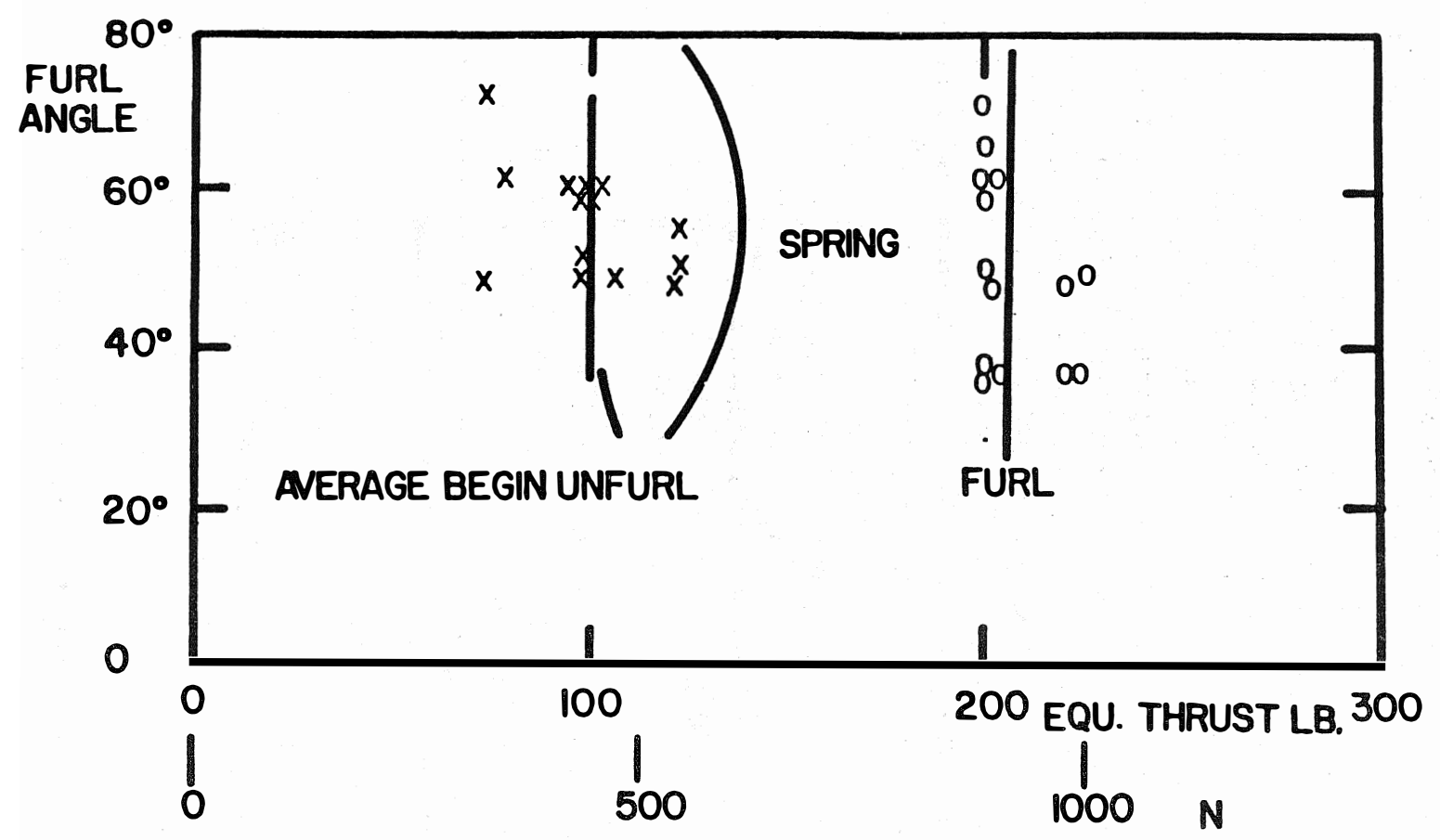

FIGURE 4-2. EQUIVALENT THRUST AT BEG IN OF FURL AND UNFURL FOR POWEROFF RUN OF MAY 14, 1981 


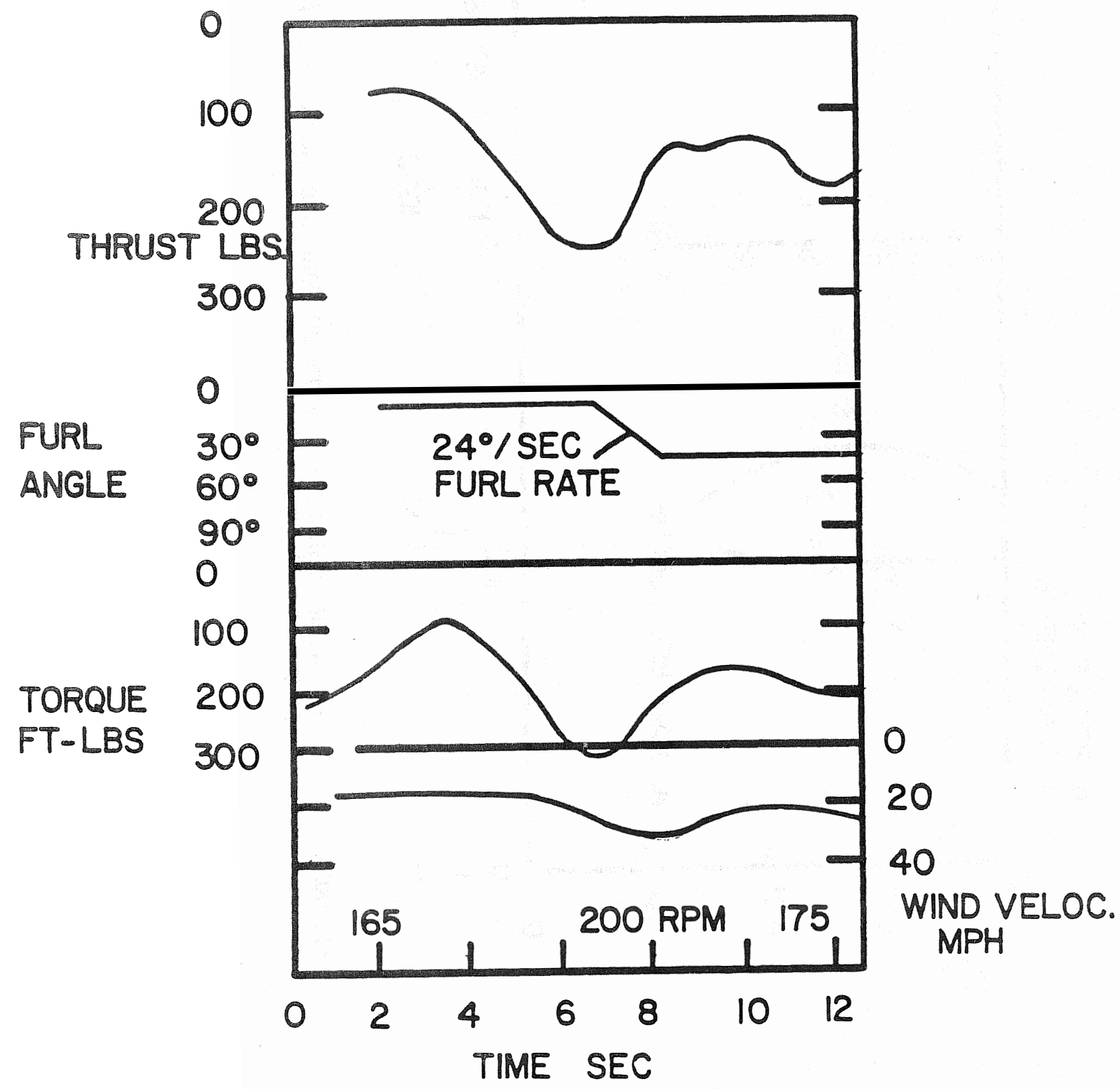

FIGURE 4-3. TYPICAL FURLING IN RESPONSE TO A GUST FROM 7 TO $14 \mathrm{M} / \mathrm{SEC}$ (15 to $30 \mathrm{MPH}$ ), POWER-ON RUN OF MAY 14, 1981 
Fig. 4-4(a) to (f) shows the results of digital data taking. The "WIND 6 " program was applied which for a power-on run has been described in Ref. 2 . Rotor torque and other fast varying quantities were sampled 128 times during one second to determine mean and amplitude. Slowly varying quantities like wind speed, $r$ pm, furl angle, yaw post angle were sampled at the end of the one second high speed sampling routine. The nest sample set was taken about 2 seconds later during which time the microcomputer updated the mean, standard deviation, global maximum and global minimum of all sampled quantities for the current wind speed "bin" which had a width of $1 / 2 \mathrm{~m} / \mathrm{sec}$. Each run consisted of 1000 to 3000 sample sets.

Fig. 4-4 (a) shows the distribution of the sample sets over the wind speed bins in a graph that represents $\log \mathrm{N}$ VS. wind speed. In the main wind speed range there were about 200 sample sets in each bin. Bins with less than 5 sample sets have been ignored.

Fig. 4-4 (b) gives a mean and standard deviation of the furl angle for each wind speed "bin". Between 3 and $6 \mathrm{~m} / \mathrm{sec}$ wind speed there were about 200 sample sets per bin, below 3 and above $6 \mathrm{~m} / \mathrm{sec}$ there mere fewer sample sets per bin for a total of 1180 sample sets. Up to $8 \mathrm{~m} / \mathrm{sec}$ the mean furl angle remained close to $15^{\circ}$ determined by the elastic unfurling stop. At higher wind speeds there occurred quite high furl angles with means close to $40^{\circ}$. The large standard deviation of the furl angle for these bins was presumably caused in part by the influence of the bearing break-out friction.

Fig.4-4 (c) shows for the same run the rpin statistics for each wind speed bin. The tip speed ratios $\lambda=\Omega R / V$ are superimposed in dotted lines. Mean, standard deviation, maximum and minimum of the rpm for each wind speed bin are plotted. The maximum rotor speed for all bins is close to $210 \mathrm{rpm}$.

Fig. 4-4(d) shows for the same run the rotor torque statistics for each wind speed bin. Again, mean, standard deviation, maximum and minimum are plotted. The maximum torque is held throughout to about $410 \mathrm{Nm}$ (300 ft-1b). The data prove that the passive yaw control system limits rotor speed and rotor torque rather accurately during an extended run with widely varying wind speeds.

Fig. 4-4(e) shows the rotor thrust statistics. The thrust has been computed from the measured blade flap-bending moment at the rotor center under the assumption that the center of the thrust distribtuion is located at two-thirds of the rotor radius. This assumption was checked by measuring the yaw post bending moment which is mainly determined by the thrust. Good agreement was found, see Ref. 2. The thrust is limited by the passive furl control system to about $120 \mathrm{~N}(270 \mathrm{lb})$.

Fig. 4-4(f) shows the cyclic pitch amplitude vs. wind speed. The mean value is about 4 degrees. The standard deviation is quite high.

The anemometer used for the tests was located $4.5 \mathrm{~m}$ ( $15 \mathrm{ft}$ ) below the rotor center on an arm attached to the tower in the western direction. Since only results for westerly winds are reported here, there were no obstacles up wind of the anemometer. Later, a second anemometer of the same type was installed 


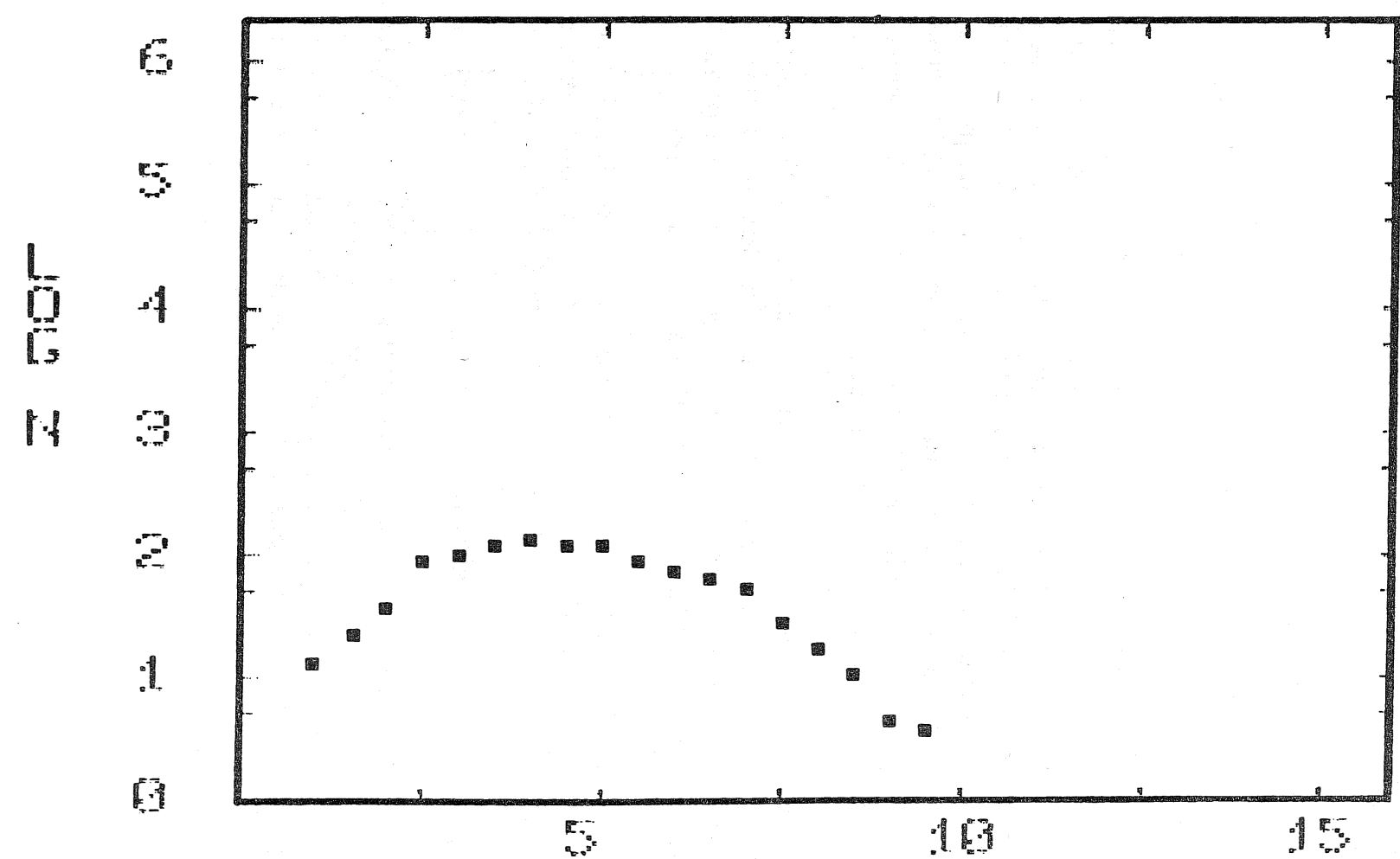

FIGURE 4-4. DIGITAL DATA FOR POWER-ON RUN WITH ALTERNATOR ON MAY 14, 1981

(a) LOG SAMPLES (N) VS. WIND SPEED (M/S) 


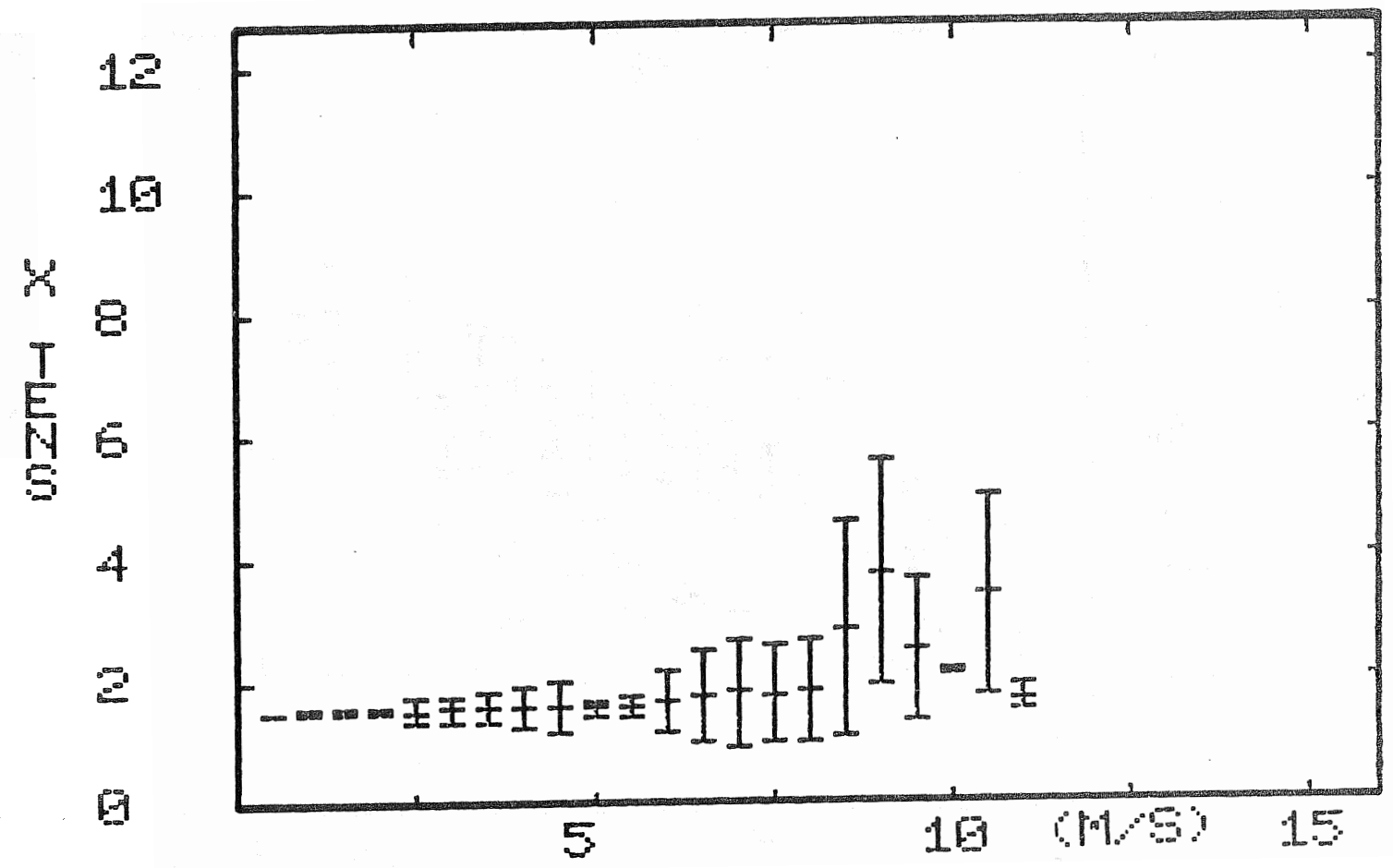

FIGURE 4-4. continued

(b) FURL ANGLE (X) VS。 WIND SPEED (M/S) 


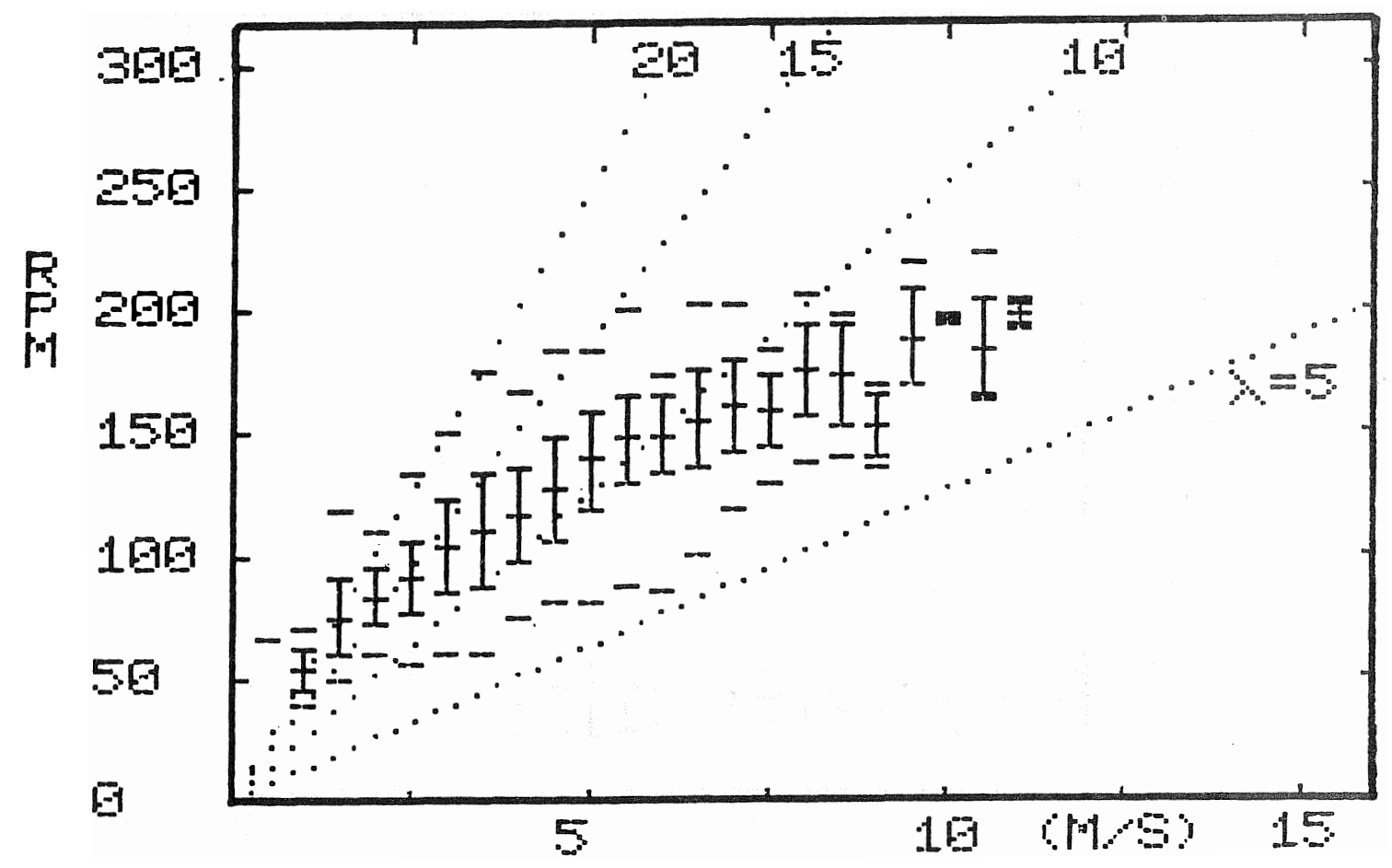

FIGURE 4-4. continued

(c) RPM VS. WIND SPEED (M/S) 


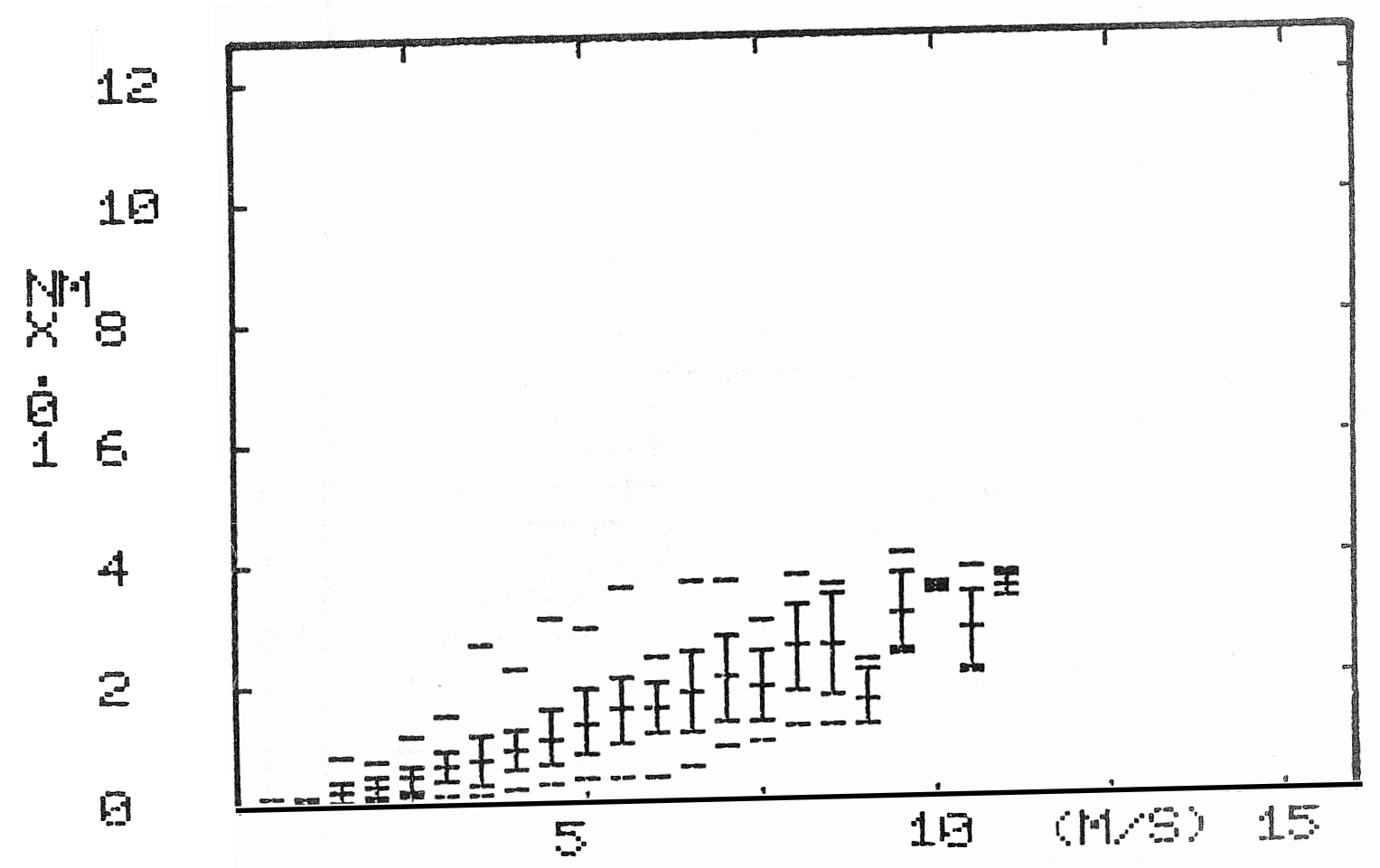

FIGURE 4-4. continued

(d) ROTOR TORQUE (NM) VS. WIND SPEED (M/S) 


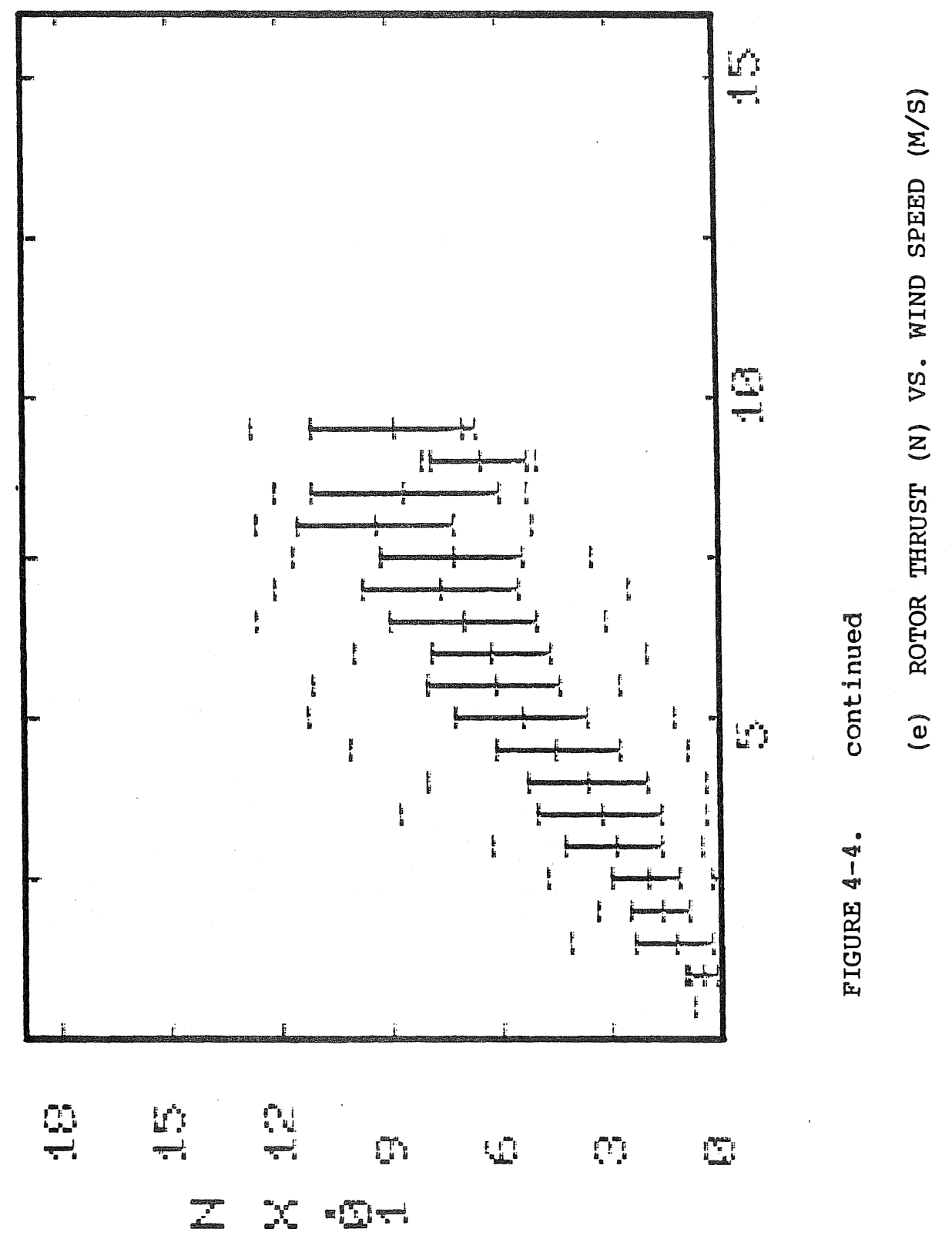




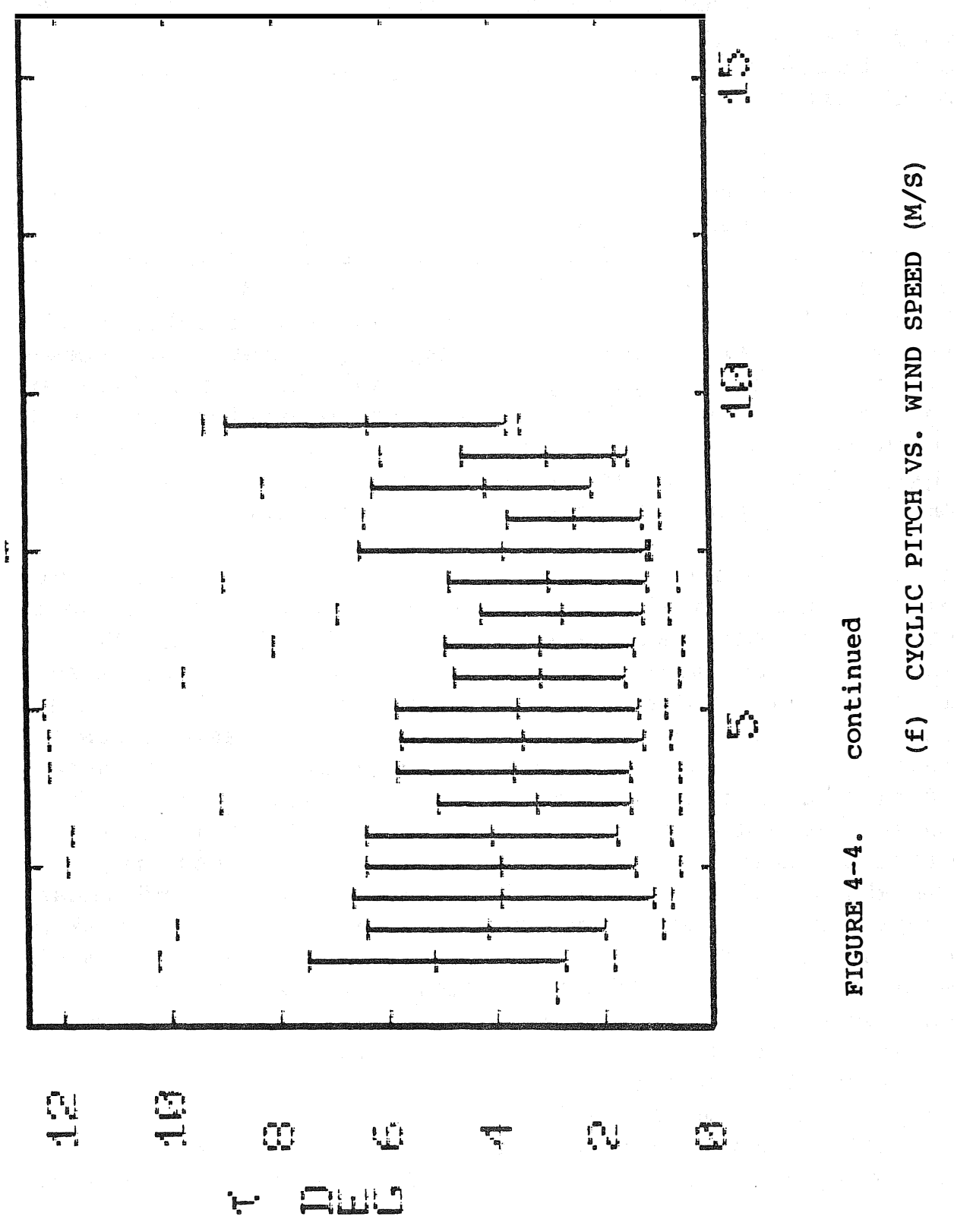


somewhat above rotor center. The readings of the two anemometers were compared for westerly winds while the turbine was furled and stopped, so that the wind had undisturbed access also to the higher anemometer. Fig. 4-5 shows mean and standard deviation of the upper anemometer for each "bin" of the lower one. For $5 \mathrm{~m} / \mathrm{sec}$ both anemometers give the same mean reading. For lower wind speeds the upper instrument reads higher, for higher wind speeds it reads lower. This is apparently a Reynolds number effect of the flow across the ridge. At low velocity the two anemometers are inside the boundary layer, so that the velocity increases with height. For high velocity the potential flow pattern comes into effect for which the flow velocity is higher closer to the top of the ridge.

When correcting the wind speed of the lower anemometer to that of the upper one, mean $c_{p}$ values for the various bins of over 0.50 were obtained. The weighted average (weighted with the number of sample sets for each bin) of these $c_{p}$ values for the run of Fig. 4-4 was 0.58. This is close to the Betz limit and could not occur in a steady flow. This result was also obtained for other runs. Similar values of average $c_{p}$ numbers have been found by other researchers. For example Spera and Janetzke, Ref. 14, report 10 minute averages of $c_{p}$ of over 0.5 for fixed pitch operations of the MOD-OA and MOD-1 wind turbines. It seems that for the type of averaging used, the Betz limit is not applicable. A proper probabilistic treatment of energy conversion in random flow fluctuations appears to be called for.

The values on loads given in Ref. 2 still apply for the passive furl control system with exception of the $2 \mathrm{P}$ blade coning oscillations. During rapid poweron furling such oscillations with up to $\pm 1360 \mathrm{Nm}( \pm 12,000 \mathrm{in}-1 \mathrm{~b})$ blade root bending moment were measured. The coning amplitudes increased with increasing cyclic pitch amplitudes which in turn increased with furl rate. Unfurling resulted in substantially smaller 2P blade coning amplitudes. The indications are that partial blade stall caused this phenomenon. The dynamic yaw analysis showed that for high furl rates high blade angles of attack occur in the upper region of the rotor disk, see Fig. 2-5. The same rates in the unfurling direction produced lower angles of attack. The reason is that for furl rates the aerodynamic blade forces that produce thrust and those that overcome gyroscopic moments add in the upper region of the rotor disk with its reduced relative velocity due to side flow. For unfurl rates the maximum aerodynamic force on the blade is in the lower region of the rotor disk with its increased relative velocity due to side flow. Thus stall will first occur during furl in the upper rotor disk region. Stall in this region increases the cyclic pitch amplitude and it increases the $2 \mathrm{P}$ coning excitation. Due to the $2 \mathrm{P}$ coning mode resonance at $280 \mathrm{rpm}$ (see Ref. 2) there is at the operational rotor speed a substantial resonance amplification. Partial blade stall not only increases the $2 \mathrm{P}$ coning mode excitation but it also reduces the modal damping.

During power-off operation the 2P coning oscillations are smaller. In fact, even at the resonance rotor speed of $280 \mathrm{rpm}$ which could only be reached in the power-off condition, the 2P coning oscillations were smaller than those during rapid power-on furling at $210 \mathrm{rpm}$. This could be explained by the dynamic yaw analysis which showed that the stall margin is greater for power-off than for 


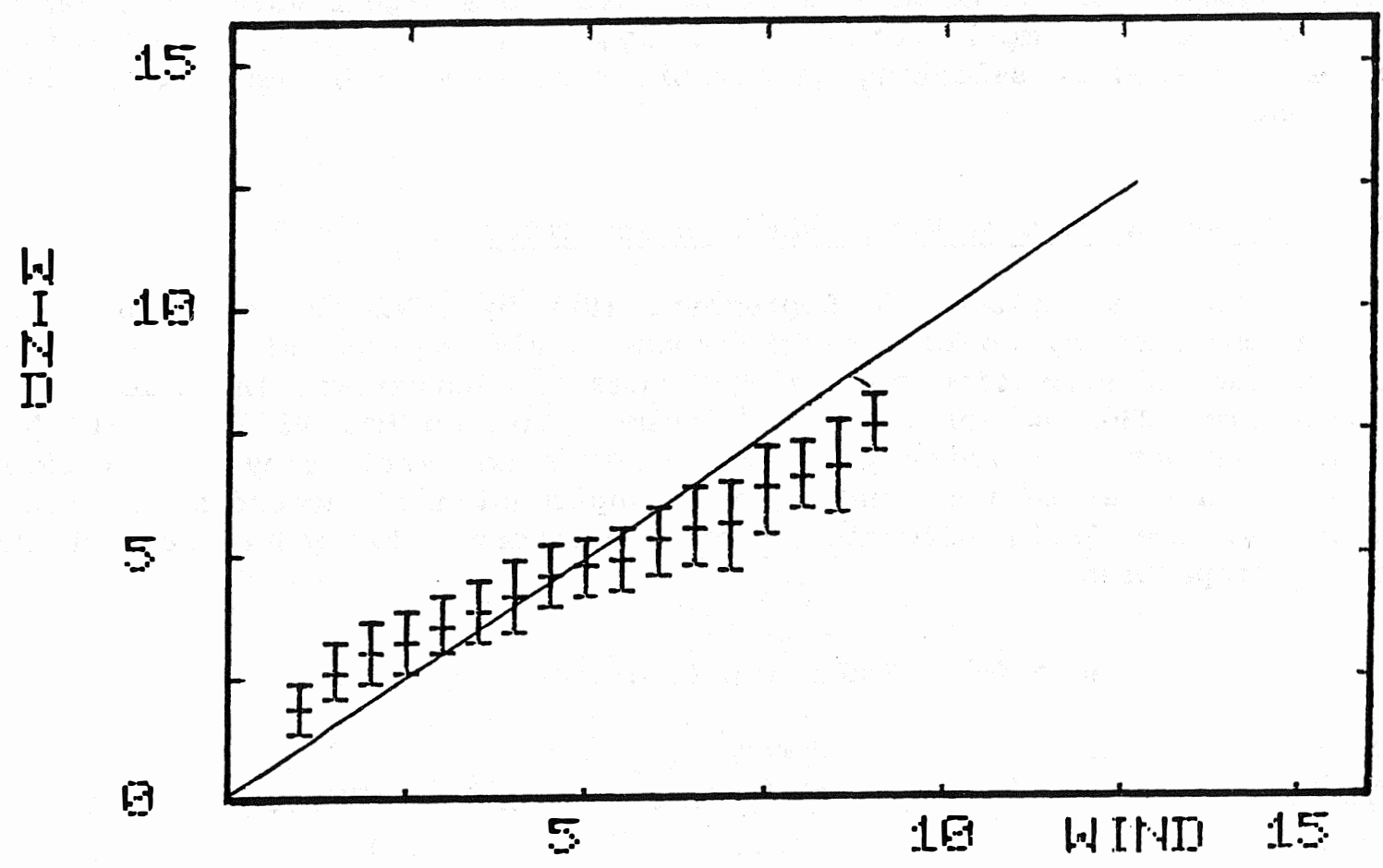

FIGURE 4-5. UPPER WIND SPEED VS. LOWER WIND SPEED 
power-on operation. The 2P coning oscillations couple with the rotor support structure and cause 2P linear accelerations in the direction of the rotor axis which were measured with a linear accelerometer. Without measuring blade loads in the rotating frame, such a linear accelerometer would be in a prototype a useful and simple instrument to monitor the blade coning oscillations.

There are several ways how the blade coning loads could be reduced. One way is to decrease the maximum furl rate. By increasing the damper force the maximum furl rate has been reduced from originally 60 degree per second to 20 degree per second. . A further decrease is anticipated by alleviating the break-out friction of the furl system. Another way of reducing partial blade stall may be to increase the elastic restraint of the cyclic pitch motion. Presently this restraint covers the range between \pm 11 degree and \pm 12 degree cyclic pitch amplitude. Extending the elastic restraint down to lower amplitudes may reduce cyclic pitch excursions and the associated partial blade stall in the upper region of the rotor disk. However, a penalty will have to be paid due to an increased $1 P$ bending moment on the rotor shaft. In a prototype the 2P resonance $r$ pm of the coning mode could be moved to a higher value in order to reduce the resonance amplification. Finally, in a prototype the stall margin could be increased by selecting an airfoil section with higher maximum lift coefficient.

\subsubsection{Passive Yaw Control With Inäuction Generator}

The alternator was replaced in September, 1981 by a single phase induction generator obtained by Gould Electric Motor Division free of charge. The generator was an adaptation of a single phase 10 horsepower induction motor with $1800 \mathrm{rpm}, 230 / 460$ volt, S $215 \mathrm{~T}$ frame, catalog No. V303. Gould had modified this motor to shift the optimum generator efficiency toward lower power as is desireable for wind turbine applications. According to tests conducted at the Gould Electric Motor laboratory, the generator had the following properties.

Table 4-1. Induction Generator Properties

\begin{tabular}{ccccc}
$\begin{array}{c}\text { Electric } \\
\text { Power kW }\end{array}$ & $\begin{array}{c}\text { Slip } \\
8\end{array}$ & $\begin{array}{c}\text { Power } \\
\text { Factor }\end{array}$ & Efficiency & $\begin{array}{c}\text { Drive } \\
\text { Power }\end{array}$ \\
\hline 1.5 & 1.1 & 0.90 & 0.60 & 2.5 \\
3.0 & 1.8 & 0.95 & 0.73 & 4.1 \\
4.5 & 2.7 & 0.95 & 0.77 & 5.8 \\
6.0 & 3.7 & 0.94 & 0.79 & 7.6 \\
7.5 & 4.6 & 0.92 & 0.78 & 9.6
\end{tabular}

The generator has type $B$ insulation with a maximum allowable continuous temperature of 140 degree $C$. Type $F$ insulation would have increased the allowable temperature to 160 degree $C$. In the laboratory 140 degree $C$ was reached during continuous operation with $5 \mathrm{~kW}$ electric output. During this test the generator was cooled with a small fan. Installed on the tower and 
exposed to the wind associated with power output much better cooling is achieved so that safe operation at more than $5 \mathrm{~kW}$ electric output could be expected. A thermocouple was installed to monitor the temperature. The efficiencies of the induction generator were somewhat less than estimated for the alternator, see Ref. 2. The power factor was very good.

The single phase motor had a phase winding and in series either a starting capacitor or a running capacitor. The capacitors had to be switched between starting and running. As generator the phase winding had to be reversed and connected in such a way that it is cut out together with the main windings in order to prevent self excitation. Since motor starting was not required in the self starting wind turbine application, the starting capacitor and the switching circuit were omitted.

An electrical control system for the induction generator was designed with the purpose of connecting the electrical grid when synchronous speed was reached from below and of disconnecting the electrical grid when synchronous speed was reached from above. The center piece of the electrical control system was an Electromatics wind turbine relay. It powered a mechanical contacter which connected the generator to the electric grid at 18 below synchronous speed. It disconnected it from the grid if after 5 seconds the generator had not reached synchronous speed. Disconnect from the grid was also obtained 2 seconds after the generator speed dropped below the synchronous speed. The 2 second time delay was not adjustable so that some motoring took place when the wind varied frequently about its cut-in value. The delay had the purpose to avoid too frequent operation of the mechanical contacter. To reduce motoring losses it would seem better to use a solid state switch and a relay with a shorter delay time.

Originally an overcurrent relay had been incorporated in the electric control system. It turned out that this relay tripped whenever the grid was zut-in. The overcurrent relay was then manually bridged during grid cut-in. It was soon found out that the passive furl control system effectively protected the generator from overcurrents, so that the overcurrent relay could be omitted.

The local utility, Union Electric, installed, free of charge, three kW-hour meters, two at the grid terminals and one at the generator terminals. One of the meters at the grid terminals measured the inflowing energy, the other the outflowing energy which was equal to the generated energy minus the energy used by the test equipment for the computer, the oscillograph, the strain gage conditioner, the lights, the battery charger, etc. The meter at the generator terminals measured the generated energy minus the line losses in the cables from the tower top to the instrument shed. Union Electric made some measurements on the quality of the generated electricity which is often unsatisfactory when synchronous inverters are used. In contrast, the quality of electric energy from the atmospheric test equipment at Tyson Research Center was found to be good with almost no wave distortion. The power factor was almost unity as was mentioned before. The power fluctuations from varying wind speeds were of no concern to the utility. 
The passive furl control system limited the rotor torque accurately to the set value while the induction generator, when connected to the electric grid, kept the rotor speed almost constant. The delayed unfurling due to furl system friction was again observed. Unfurling only began below synchronous speed after the induction generator had been disconencted from the grid by the action of the Electromatics relay.

Fig. 4-6(a) to (f) shows for power-on run with the induction generator the results of digital data taking using the "WIND-6" program. Fig. 4-6(a) gives the distribution of the sample sets over the wind speed bins. Fig. 4-6(b) shows shows the furl angle statistics which is similar to that with the alternator configuration, see Fig. 4-4(b). Fig. 4-6(c) shows the rpm statistics. In contrast to the configuration with alternator, Fig. 4-4 (c), the rpm is now nearly constant from the cut-in speed of $5 \mathrm{~m} / \mathrm{sec}$ on up. The occasional deviations from the $200 \mathrm{rpm}$ level were presumably caused by the time delays in the switching of the generator. Fig. 4-6(d) shows the rotor torque statistics. Same as for the alternator configuration, Fig. 4-4(d), the torque is limited accurately to $410 \mathrm{Nm}(300 \mathrm{ft}-\mathrm{lb})$. However, unlike the alternator distribution of Fig. 4-4(d), the torque is now almost zero below $5 \mathrm{~m} / \mathrm{sec}$ wind speed because the induction generator is switched off below synchronous speed while the alternator generated power down to low $\mathrm{rpm}$ values. While for the run with alternator shown in Fig. 4-4 the average aerodynamic efficiency $c_{P}$ based on the reading of the lower anemometer was 0.46 , the corresponding value of $c_{p}$ for the run with the induction generator shown in Fig. 4-6 was 0.34. Most of this loss occurred in the low wind speed region. It was found that at synchronous speed the combined loss of gears, belt drive and generator was over $1.5 \mathrm{~kW}$ which accounted for the relatively high wind speed at synchronous $\mathrm{rpm}$ of 5 to $6 \mathrm{~m} / \mathrm{sec}(11.2$ to $13.4 \mathrm{mph})$. In a redesign, both the transmission and the generator losses at synchronous rpm could be substantially reduced which would lead to a lower wind speed at synchronous $\mathrm{rpm}$ and to a better average $c_{p}$ value, since in this average the wind energy over the entire speed range has been used including very low wind velocities.

Fig. 4-6(e) shows the thrust statistics. Same as for the alternator configuration, Fig. 4-4(e), the thrust is limited by the passive furl control system to about $120 \mathrm{~N}(270 \mathrm{lb})$. Fig. 4-6(f) shows the cyclic pitch amplitude statistics. The mean values are here about 2 degree vs. 4 degree for the alternator configuration, see Fig. 4-4(f). Keeping the rpm constant has obviously the effect of lowering the mean cyclic pitch amplitude.

Fig. 4-7(a) to (c) shows for a power-off run the results of digital data taking. The "WIND-2 FAST" program was applied which has also been described in Ref. 2. The program produces statistical data on $r p m$ and on rotor torque much faster than the "WIND-6" program with its 6 sampled fast variables. Fig. 47 (a) gives the distribution of the sample sets over the wind speed bins. As before, the bins in the main wind speed range have about 200 sample sets each. Fig. 4-7(b) gives the rotor speed statistics for this power-off run. The mean rotor speed levels off below $250 \mathrm{rpm}$. Fig. 4-7(c) shows the rotor power vs. wind speed. At $5 \mathrm{~m} / \mathrm{sec}$ or $200 \mathrm{rpm}$ the mean rotor power is $0.6 \mathrm{~kW}$, at 7 to 10 $\mathrm{m} / \mathrm{sec}$ or $250 \mathrm{rpm}$ the mean rotor power is $0.7 \mathrm{~kW}$. This represents the mechanical 


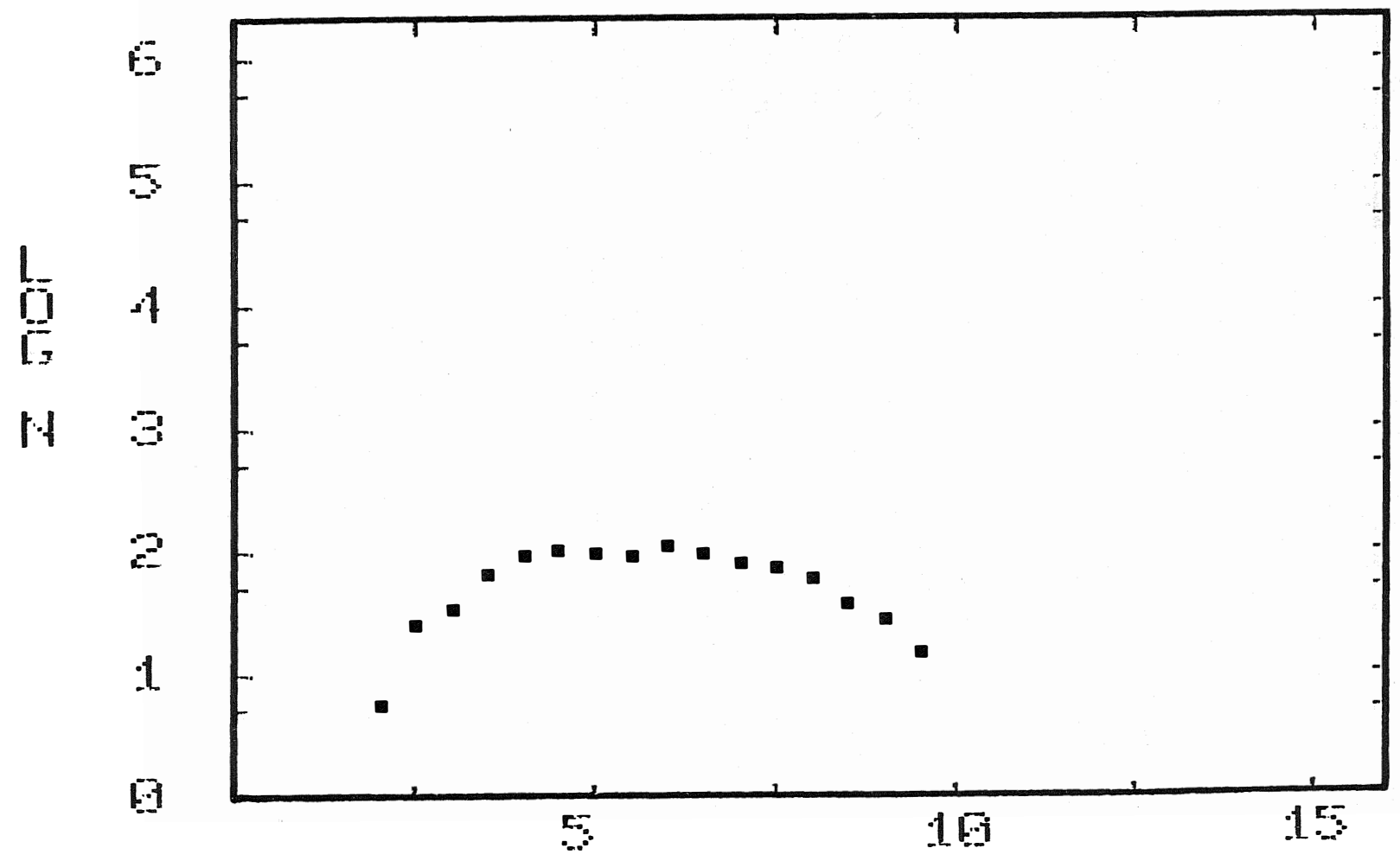

FIGURE 4-6. DIGITAL DATA FOR POWER-ON RUN WITH INDUCTION GENERATOR, OCTOBER 18, 1981

(a) LOG SAMPLES (N) VS. WIND SPEED (M/S) 


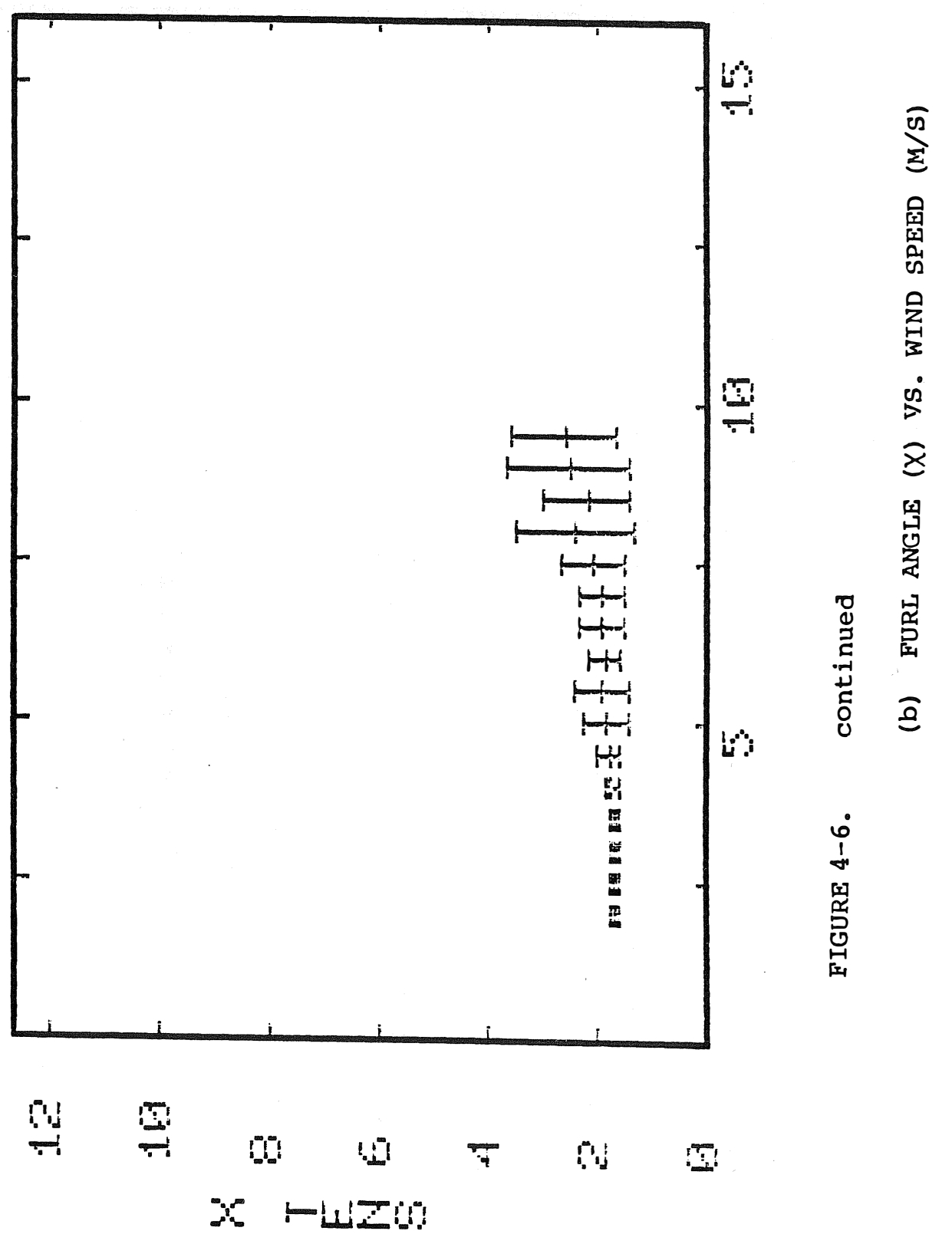




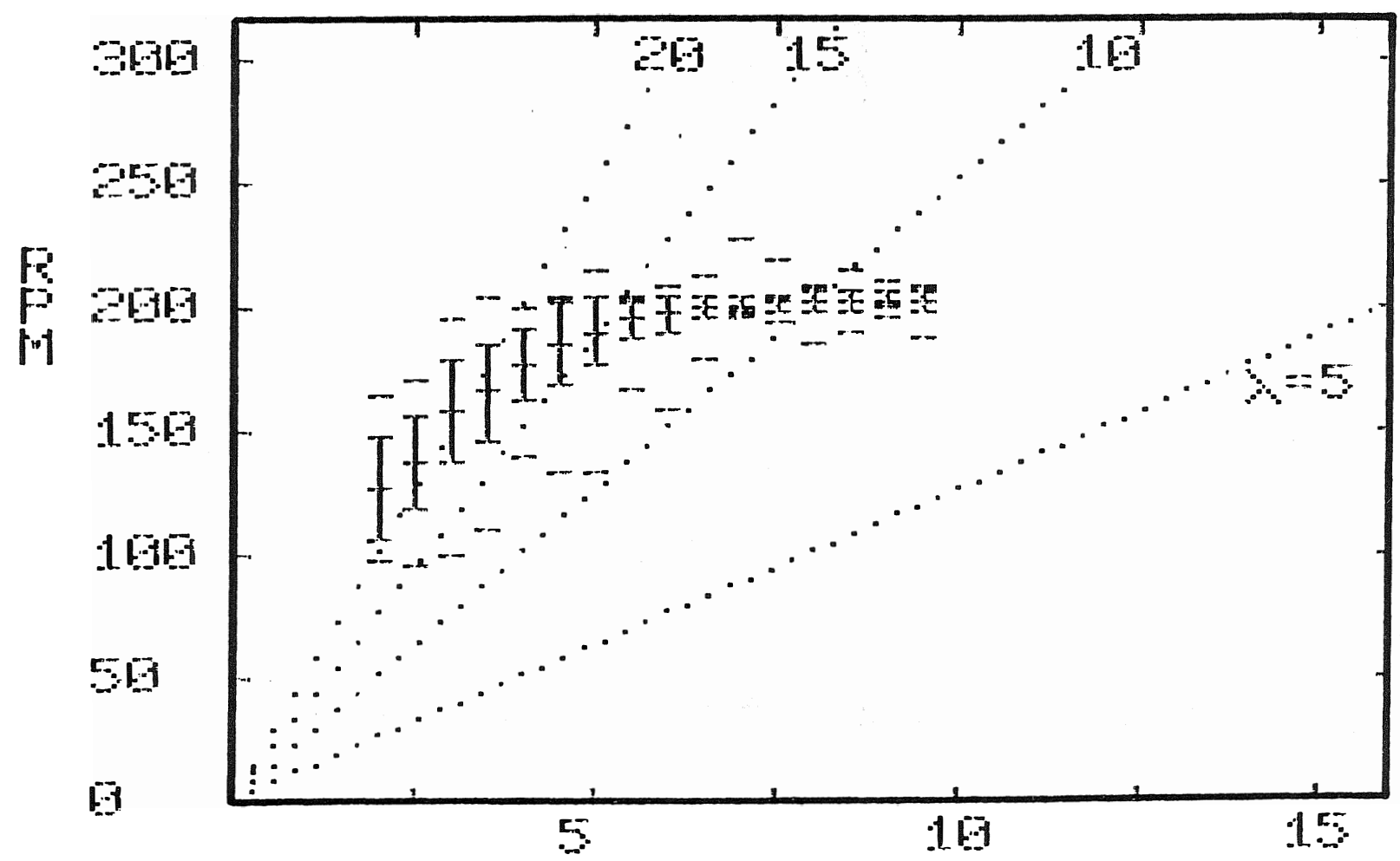

FIGURE 4-6. continued

(c) RPM VS. WIND SPEED (M/S) 


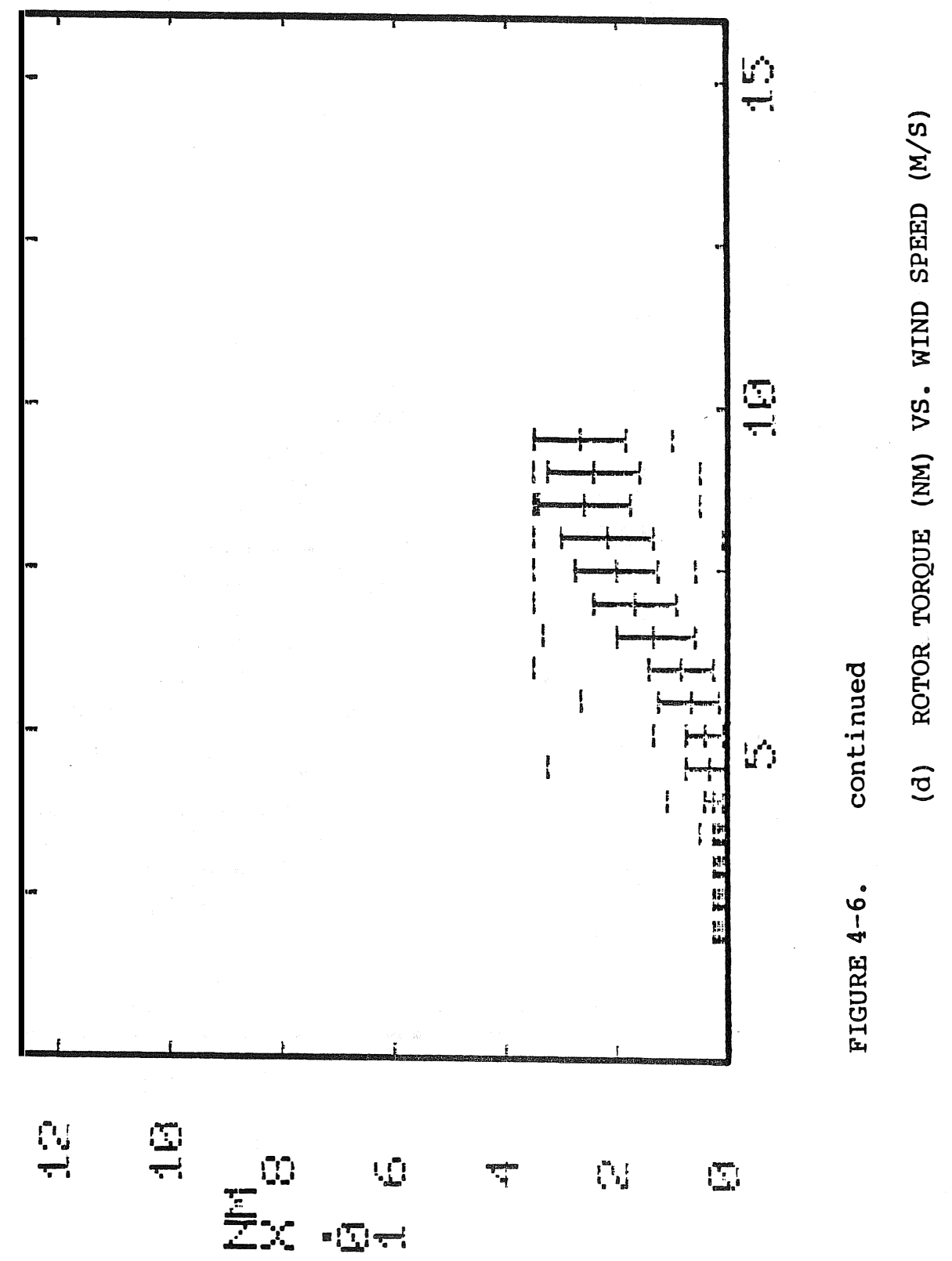




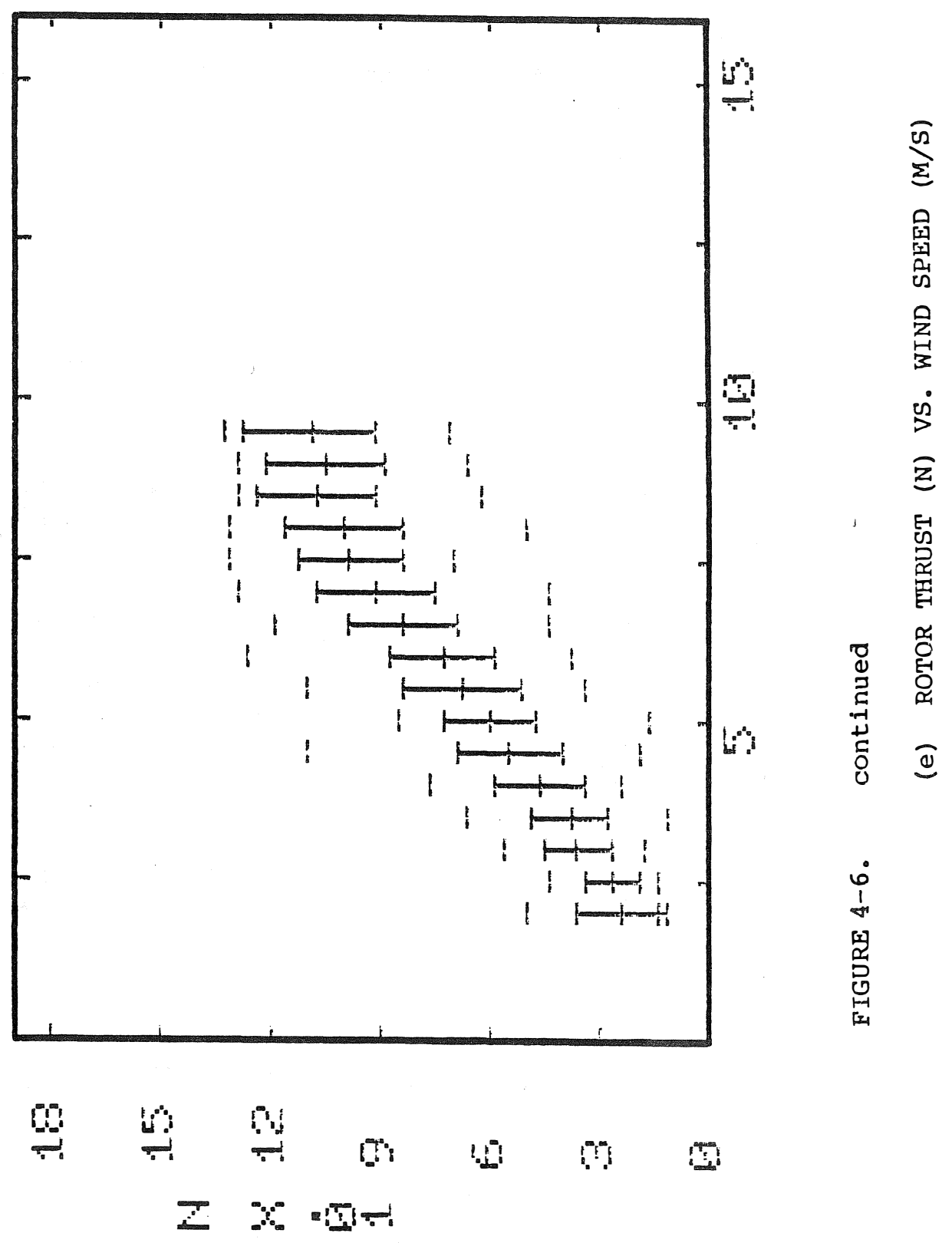


मे

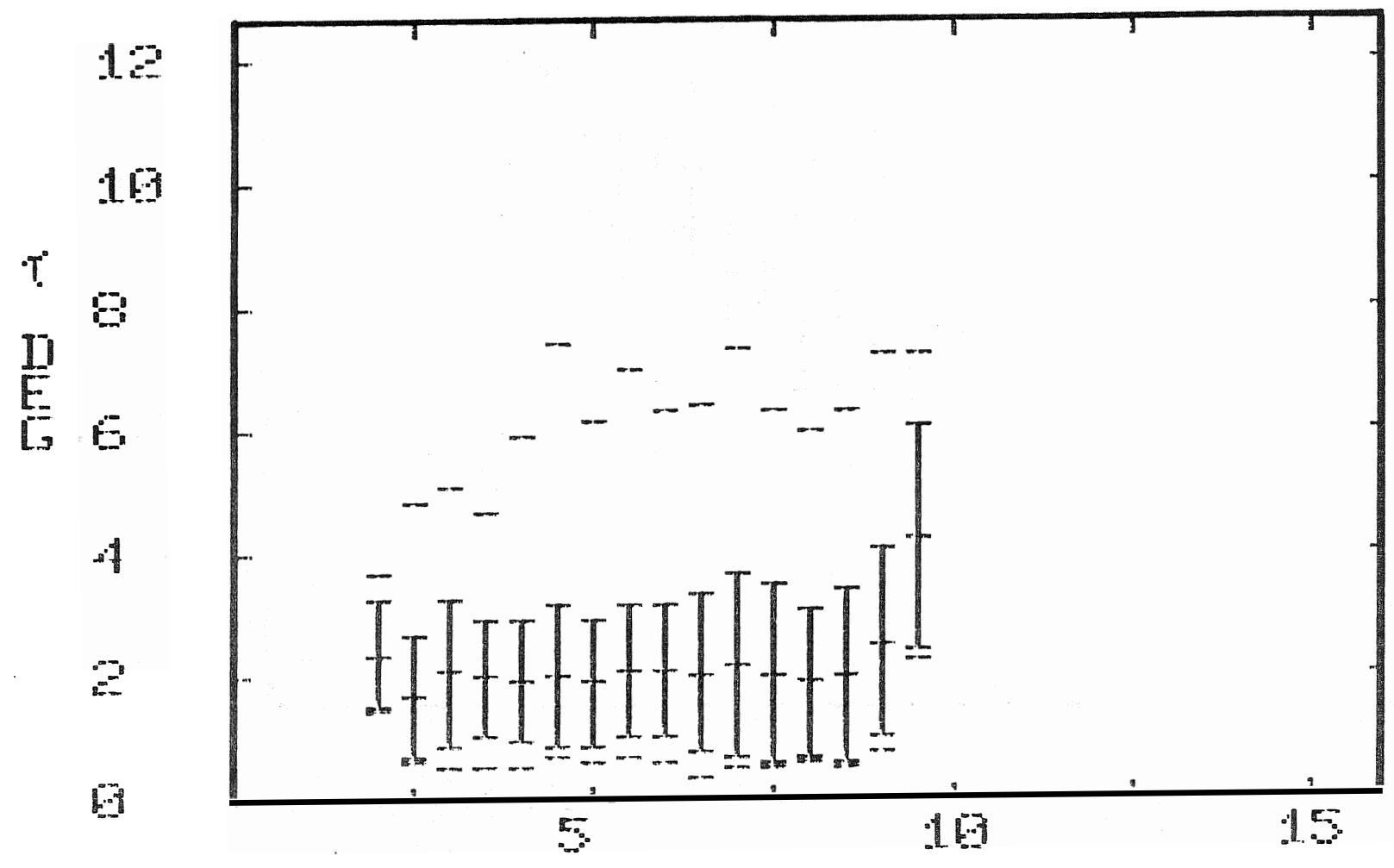

FIGURE 4-6. continued

(f) CYCLIC PITCH VS. WIND SPEED (M/S) 


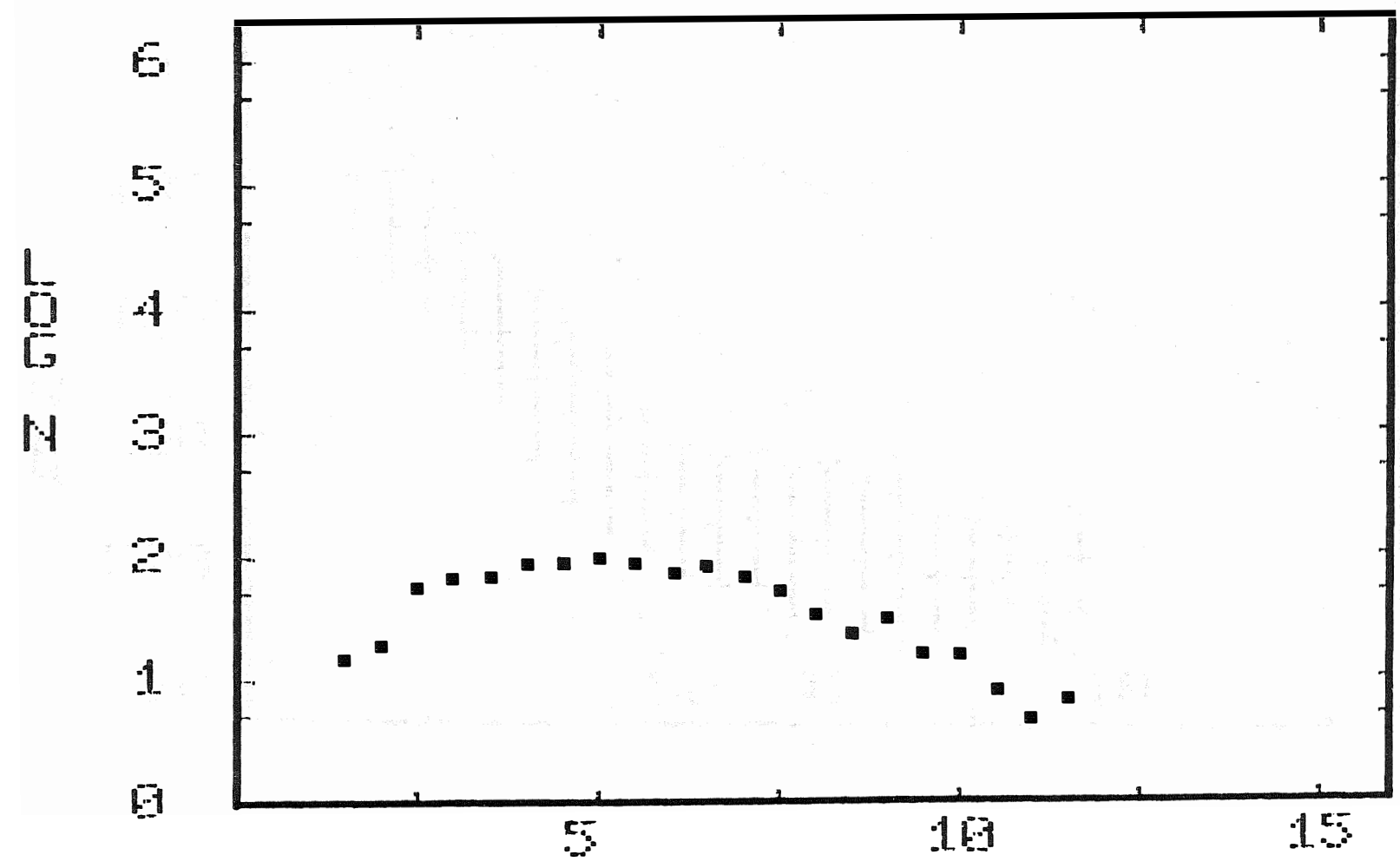

FIGURE 4-7. DIGITAL DATA FOR POWER-OFF RUN WITH INDUCTION GENERATOR, OCTOBER, 18, 1981

(a) LOG SAMPLES (N) VS. WIND SPEED (M/S) 


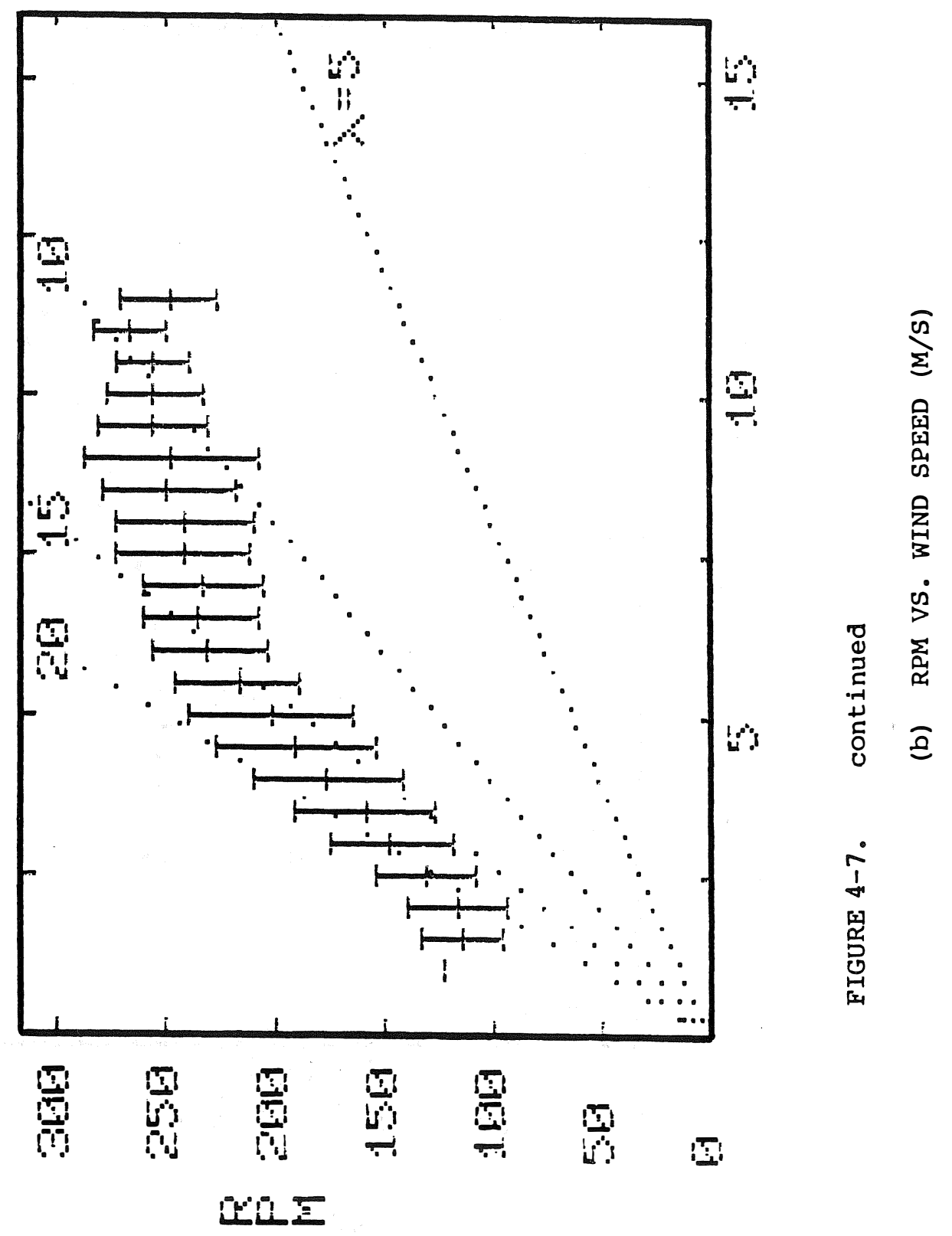




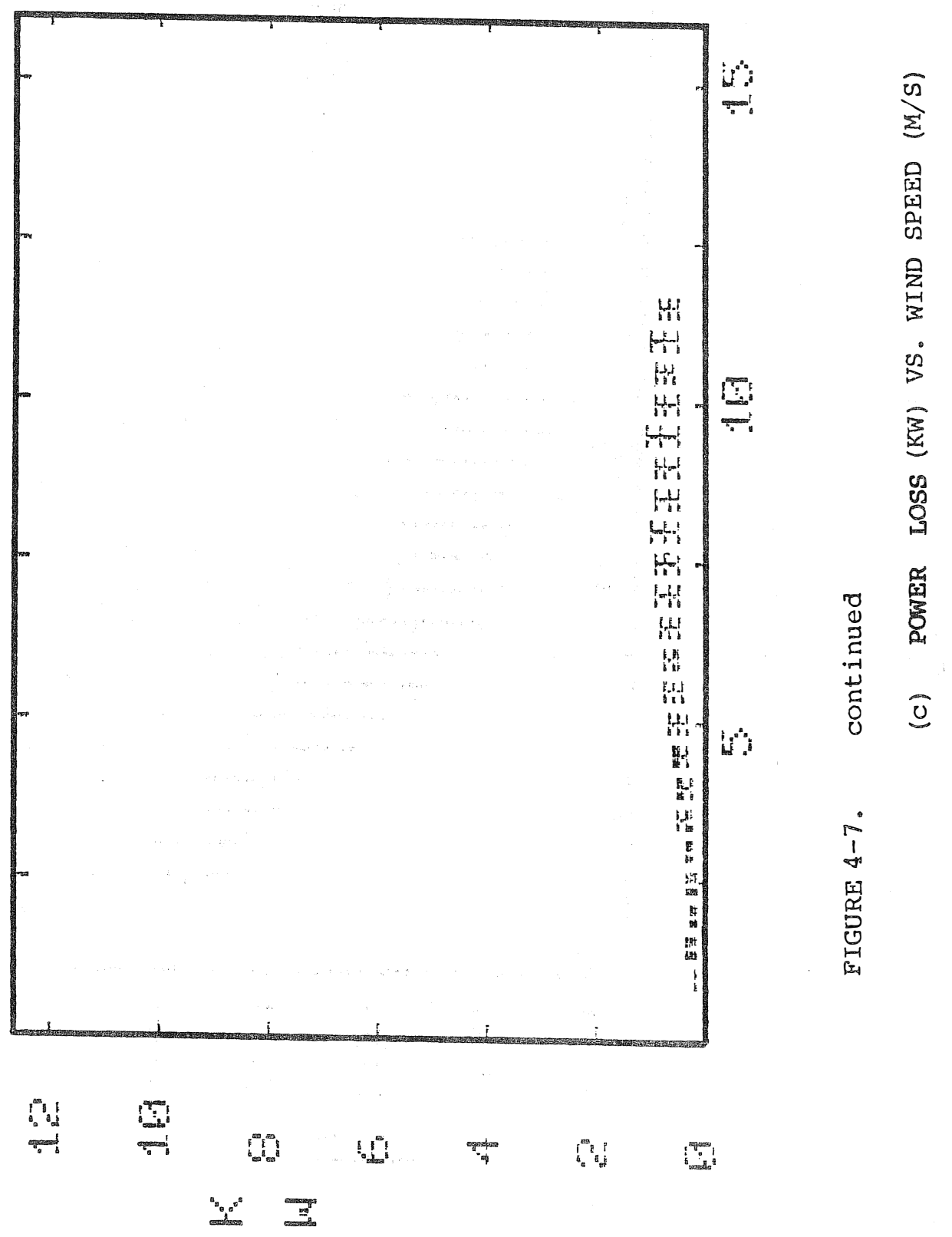


loss in the drive train including the belt drive and in the induction generator when it is not connected to the electrical grid. After grid connection the rotor power increases substantially to over $1.5 \mathrm{~kW}$ because of the additional magnetizing loss. 
SECTION 5.0

CONCLUSIONS

Analysis of and atmospheric experiments with a two-bladed $7.6 \mathrm{~m}$ diameter vane stabilized wind rotor having passive cyclic pitch variation allow the following conclusions.

- For steady state the classical rotor yaw analysis with constant inflow agreed quite well with a much more refined variable inflow analysis.

- Blade angle of attack distributions obtained with the yaw dynamics analysis allow rough estimates of the blade stall envelope.

- A two-bladed wind rotor with passive cyclic pitch variation was capable of sufficient rapid yaw rates to use the yaw mode as exclusive means of rotor speed and torque control.

- Both the active yaw control system using a hydraulic propeller speed governor and the passive system using a combination of rotor thrust and torque were capable of effective speed and torque limitations during strong gusts.

- The passive furl control system showed greater promise because no emergency control system is needed, because it is simpler and more reliable and requires less maintenance, and because it is applicable also in the case of a constant speed electric generator for which the active speed control system is not suitable.

For efficient wind energy conversion the atmospheric test equipment with the passive cyclic pitch rotor, the passive furl control system, and the induction generator needs to be improved in several respects.

- The friction of the passive furl control system should be greatly reduced to alleviate delayed unfurling with its considerable energy losses. This requires a fairly substantial redesign of the system.

- The transmission loss due to the belt drive is quite high. The belt drive should be eliminated.

- The single phase induction generator with its relatively high losses should be improved.

- The rotor, due to the long blade shanks, operates with sizeable losses and should be improved. 
All of the listed modifications affect the furl control system stability which needs to be reinvestigated.

After removing the present inadequacies, the atmospheric test equipment with the passive furl control system should be tested to considerably higher wind speeds than the maximum encountered during the preceding tests. 
SECTION 6.0

REFERENCES

1. Hohenemser, R. H. and Swift, A. H. P., The Yawing of inind Turbines With Blade Cyclic Pitch Variation. SERI Second Wind Energy Innovative Systems Conference, Colorado Springs, CO, SERI/CP-635-938, Dec. 1980, pp. 207224.

2. Hohenemser, R. H., Swift, A. H. P. and Peters, E. A., The Yawing of Wind Turbines ivith Blade Cyclic Pitch Variation. Final Report under Subcontract No. XH-9-8085-3, SERI/TR-8085-15, December 1980.

3. Hohenemser, R. H. and Swift, A. H. P., Dynamics of an Experimental TwoBladed Horizontal Axis Wind Turbine with Blade Cyclic Pitch Variation. Second DOE/NASA wind Turbine Dynamics Workshop, Cleveland, OH, DOE CONF. 810226, Feb. 1981, po. 277-285.

4. Hohenemser, R. H. and Swift, A. H. P., Atmospheric Testing of a Two-Bladed Furl Controlled wind Turbine with Passive Cyclic Pitch Variation. Fifth Biennial Wind Energy Conference and Workshop, Nashington, D.C., Oct. 5-7, 1981, Session ID.

5. Hohenemser, R. H. and Swift, A. H. P., Rotor Speed Control by Automatie Yawing of Two-Bladed wind Turbines with Passive Cyclic Pitch Variation. AIAA 2nd Terrestrial Energy Systems Conference, Colorado Springs, CO, December 1-3, 1981, Session 8.

6. Wilson, R. E. and Lissamann, P. B. S., Applied Aerodynamics of Wind Power Machines. Oregon State University, May 1974.

7. Gessow, A. and Tapscott, R. J., Tables and Charts for Estimating stall Effects on Lifting Rotor Characteristics. NASA TN D-243, May 1960.

8. Gessow, A. and Myers, G. D., Aerodynamics of the Helicopter. MacMillan Co., New York, 1952.

9. Ditt, D. M. and Peters, D. A., Theorectical Prediction of Dynamic-Inflow Derivatives. Proceed. бth European Rotorcraft and Powered Lift Aircraft Forum, Bristol, England, Sept. 1980.

10. Norton, John H. Jr., The Development and Testing of a Variable Axis Rotor Control System with 5 Meter Rotor and Direct Drive Alternator. Proceedings of Small wind Turbine Systems, Workshop coordinated by Rockwell International, Boulder, CO, Feb/March 1979, Vol 1, pp. 31-64.

11. Glasgow, C. J., Corrigan, R. D. and Miller, D. R., The Effect of Yaw on Horizontal Axis Wind Turbine Loading and Performance. Fifth Biennial Wind Energy Conference and Workshop, Washington, D.C., OCt. 5-7, 1981, Session IIB. 
12. Swift, A. H. P., Effects of Yawed Flow on Wind Turbine Rotors. Doctor of Science Thesis, washington University, Sever Institute of Technology, May 1981.

13. Viterna, L. A. and Corrigan, R. D., Tests of Fixed Pitch and Laminar Flow Airfoils on the $100 \mathrm{~kW}$ MOD-O Wind Turbine. Large Horizontal Axis Wind Turbines, a Workshop held in Cleveland, $\mathrm{OH}$, July 28-30, 1981.

14. Spera, D. A. and Janetzke, D. C., Performance and Load Data from the MOD$O A$ and MOD-l Wind Turbine Generators. Large Horizontal Axis Wind Turbines, a Workshop held in Cleveland, OH, July 28-30, 1981. 
APPENDIX A

ASSEMBLY DRAWINGS 

TOP VIEW

- YAW POST OFF-SET

- TALL BOOM - UNFURL SPRING -BOOM PIN ASSEMBLY
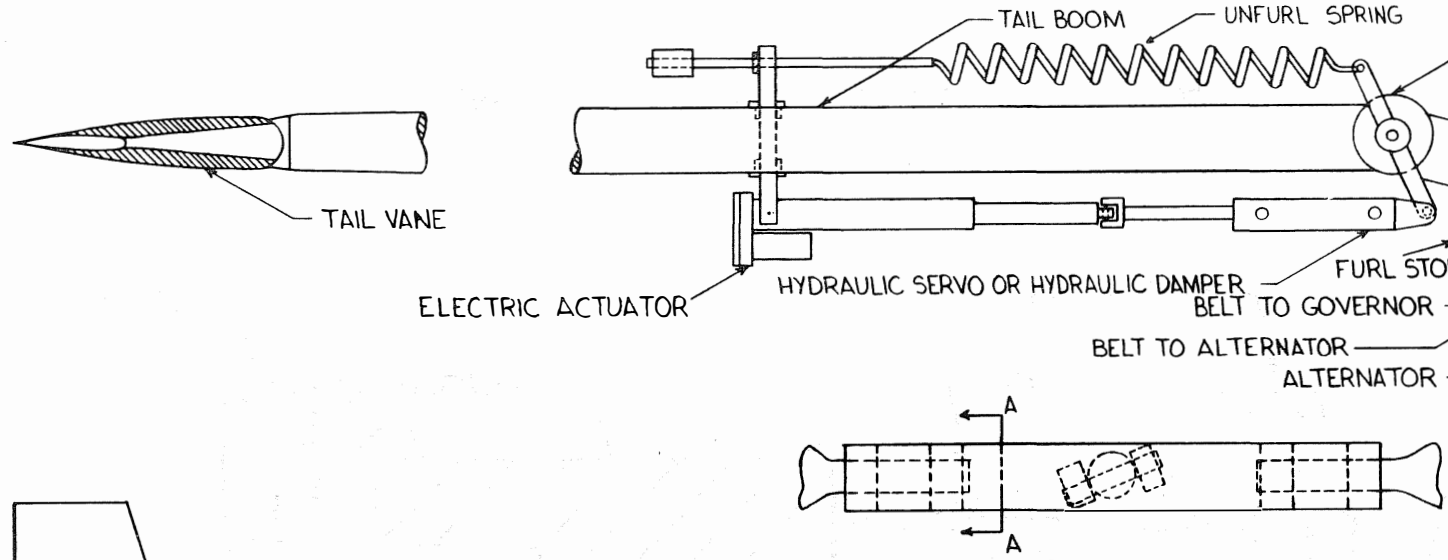

AXIAL VIEW
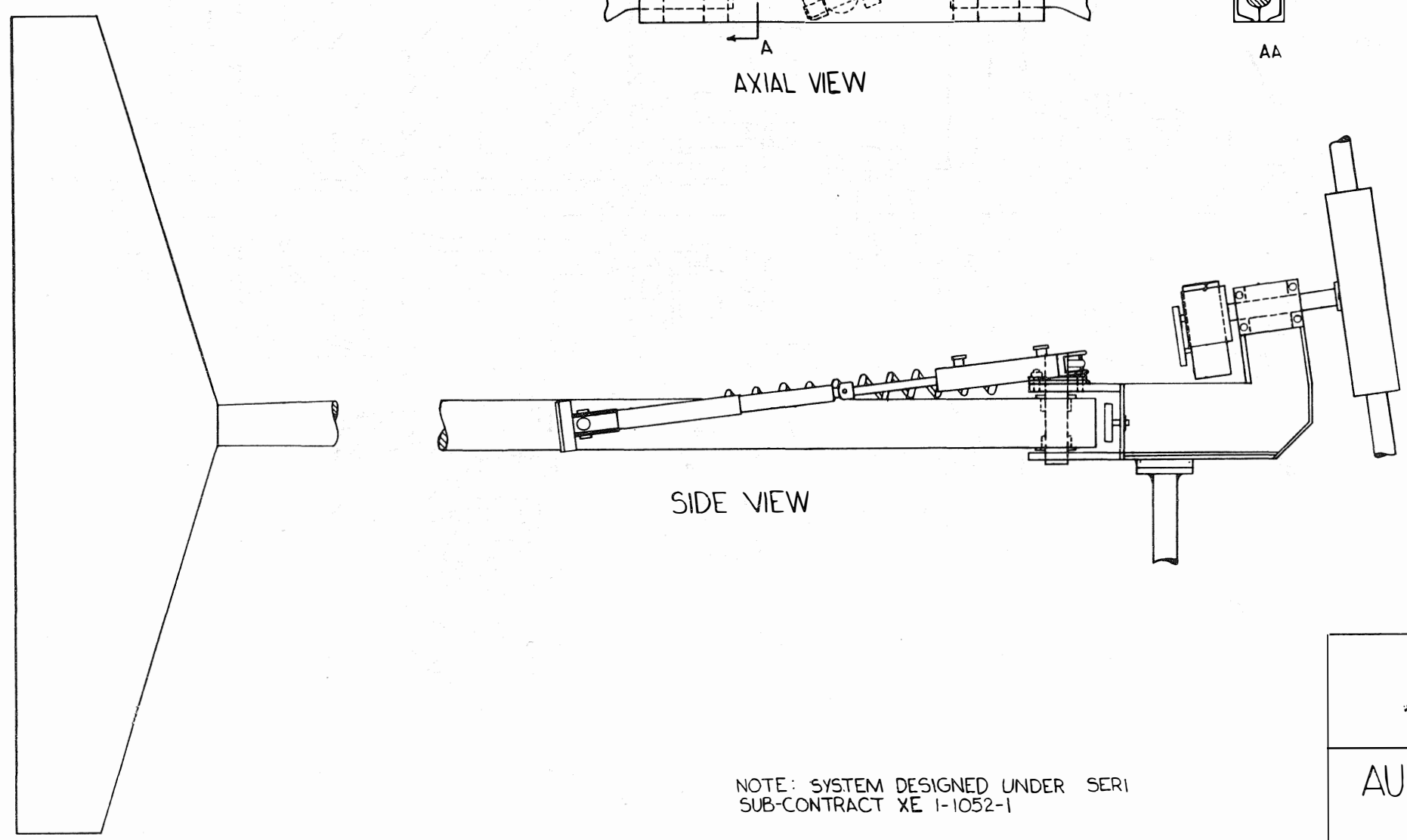

NOTE: SYSTEM DESIGNED UNDER SERI SUB-CONTRACT XE 1-1052-1

\begin{tabular}{|l|l|}
\hline WUTA, INC. \\
WHA. HINGTON UNIVERSITY \\
ST. LOUIS, MO. 63130
\end{tabular}




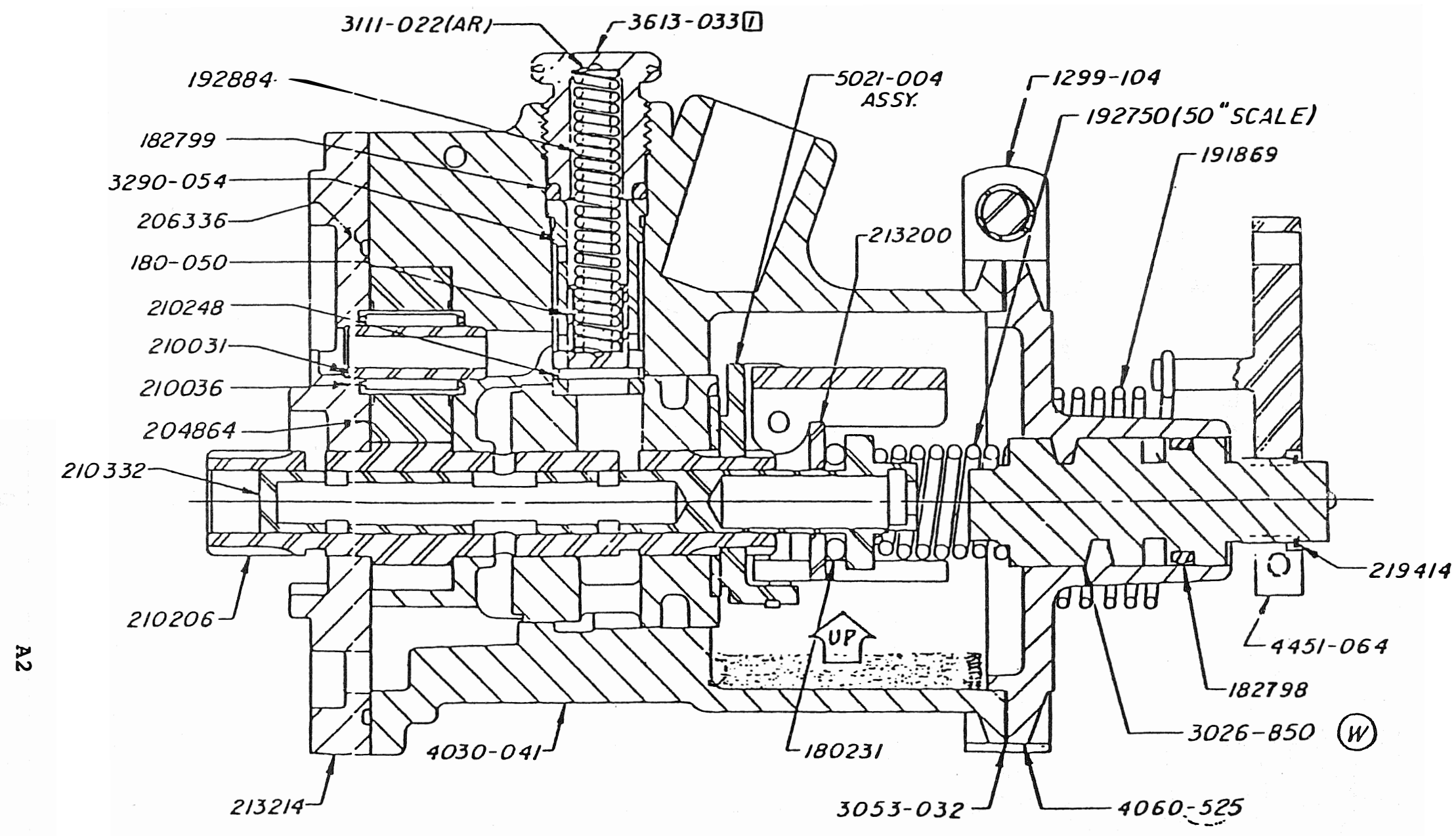

A-2. ASSEMBLY DRAWING FOR HYDRAULIC GOVERNOR 


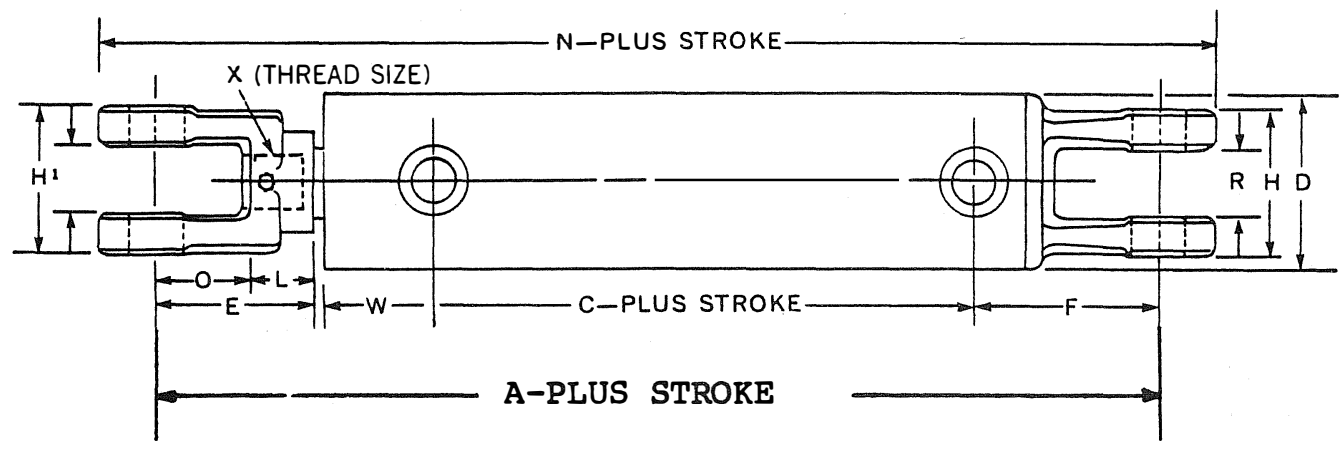

\begin{tabular}{cc} 
Item & $\begin{array}{c}\text { Dimension } \\
\text { (Inch) }\end{array}$ \\
\cline { 2 - 2 } C & $20-1 / 4$ \\
D & $1-7 / 8$ \\
E & $2-7 / 8$ \\
F & $2-7 / 8$ \\
H H & 1 \\
L & $3-3 / 8$ \\
N & $2-3 / 8$ \\
O & 1 \\
R & $12-1 / 4$ \\
W & $1-3 / 4$ \\
X & $1-1 / 8$ \\
Stroke & $1-15 / 16$ \\
\hline
\end{tabular}

A-3. ASSEMBLY DRAWING FOR HYDRAULIC CYLINDER 

APPENDIX B

ROTOR WITH PASSIVE CYCLIC PITCH VARIATION AS A MEMBER OF A FAMILY OF HINGED ROTORS 

FOREWORD to APPENDIX B

The Appendix B to the Final Report was performed under Amendment Two to Subcontract No. XH-1-1052-1 by Dr. Kurt H. Hohenemser and Dr. Andrew H. P. Swift in February, 1982. 



\section{SUMMARY OF APPENDIX B}

The two-bladed wind rotor with passive cyclic pitch variation is compared to other two-bladed hinged rotor types. The teeter rotor is shown to be impractical for dynamic reasons if both blade coning and blade flapping are present, the latter caused by high yaw angles and high rate of yaw. Solutions of the dynamic problems of the teeter rotor applied in rotorcraft technology - damped blade lag hinges or a central universal flapping hinge in combination with blade pitch control - are held to be too complex and too costly for wind turbine applications. The rotor with passive blade cyclic pitch variation is as simple and rugged as the teeter rotor and avoids its dynamic problems by suppressing flapping without otherwise changing its aerodynamic characteristics. 

TABLE OF CONTENTS OF APPENDIX B

Page

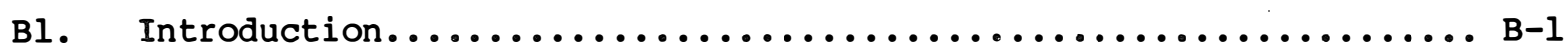

B2. Collective and Cyclic Blade Pitch Variation................ B-3

B3. Blade Coning and Flapping............................. B-5

B4. Pitch-Cone and Pitch-Flap Coupling..................... B-9

B5. Effect of Pitch-Flap Coupling on Blade Flapping............. B-13

B6. Other Applications of Blade Passive Cyclic

Pitch Variation.................................. B-19

B7. Summary and Conclusions............................ B-21

B8. References........................................ B-23 

B3-1. Flap-Coning Hinge; Axial View...................... B-7

B3-2. Flap or Teeter Hinge; Axial View....................... B-7

B3-3. Separate Coning and Flapping, Rotor side Views............. B-8

B3-4. Combined Coning and Flapping......................... B-8

B4-1. Fixed Hub with Lag, Flap-Coning and Pitch Hinges;

Axial view....................................

B4-2. Floating Hub with Coning and Pitch Hinges;

Axial view.......................................

B4-3. Floating Hub with Pitch Hinges; Axial View................ B-12

B4-4. Rotor with Passive Blade Cyclic Pitch Variation;

Axial View (Large Pitch-Flap Coupling Ratio) ............... B-12

B5-1. Blade Deflection Angles vs. Delta Three Angle, Steady state yaw 60 ............................... B-14

B5-2. Blade Deflection Angle vs. Delta Three Angle, Dynamic Yaw $56^{\circ}$ to $65^{\circ}$ at $30 \% /$ sec.............................. B-15

B5-3. Angle of Attack Profile for Case of Fig. B5-2, Delta Three $=00^{\circ} \ldots \ldots \ldots \ldots \ldots \ldots \ldots \ldots \ldots \ldots \ldots \ldots \ldots \ldots \ldots \ldots \ldots$

B5-4. Angle of Attack Profile for Case of Fig. B5-2, Delta Three $=67^{\circ} \ldots \ldots \ldots \ldots \ldots \ldots \ldots \ldots \ldots \ldots \ldots \ldots \ldots \ldots \ldots$. . . . . . . . . . . 
. 


\section{NOMENCLATURE LIST}

t

B

Bo

B

$\delta_{3}$

$\delta_{3 \mathrm{CONE}}$

$\delta_{\text {3FLAP }}$

$\theta$

$\theta_{0}$

$\theta_{C}$

$\tau$

$\phi_{\theta}$

$\phi_{F}$

$\Omega$

vX

Vz

Time

Out-of plane blade angular deflection

Coning Angle

Flapping Amplitude

Angle defining pitch-cone and pitch-flap coupling ratio-tan $\delta_{3}$

Angle defining pitch-cone coupling ratio-tan $\delta_{3 \mathrm{CONE}}$

Angle defining pitch-flap coupling ratio - $\tan \delta_{3 \text { FLAP }}$

Blade pitch angle

Blade collective pitch angle

Blade cyclic pitch amplitude

Blade angular amplitude about hinge axis

Phase angle of blade cyclic pitch motion

Phase angle of blade flapping motion

Rotor angular speed

Crosswind wind velocity component

Axial wind velocity component 


\section{SECTION BI}

INTRODUCTION

The purpose of the following discussion is to explain the characteristics of the two-bladed wind rotor with passive cyclic pitch variation in comparison to those of other hinged two-bladed wind rotor types. The rational of the SERI sponsored research into the effects of passive cyclic pitch variation applied to a twobladed wind rotor was to investigate the suitability of this rotor type for rotor speed and rotor torque control based on yawing rather than on the usually applied blade feathering method. Such a yaw control system requires high yaw rates which can cause severe vibrations in teetering rotors if the blades have a built-in coning angle or if they are elastically coned. In contrast, the two-bladed rotor with passive cyclic pitch variation runs smoothly during rapid yawing and in the presence of blade coning. Performance has been demonstrated during wind tunnel and atmospheric testing. We will attempt to show here why passive cyclic pitch variation in two-bladed rotors produces these benefits. Though some analytical results will be used, the discussion will be essentially of a qualitative nature. 

A change in blade pitch is attained by rotating the blade about its longitudinal axis. Ignoring aeroelastic effects and higher harmonic cyclic pitch variations, the change in blade pitch from a reference position is given by the sum of two terms as:

$$
\theta=\theta_{0}+\theta_{C} \cos \left(\Omega t+\phi_{\theta}\right)
$$

The collective pitch variation $\Theta$ at a given time is the same for all blades. The second term in Eq. B2-1 describes the cyclic pitch variation in terms of its amplitude $\Theta_{C}$ and its phase angle $\phi_{\Theta}$ which is different for different blades; the amplitude $\Theta_{C}^{C}$ at a given time is the same for all blades. For a two-bladed rotor the phases of the blades differ by $180^{\circ}, \theta_{0}$ and $\theta_{C}$ are time functions. Collective and cyclic pitch can be imposed on the blades by a control mechanism. This is called active blade pitch variation. Collective and cyclic pitch can also be varied by passive means under the influence of aerodynamic and inertia forces. Active controls involve hydraulic or electric actuators and usually require electronic controls, all of which are subject to component malfunctions. Passive controls are simpler and more reliable except possibly under conditions of icing. In propeller and wind turbine terminology, collective blade pitch variation is called blade feathering or unfeathering. Cyclic pitch variation is not used in propellers nor in most wind turbines. 

SECTION B3

BLADE CONING AND FLAPPING

If blades are hinged to the hub with hinges perpendicular to the blade axes and positioned in the plane perpendicular to the rotor axis, see Fig. B3-1, and if aeroelastic affects and higher harmonics are ignored, the change in angular blade deflection about the hinge from a reference position is given by the sum of two terms as:

$$
\beta=\beta_{0}+\beta_{F} \cos \left(\Omega t+\phi_{F}\right)
$$

The blade coning angle $\beta$ is at any given time the same for all blades. The second term in Eq. B3-1 $1^{\circ}$ describes blade flapping in terms of the flapping amplitude $\beta_{F}$ and the phase angle $\phi_{\mathrm{F}}$ which is different for different blades; the flapping amplitude at a given time is the same for all blades. In a two-bladed rotor the phase angle for the two blades differs by $180^{\circ}$. $\beta_{\text {and }} \beta_{F}$ are time functions. If the two blades are rigidly connected to the hub and can swivel about a teeter hinge, see Fig. B3-2, then only blade flapping is possible but no change in coning angle occurs except for aeroelastic effects. However, there may be a built-in fixed coning angle. In the literature the sum of what we call coning and flapping, the right hand side of Eq. B3-2, is usually denoted as flapping angle. The harmonic term would then be called cyclic flapping. Since the word flapping has the connotation of a periodic motion and not of a steady state, we believe our definition of flapping to be more appropriate. It also shortens the text.

Fig. B3-3(a) shows the schematic sideview of a rotor when the blades are coned by the angle $\beta$. Fig. B3-3(b) shows the schematic sideview of the rotor when the blades flap with the amplitude $\theta_{F}$ in such a phase that for $t=0,2 \pi / \Omega, 4 \pi / \Omega$, etc. and $\phi_{\mathrm{F}}=0$, a blade is in the upward position. The blade tips then rotate in a tip path plane which is not perpendicular to the rotor axis but rather inclined downward.

Fig. B3-4(a) shows what happens when the separate coning and flapping indicated in Fig. B3-4(a) and (b) are superimposed. When the blade is in the horizontal position its projection is parallel to the rotor axis. It therefore can not participate in the blade tip path plane tilting motion. Seen in the direction of the arrow which is perpendicular to the blade tip path plane it has the view shown in Fig. B3-4(b). The two opposite blades in Fig. B3-4(b), when in the horizontal position, form an angle with each other given by twice the product of coning and flapping angle. In the blade tip path plane the blade tips move with nonuniform angular velocity, this angular velocity being larger for the lower portion and smaller for the upper portion of the tip path. These in-plane oscillations produce in-plane oscillatory blade loads and a 2 per revolution vertical excitation of the rotor support. The analysis of these loads is usually performed in a reference system which rotates uniformly about the rotor axis. The in-plane loads then appear as Coriolis forces and are found to be significant. 
The conclusion is that rotors with hinges as shown in Fig. B3-1 which are subject to both blade coning and blade flapping have a dynamic problem. Cierva, who began his autogiro development in the 1920's with a rotor according to Fig. B3-1, learned this lesson soon and added damped lag hinges, Fig. B4-1, which are still used in most rotorcraft. The lag dampers are needed to prevent dynamic lag motion instabilities. The problem indicated in Fig. B3-4 not only arises in Fig. B3-1 type rotors which are free to cone but also occurs in rotors with a teeter hinge, Fig. B3-2, if the blades have a built-in coning angle or if they are aeroelastically coned. The Bell Helicopter Company began its teetering rotor development with a configuration according to Fig. B3-2. It later adopted a universal flap hinge, Fig. B4-3, which is now incorporated in all two-bladed rotorcraft. Ulrich Huetter began his $100 \mathrm{~kW}$ wind turbine development in the 1950's with a wind rotor according to Fig. B3-2 whereby the blades had substantial built-in coning angles. Apparently he encountered difficulties since in his U.S. Patent (Ref. 1) he applies the Bell Helicopter solution with the universal flapping hinge to horizontal axis wind turbines.

The upwind rotor MOD-2 configuration is, despite of its teeter hinge, relatively free of the problem indicated in Fig. B3-4. The reasons are that the blades have no built-in coning angle, that due to the high bending stiffness of the steel blades elastic coning is small, and that the yaw rate from the yaw gear drive is also small. With aluminum, fiberglas or wooden blades elastic coning can be considerable so that, even without built-in coning angle, Coriolis forces from combined coning and flapping can be significant at high yaw rates. 


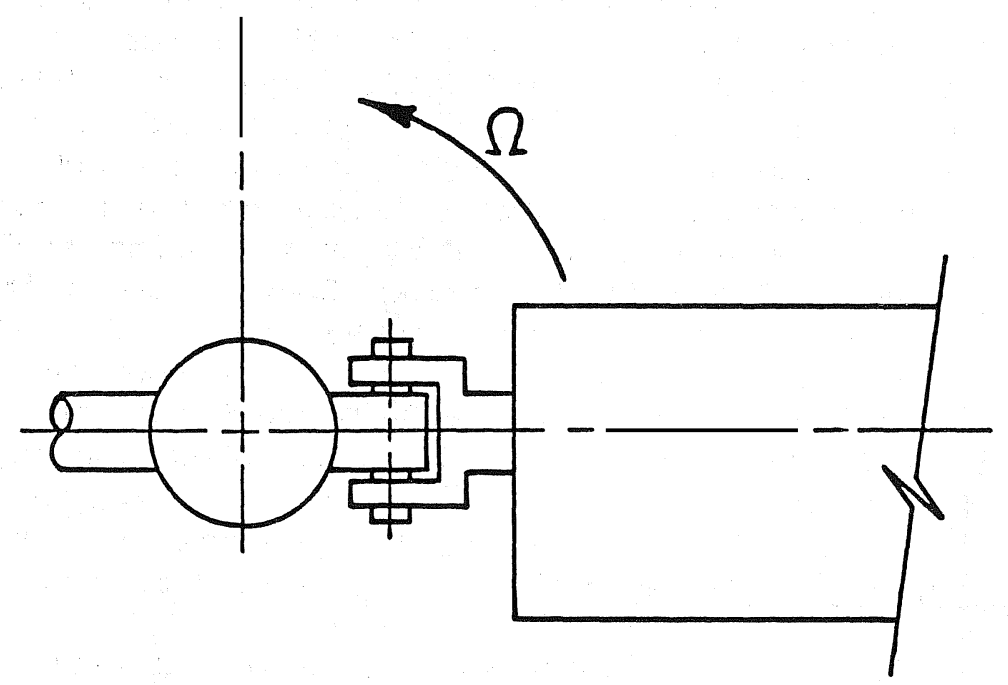

FIGURE B3-1. FLAP-CONING HINGE; AXIAL VIEW

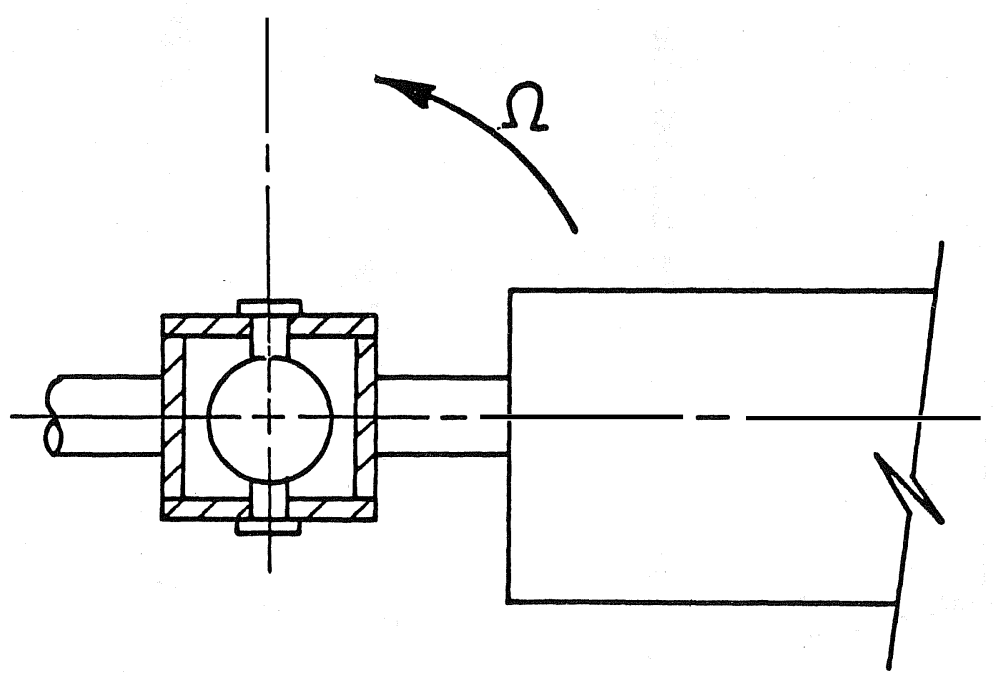

FIGURE B3-2. FLAP OR TEETER HINGE; AXIAL VIEW 

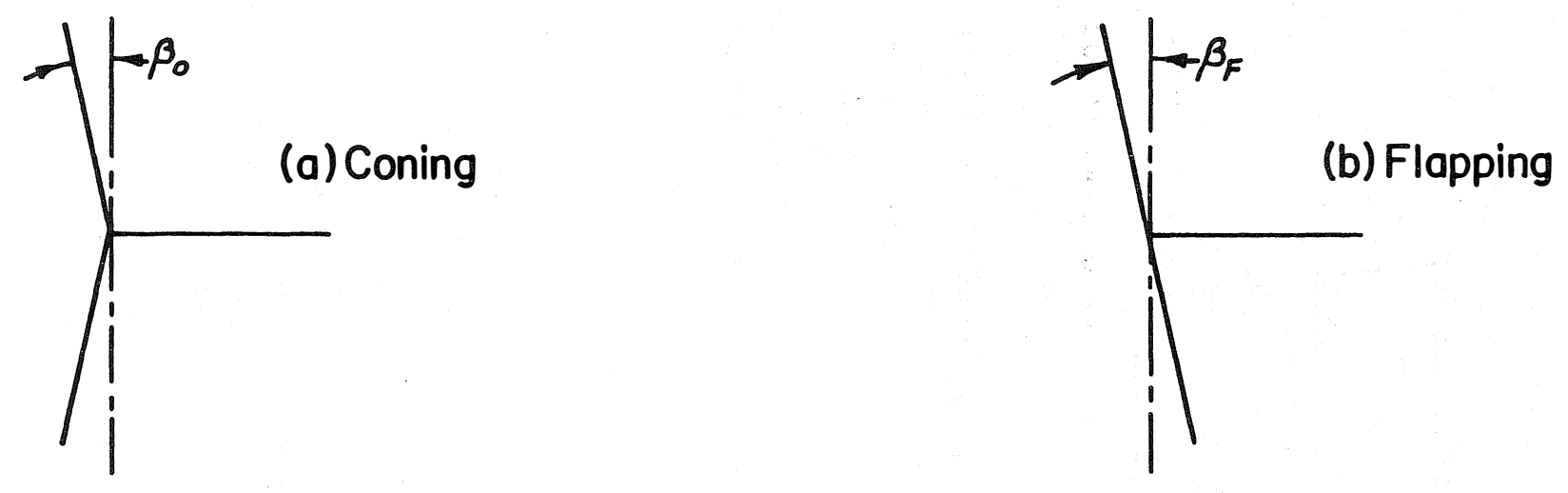

FIGURE B3-3. SEPARATE CONING AND FLAPPING, ROTOR SIDE VIEWS
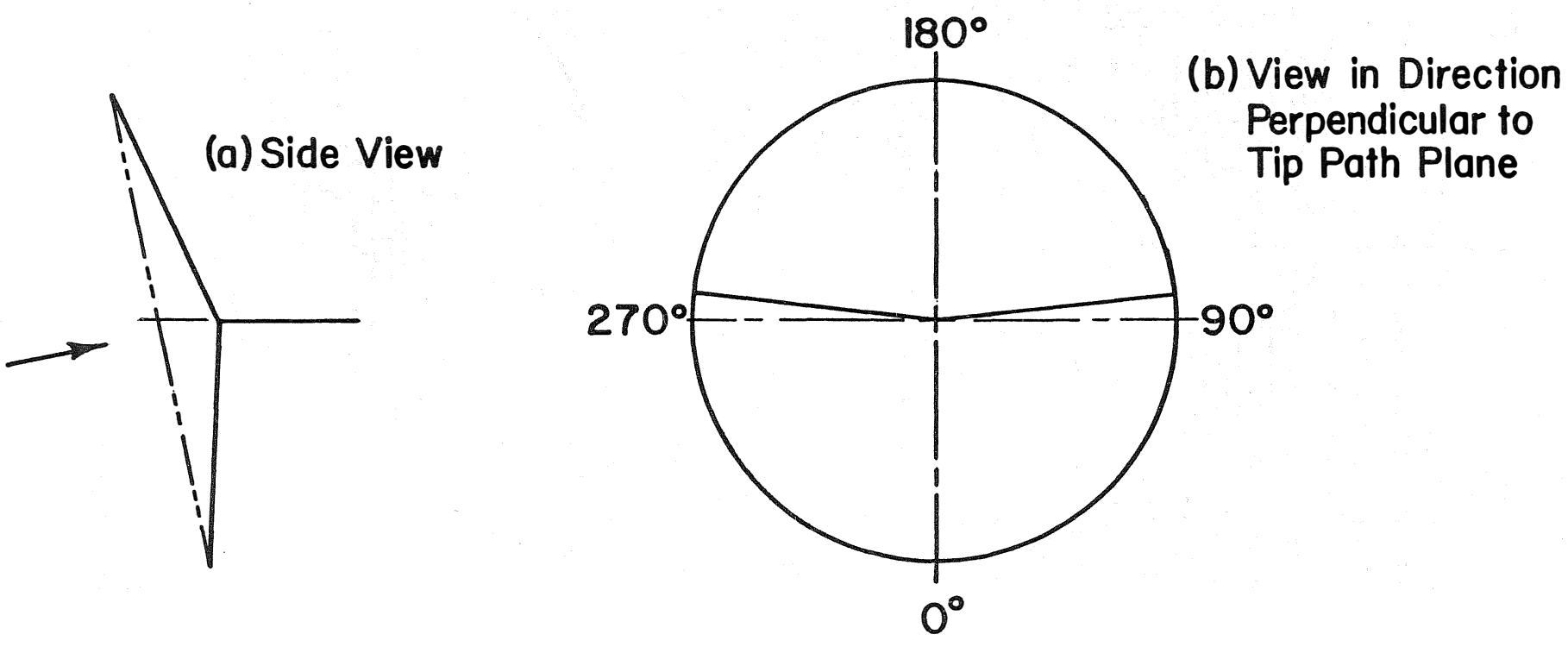

FIGURE B3-4. COMBINED CONING AND FLAPPING 
Fig. B4-l shows the schematic axial view of the blade-hub attachment frequently used for rotorcraft. The blade can be rotated about its longitudinal axis (blade pitch varying hinge) via a control horn and a control link extending parallel to the rotor axis and attached to the control horn at point A. There is a flapconing hinge perpendicular to the blade axis and extending in the plane perpendicular to the rotor axis, same as in Fig. B3-1, and there is a blade lag hinge extending parallel to the rotor axis. The blade lag hinge enables the blade to cancel the in-plane oscillations seen in Fig. B3-4(b), so that the Coriolis forces are eliminated. For reasons of dynamic stability the lag hinge motion must be strongly damped. Since for a given control position point $A$ is fixed, the blade cones and flaps about the oblique axis $A-B$ which is inclined with respect to the flap-coning hinge by the angle $\delta 3^{\circ}$. Thus coning by the angle $\beta$ will produce a negative collective pitch change $\theta=-\beta_{F} \tan \delta_{3^{\circ}}$ Flapping with the amplitude $\beta_{F}$ will produce a cyclic pitch amplitude $F_{C}=-3_{F} \tan \delta 3^{\circ}$ The pitch-cone coupfing ratio $\Theta \beta$ is the same as the pitch-flap coupling ratio $\theta_{1} \beta_{F^{\prime}}$ namely - $\tan \delta_{3}$. The pitch-cone coupling is quite effective in alleviating the rotor thrust increase from gusts, even if $\delta_{3}$ is only moderate. In contrast, the pitch-flap coupling has little effect on the rotor characteristics, unless large values of $\delta$ near $90^{\circ}$ are selected. The effects of pitch-flap ratio are undesirable for rotorcraft since they reduce the rotor angular damping which is important for good rotorcraft flight characteristics. For this reason rotorcraft have moderate values of $\delta_{3}$ of $15^{\circ}$ to $30^{\circ}$.

Fig. B4-2 shows a schematic axial view of a rotor-type which allows the combination of a large pitch-cone coupling ratio with a small or zero pitch flap coupling ratio. There is a universal flap hinge in the rotor center (floating hub) and pure coning hinges further out. The blade is controllable about its longitudinal axis. Pitch is controlled via a control horn and a control link attached to point $A$. Coning takes place about the axis A-B with a large $\delta_{3}$ angle, so that the pitch cone ratio $\theta_{O} / \beta_{0}=-\tan \delta_{3 \operatorname{con}}$ is large. Flapping takes place about the axis $A-C$ whereby the pitch-flap ration $/ B_{F}=-\tan \delta_{3 F}$ is small. The universal flap hinge allows the coned rotor to tilt so $C_{\text {ffiat }}$ the in-plane oscillations shown in Fig. B3-4 and the associated Coriolis forces are avoided. The rotor type shown in Fig. B4-2 was analyzed aerodynamically in Ref. 2 and dynamically in Ref. 3. It was applied to the Army-McDonnell XV-1 Convertiplane developed in the 1950's. Due the large pitch-cone coupling this rotorcraft was gust insensitive. Due to the universal hub hinge the rotor ran smoothly with a low vibration level. Damping of hinge motions was not required. During cruising flight when the rotor was unloaded by the fixed wing and not needed any more, the central universal flapping hinge was blocked. The rotor then had not only a large pitch-cone coupling ratio but also a large pitch-flap coupling ratio. The rotor speed was accurately controlled by rotor angle of attack changes. Flapping was effectively suppressed so that the rotor followed rapid rates of pitch or rates of roll without resistance. It was the experience with this rotor type 
which suggested its application in a simplified form to wind turbines. The XV-1 Convertiplane was the only rotorcraft that used a large pitch-flap coupling ratio for part of the flight envelope. The XV-l Convertiplane was underpowered and its development was terminated for this reason despite its good flying qualities.

A similar rotor type without the coning hinges is shown in Fig. B4-3. This rotor has no pitch-cone coupling and a small pitch-flap coupling ratio $\theta_{C}^{\prime}{ }_{F}=-\tan$ $\delta_{3}$. The universal flap hinge in the hub center allows the use of a built-in fixed coning angle without producing the in-plane blade oscillations shown in Fig. B3-4 and the associated Coriolis forces. The Fig. B4-3 rotor type has been incorporated in all modern Bell helicopters and has been proposed for horizontal axis wind turbines in Ref. 1. Though it has excellent operating characteristics it is rather complex and costly, much the same as the lag hinge rotor of Fig. B4-1. In wind turbines with rotor speed and torque control by yawing, an active blade pitch control system is not needed. Without the pitch control mechanism the universal flap hinge in the hub center is not usable since the rotor plane could then wander off without aerodyanmic feed back. The teeter rotor of Fig. B3-2 is impractical if the blades have either a built-in fixed coning angle or if coning is produced aeroelastically. The rotor with passive cyclic pitch variation shown in Fig. B4-4 combines the simplicity of the teeter rotor, Fig. B3-2, with the operational smoothness of the much more complex Bell helicopter rotor of Fig. B4-3. The pitch-flap coupling ratio $\theta_{C} /{ }_{F}=-\tan \delta_{3}$ is very high so that flapping is largely suppressed and replaced by cyclic pitch variation. Due to the suppressed flapping the effect shown in Fig. B3-4 is small, particularly if built-in blade coning is avoided and aeroelastic coning is kept moderate by reasonably stiff blades. The rotor of Fig. B4-4 could not be used in conventional rotorcraft since it lacks collective blade pitch control and since the suppression of flapping all but eliminates rotor yaw damping. When applied to the vane stabilized horizontal axis wind turbine where rotor speed and rotor torque is controlled by yawing, the lack of collective blade pitch control and of rotor yaw damping is not detrimental. 


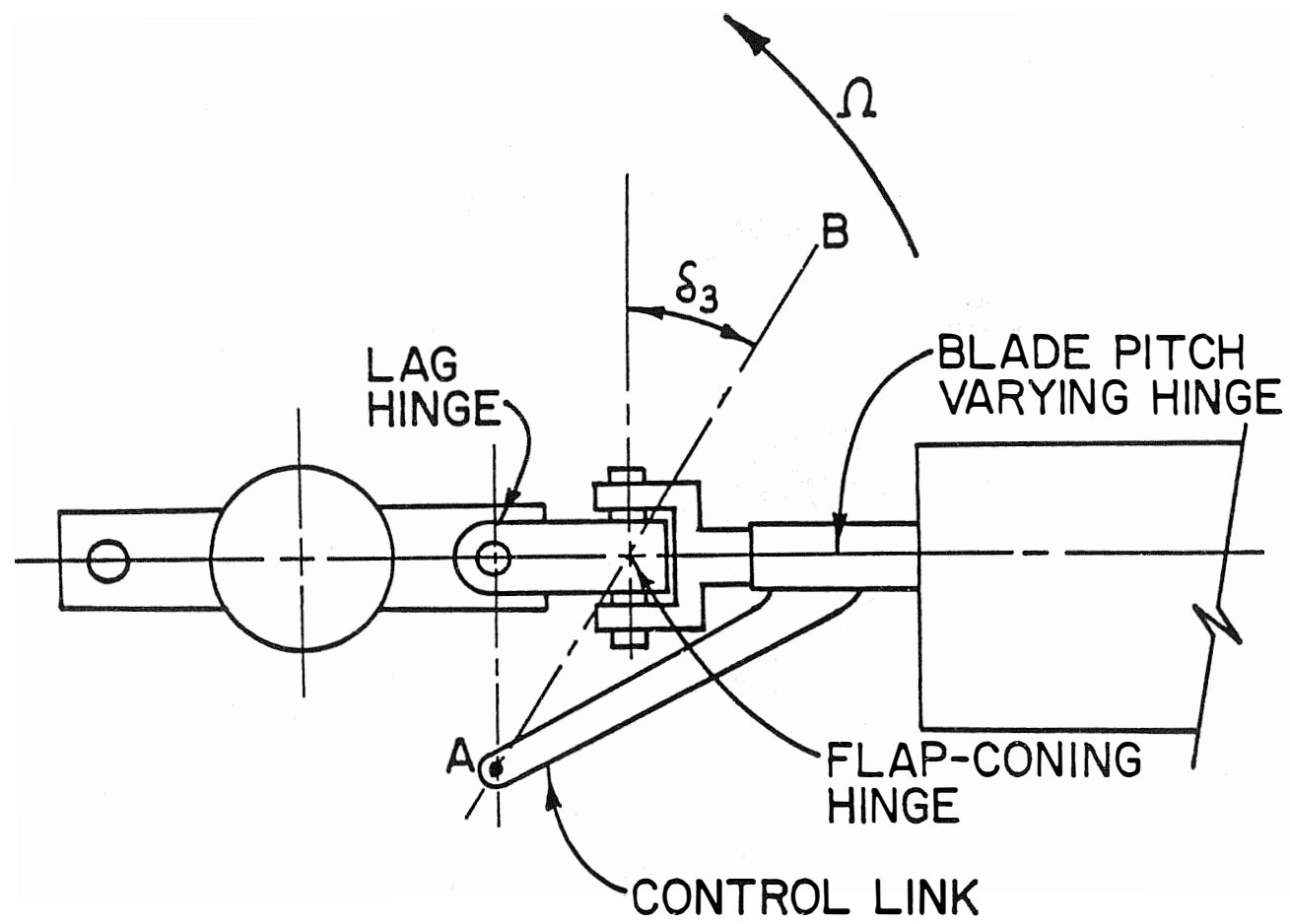

FIGURE B4-1. FIXED HUB WITH LAG, FLAP-CONING AND PITCH HINGES; AXIAL VIEW

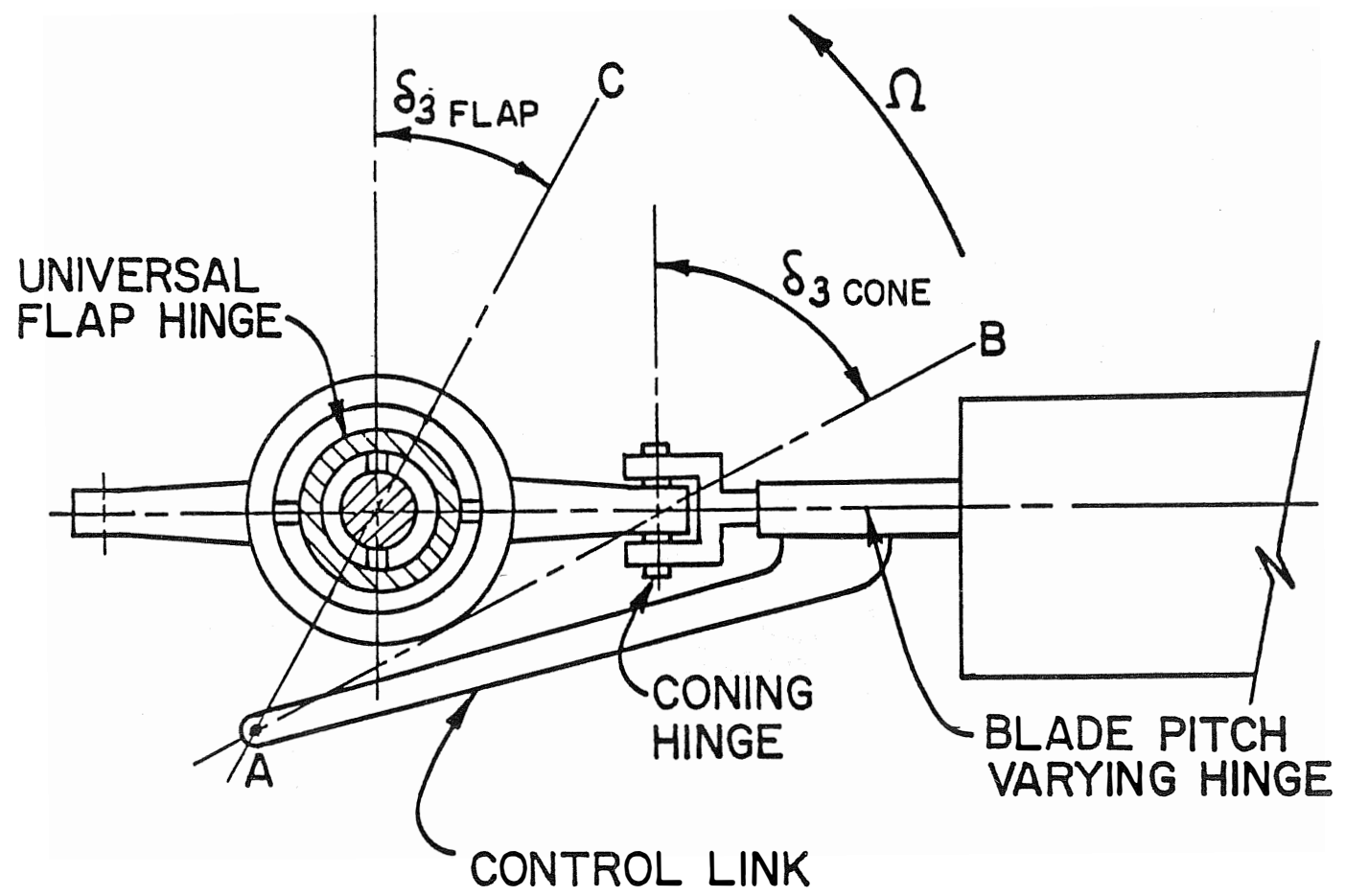

FIGURE B4-2. FLOATING HUB WITH CONING AND PITCH HINGES; AXIAL VIEW 


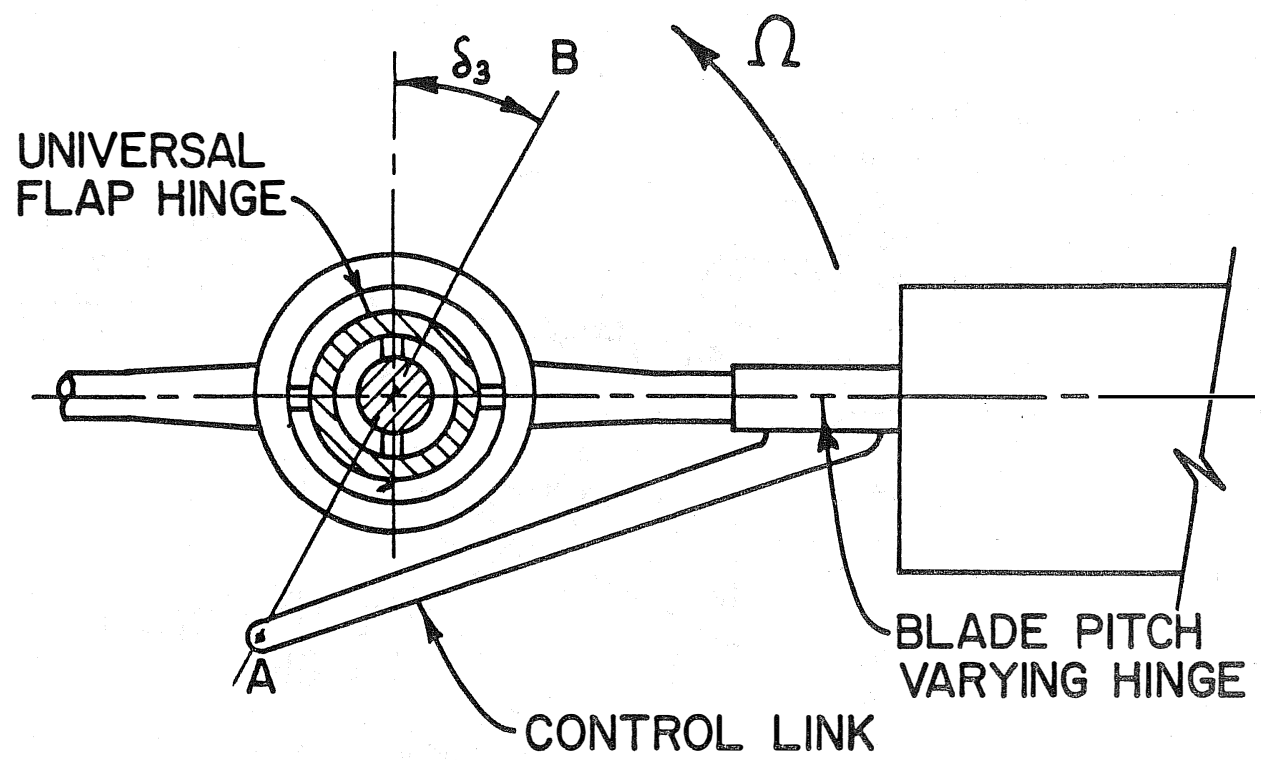

FIGURE B4-3. FLOATING HUB WITH PITCH HINGES; AXIAL VIEW

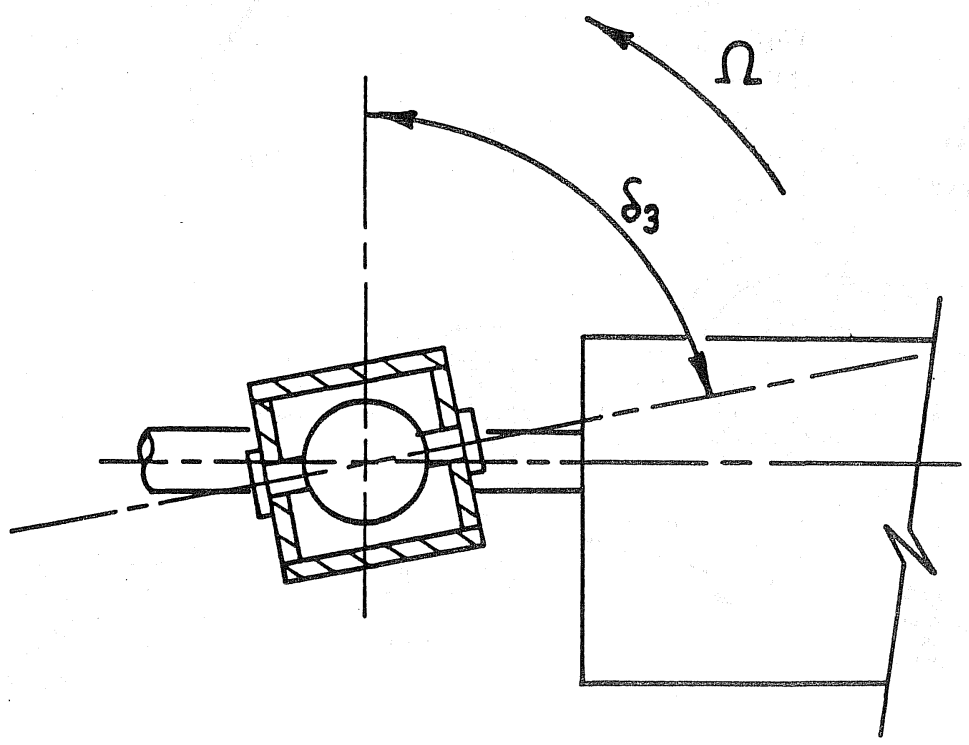

FIGURE B4-4. ROTOR WITH PASSIVE BLADE CYCLIC PITCH VARIATION; AXIAL VIEW (LARGE PITCH-FLAP COUPLING RATIO) 
For the rotor type shown in Fig. B4-4, the effect of $\delta_{3}$ on blade flapping for a steady yaw angle and for a steady yaw rate has been determined using dynamic yaw analysis, Ref. 4. This analysis has two shortcomings. First, the induced flow caused by the aerodynamic pressure which resists the rotor gyroscopic moment has been neglected. As a result, the transition from a steady yaw condition to the new equilibrium for a steady yaw rate is almost instantaneous, while in reality it takes a certain time to build up the new induced flow pattern. Second, blade stall effects were neglected, while actually the inner portion of the retreating blade is stalled. As a result, the flapping and cyclic pitch amplitudes predicted by the analysis for a given yaw rate are only about two-thirds of the measured values. However, the trend of the change of cyclic pitch and flapping amplitudes with $\delta_{3}$ should be correct.

In Fig. B5-1 and 2, $\tau$ denotes the amplitude of the angular motion about the hinge. It is compared to the flap amplitude and to the cyclic pitch amplitude. At $\delta_{3}=0$, which represents the teeter rotor of Fig. B3-2, the cyclic pitch amplitude is zero and $\tau$ is equal to the flapping amplitude. At $\delta_{3}=70^{\circ}$ the flapping amplitude is small and $\tau$ is almost equal to the cyclic pitch amplitude. Thus at $\delta_{3}=70^{\circ}$ which is close to the value used for the full scale test rotor, the hinge motion represents almost pure cyclic pitch and little flapping, thus providing the rationale for the designation "rotor with passive cyclic pitch variation". Note that with increasing $\delta_{3}$ angle from the value $\delta_{3}=0$, the flapping amplitude decreases slowly. For $\delta_{3}^{3}=15^{\circ}$ to $30^{\circ}$ (the normal range of $\delta_{3}$ ), flapping has not decreased much from its value for the teeter rotor, $\delta 3 \stackrel{3}{=} 0$. In order to effectively suppress flapping one has to select a $\delta_{3}$ angle of about $70^{\circ}$. The amplitude $\tau$ of the angular motion about the hinge does not change much with $\delta_{3}$. Thus the required hinge motion between limiting stops is about the same for the rotor with passive cyclic pitch variation as for the teeter rotor though the flapping limits are much lower.

The results presented in Fig. B5-1 through B5-4 refer to the test rotor described in Ref. 5 for an angular rotor speed of $\Omega=21 \mathrm{rad} / \mathrm{sec}$ and a wind velocity of 18 $\mathrm{m} / \mathrm{sec}(40 \mathrm{mph})$. Fig. B5-1 assumes a steady yaw angle of $60^{\circ}$. Fig. B5-2 assumes a steady yaw rate of $30^{\circ} / \mathrm{sec}$ for a yaw angle between $56^{\circ}$ and $65^{\circ}$. This yaw rate increases $\tau$ from about $2.5^{\circ}$ to $7^{\circ}$. The $\delta_{3}$ angle has little effect on rotor performance. The rotor power output is about $9.5 \mathrm{~kW}$ throughout the $\delta$ range. Fig. B5-3 and B5-4 show for the yaw rate case of Fig. B5-2 the angle of attack profiles for $\delta_{3}=0^{\circ}$ and $\delta_{3}=67^{\circ}$ respectively. The profiles are approximately the same. The suppression of flapping, according to the analysis, has little effect on the aerodynamic rotor characteristics. Test results obtained with teeter rotors and reported in Ref. 6 and 7 should be approximately applicable to rotors with passive cyclic pitch variation. For example, the effect of yaw rate on the teeter amplitude should be about the same as its effect on the cyclic pitch amplitude. The effect of blade stall on the teeter amplitude should be similar to its effect on the cyclic pitch amplitude. 


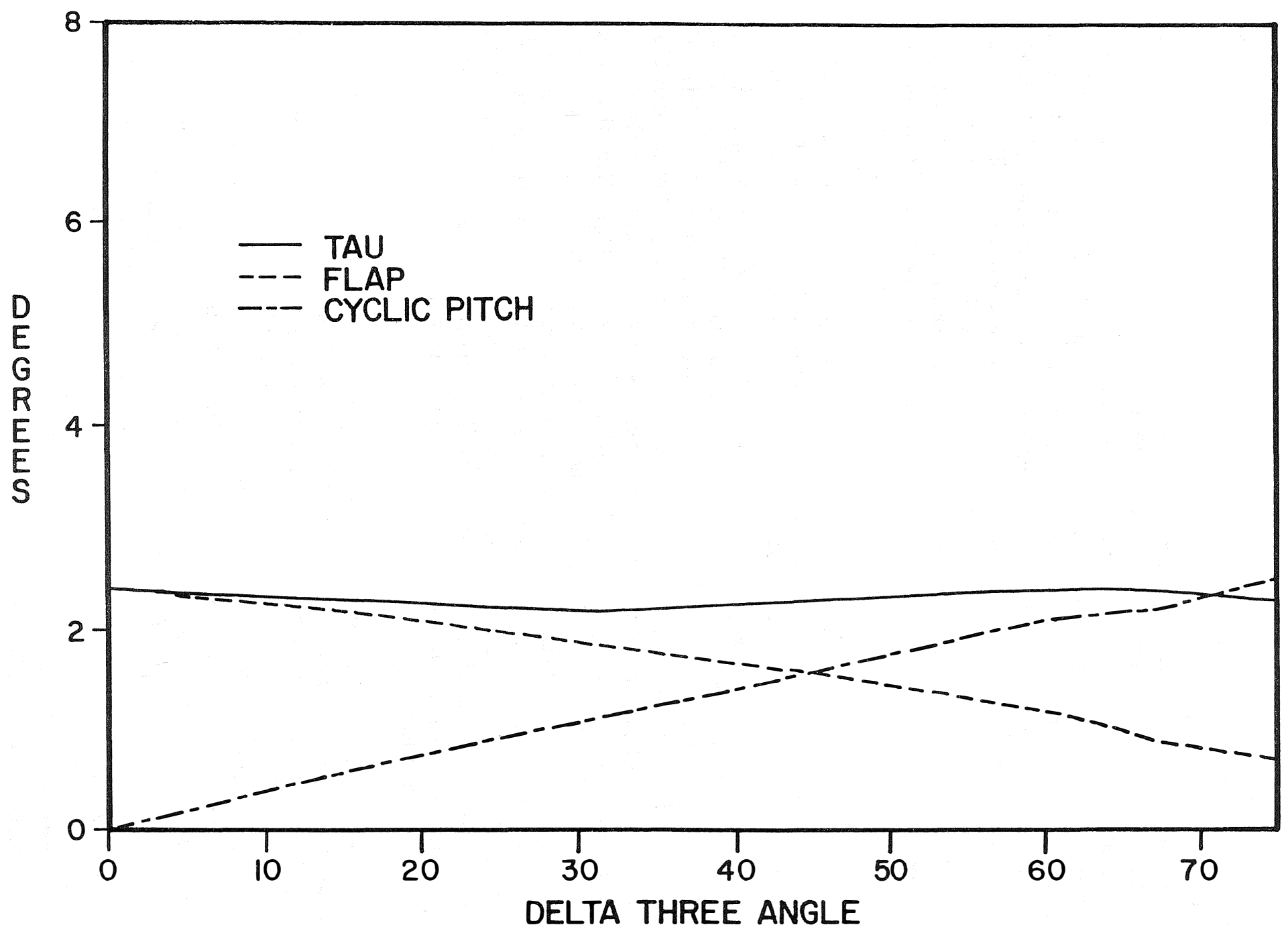

FIGURE B5-1. BLADE DEFLECTION ANGLES VS. DELTA THREE ANGLE, STEADY STATE YAW $60^{\circ}$ 


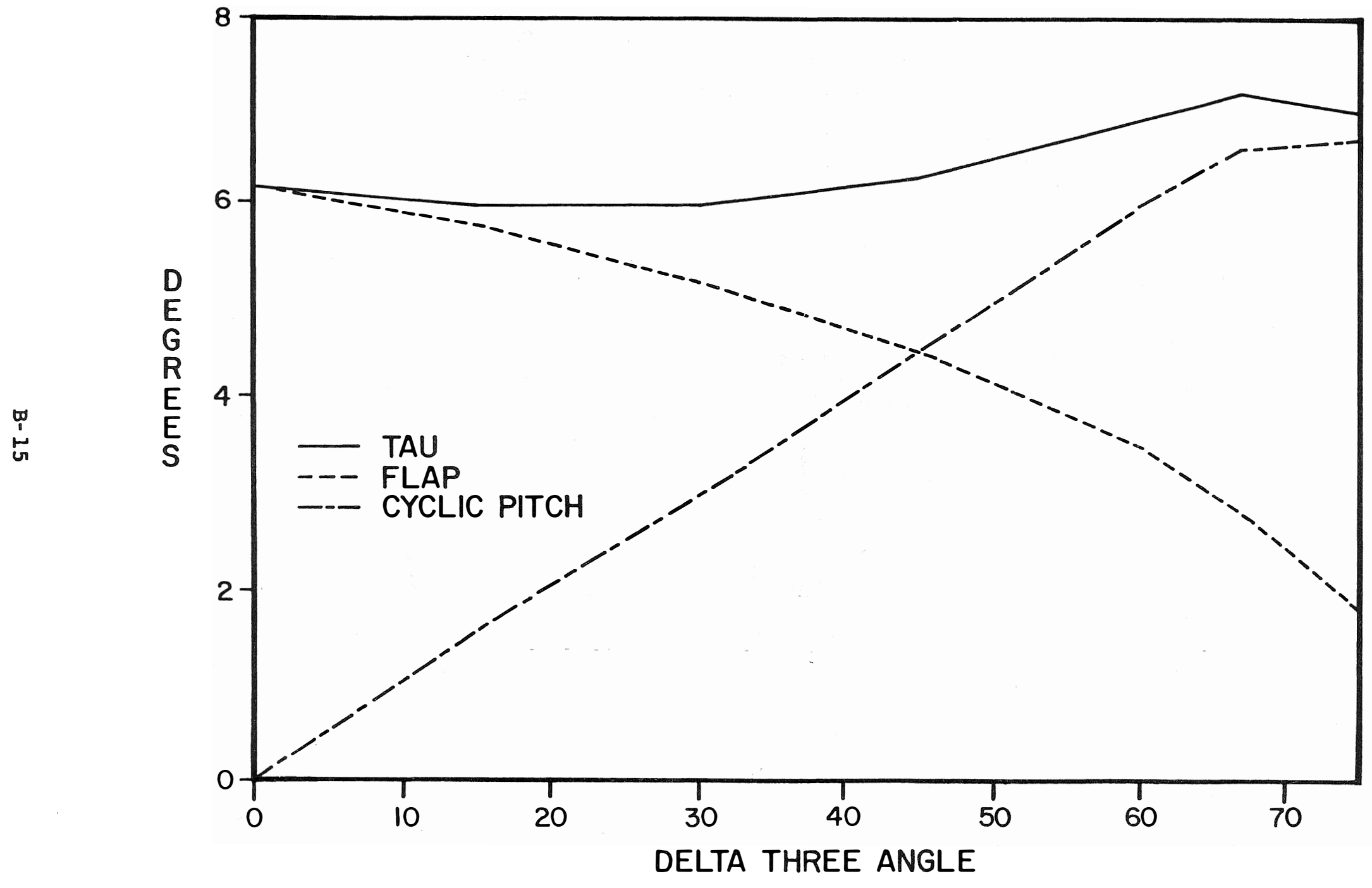

FIGURE B5-2. BLADE DEFLECTION ANGLE VS. DELTA THREE ANGLE, DYNAMIC YAW $56^{\circ}$ to $65^{\circ}$ AT $30 \%$ SEC 


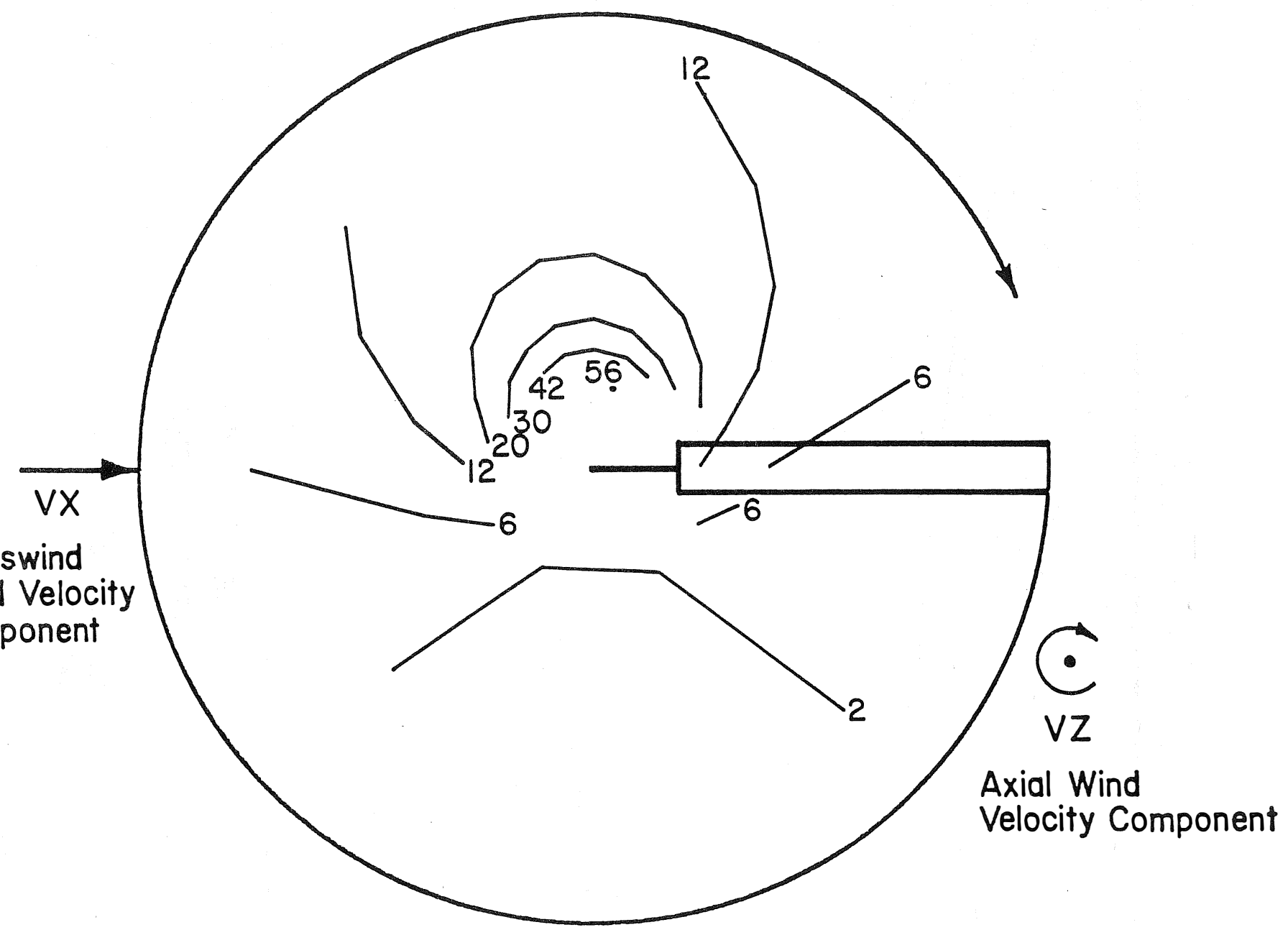

FIGURE.B5-3. ANGLE OF ATTACK PROFILE FOR CASE OF FIG. B5-2,
DELTA THREE $=0^{\circ}$ 


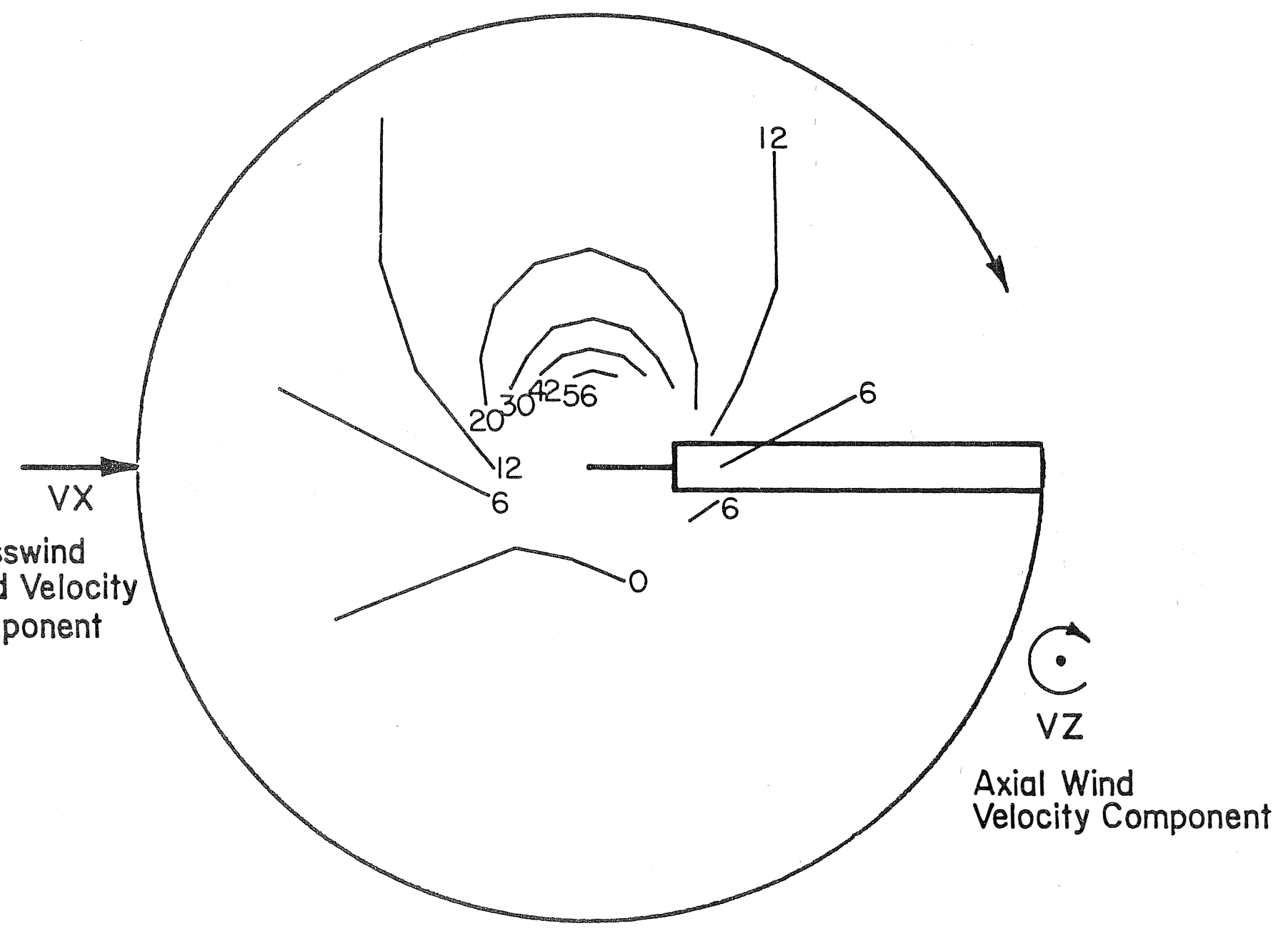

FIGURE B5-4. ANGLE OF ATTACK PROFILE FOR CASE OF FIG. B5-2, DELTA THREE $=67^{\circ}$ 

OTHER APPLICATIONS OF PASSIVE CYCLIC PITCH VARIATION

While the principal application of passive cyclic pitch variation was to the wind turbine with rotor speed and torque control by yawing, other useful applications are possible. For example, a wind rotor which is located downwind of the mast and which is designed to self-align with the wind direction needs substantial blade coning. If a teeter hinge is used, combined coning and flapping with its detrimental effects could occur during rapid wind direction changes which the rotor is incapable of following immediately. The temporary yaw angles as well as the yaw rates will cause flapping. The vertical boundary layer will also cause flapping. Suppression of flapping by passive cyclic pitch variation would appear desirable. The usual $\delta_{3}$ angles of $15^{\circ}$ to $30^{\circ}$ will have little effect. One needs to use $\delta_{3}$ angles of about $70^{\circ}$, an approach which has never been tried prior to the SERI project, Ref. 5. Self-aligning wind turbines must be stopped at high wind velocities. The blades will then bounce between the elastic stops which limit the flapping motion unless centrifugally variable stops are used. With passive cyclic pitch variation the flapping motions between stops are much smaller than for the teeter rotor. This will improve the interference margin between blades and mast and will reduce the blade loads from stop impacts. The passive cyclic pitch feature could also be used for wind rotors with feathering controls if one desires in case of a failure of the feathering control an independent shut down by rapidly yawing the rotor out of the wind. The large flapping amplitudes of a teeter rotor during this procedure would be suppressed by the passive cyclic pitch feature. 

SECTION B7

SUMMARY AND CONCLUSIONS

The following conclusions can be drawn for two-bladed wind rotors.

1. A teeter rotor with built-in or aeroelastic coning angles is not suited for operation at high yaw angles or at high yaw rates because simultaneous coning and flapping causes high in-plane Coriolis forces on the blades and a high 2 per revolution excitation on the rotor support.

2. One way to avoid in-plane blade oscillations from combined coning and flapping is to add damped blade lag hinges as is done in most helicopter rotors.

3. Another way to avoid in-plane blade oscillations from combined coning and flapping is to use a universal flapping hinge at the rotor center. This is only feasible if the rotor has blade pitch control. The combination of blade pitch control and a universal central flapping hinge is used in Bell helicopters. The same arrangement has been proposed for wind rotors in a U.S. patent by Ulrich Huetter. Though the dynamic performance is good, such a rotor is complex and costly.

4. In the absence of blade pitch control a universal central flapping hinge is not feasible and the only way to alleviate the in-plane Coriolis forces and vibrations from combined coning and flapping of the teeter rotor is to suppress flapping by a large pitch-flap coupling with a $\delta_{3}$ angle of the hinge of about $70^{\circ}$. The amplitude of the angular motion about the hinge is then almost equal to the cyclic pitch amplitude and therefore justifies the term "passive cyclic pitch variation". A two-bladed rotor with this feature is as simple and as rugged as a teeter rotor.

5. Except for suppressing flapping, passive cyclic pitch variation does not affect the remaining aerodynamic characteristics of a teeter rotor like thrust, torque and power output.

6. A moderate pitch-flap ratio with a $\delta_{3}$ angle between $15^{\circ}$ and $30^{\circ}$ as it is usually applied has little effect on flapping and is all but useless for its suppression.

7. The suppressed flapping resulting from passive cyclic pitch variation appears to be warranted in other wind turbine configurations in addition to those with rotor speed and torque control by yawing. 

1. Ulrich Huetter, US Patent No. 4,201,514 of May 6, 1980 .

2. Hohenemser, K., A Type of Lifting Rotor with Inherent Stability, J. Aeron. Sc. Vol. 17 No. 9, Sept. 1950, pp. 555-564.

3. Hohenemser, K. H. and Perisho, C. H., Analysis of the Vertical Flight Dynamic Characteristics of a Lifting Rotor with Floating Hub and Off-Set Coning Hinges, J. Amer. Hel. Soc. Vol. 3, No. 4, October 1958, pp. 20-33.

4. Swift, A. H. P., The Effects of Yawed Flow on Wind Turbine Rotors, Doctor of Science Dissertation, Washington University, Sever Institute of Technology, May 1981.

5. Hohenemser, K. H., Swift, A. H. P., Peters, D. A., The Yawing of Wind Turbines with Blade Cyclic Pitch Variation, Final Report, SERI/TR-8085-15, Dec. 1980.

6. Glasgow, J. C., Pfanner, H. G., and Westerkamp, E. J., The Response of a $38 \mathrm{~m}$ Horizontal Axis Teetered Rotor to Yaw, Large Horizontal Axis Wind Turbines, A Workshop held at Cleveland, Ohio, July 28-30, 1981.

7. Glasgow, J. C., and Corrigan, R. D., Stall Induced Instability of a Teetered Rotor, Large Horizontal Axis Wind Turbines, A Workshop held at Cleveland, Ohio, July 28-30, 1981. 


\begin{tabular}{|c|c|c|}
\hline $\begin{array}{l}\text { Document Control } \\
\text { Page }\end{array}$ & $\begin{array}{l}\text { 1. SERI Report No. } \\
\text { SERI/TR-11052-2 }\end{array}$ & 3. Recipient's Accession No. \\
\hline \multirow{2}{*}{\multicolumn{2}{|c|}{$\begin{array}{l}\text { 4. Title and Subtitle } \\
\text { The Investigation of Passive Blade Cyclic Pitch } \\
\text { Variation Using an Automatic Yaw Control System }\end{array}$}} & Auqust 1982 \\
\hline & & 6. \\
\hline \multicolumn{2}{|c|}{$\begin{array}{l}\text { 7. Author(s) } \\
\text { Richard Mitchel1, Technical Monitor }\end{array}$} & 8. Performing Organization Rept. No. \\
\hline \multicolumn{2}{|c|}{$\begin{array}{l}\text { 9. Performing Organization Name and Address } \\
\text { Washington University Technology } \\
\text { Associates Inc., St. Louis, Missouri }\end{array}$} & $\begin{array}{l}\text { 10. Project/Task/Work Unit No. } \\
1067.10 \\
\text { 11. Contract (C) or Grant (G) No. } \\
\text { (C) XH-1 }-1052-1 \\
\text { (G) }\end{array}$ \\
\hline \multicolumn{2}{|c|}{ 12. Sponsoring Organization Name and Address } & \multirow{2}{*}{$\begin{array}{l}\text { 13. Type of Report \& Period Covered } \\
\text { Technical Report }\end{array}$} \\
\hline \multirow{2}{*}{\multicolumn{2}{|c|}{$\begin{array}{l}\text { Solar Energy Research Institute } \\
1617 \text { Cole Boulevard } \\
\text { Golden, Colorado } 80401\end{array}$}} & \\
\hline & & 14. \\
\hline
\end{tabular}

15. Supplementary Notes

16. Abstract (Limit: 200 words)

The purpose of this study was to determine by analysis and full-scale experiments, whether a two-bladed wind turbine rotor with passive cyclic pitch variation, automatically yawed for rotor torque and speed control, is potentially cost-effective for wind energy conversion. A simple mechanism for obtaining passive cyclic pitch variation, adapted from rotorcraft technology, eliminates transfer of gyroscopic moments from simultaneous blade coning and flapping. Thus, as a result of the suppression of blade flapping by passive cyclic pitch variation, rapid yaw rates without vibratory hub moments or appreciable outof-plane blade excursions are feasible for two-bladed rotors with substantial blade elastic coning. A 7.6-m diameter vane-stabilized wind turbine rotor of low solidity was tested with both passive and active automatic furl control systems and with both a variable speed alternator and a constant speed induction generator. The tests were supported by a yaw dynamics analysis. Within the tested performance envelope, the rotor ran smoothly with good performance and without excessive vibrations or loads even at high yaw angles and yaw rates. The passive automatic furl control appeared to be the more desirable configuration for both variable speed alternators and constant speed induction

17. Document Analysis generators.

a. Descriptors Control equipment ; Field tests ; Rotors ; Turbine blades ; Wind turbine

b. Identifiers/Open-Ended Terms

Yaw dynamics ; Rotor furling ; Yawing

c. UC Categories

60

18. Availability Statement

National Technical Information Service

U.S. Department of Commerce

5285 Port Royal Road

Springfield, Virginia 22161 